NIST Technical Note 2145

\title{
Urban Greenhouse Gas Measurements: Urban Testbed Systems and International Cooperation
}

Workshop Summary Report

Hratch G. Semerjian

James R. Whetstone

This publication is available free of charge from:

https://doi.org/10.6028/NIST.TN.2145

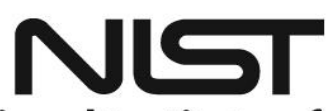

National Institute of Standards and Technology U.S. Department of Commerce 


\title{
Urban Greenhouse Gas Measurements: Urban Testbed Systems and International Cooperation
}

\section{Workshop Summary Report}

\author{
Hratch G. Semerjian \\ Material Measurement Laboratory
}

James R. Whetstone

Special Programs Office

This publication is available free of charge from: https://doi.org/10.6028/NIST.TN.2145

April 2021

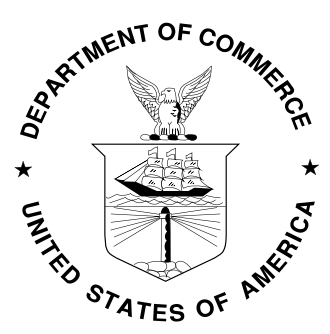

U.S. Department of Commerce Gina M. Raimondo, Secretary

National Institute of Standards and Technology James K. Olthoff, Performing the Non-Exclusive Functions and Duties of the Under Secretary of Commerce for Standards and Technology \& Director, National Institute of Standards and Technology 
Certain commercial entities, equipment, or materials may be identified in this document in order to describe an experimental procedure or concept adequately. Such identification is not intended to imply recommendation or endorsement by the National Institute of Standards and Technology, nor is it intended to imply that the entities, materials, or equipment are necessarily the best available for the purpose.

National Institute of Standards and Technology Technical Note 2145

Natl. Inst. Stand. Technol. Tech. Note 2145, 104 pages (April 2021)

CODEN: NTNOEF

This publication is available free of charge from:

https://doi.org/10.6028/NIST.TN.2145 


\begin{abstract}
This workshop, held at NIST on January 30 and 31, 2020 brought together measurement science researchers focused on improving urban measurements of greenhouse gases and stakeholders interested in mitigation. Many were principal investigators of the research undertaken in the three testbeds of NIST's Urban Greenhouse Gas Measurements Testbed System. Testbeds are located in Indianapolis, Indiana (the INFLUX Project), Los Angeles, California and the South Coast Air Basin (the LA Megacities Project), and the Northeast Corridor Project - Baltimore/Washington Region (NEC/BW Project). The testbed system has been in operation since the early to mid-2010's. Significant accomplishments marked these research efforts advancing urban greenhouse gas quantification capabilities and skill. The purpose of the workshop was to share accomplishments and current status of research supported by the Testbed System, assess the state and maturity of research results, discuss national and international implications of these results, and plan research directions for the next few years. The workshop emphasized the value of time for discussion. Therefore, limited time was allotted to presentations, rather the agenda focused on several panels dealing with various research topics and stakeholder interests. Here we report on these presentations, discussions of scientific and technical successes, barriers, impacts, knowledge gaps, and conclusions.
\end{abstract}

\title{
Key words
}

Greenhouse Gases; Urban Greenhouse Gas Measurement Testbeds, Urban Observing Networks; Emissions Models and Data Products; Atmospheric Inversion Modeling; Urban Biogenic Sinks/Sources; Atmospheric Transport Models. 


\section{Table of Contents}

Executive Summary 1

1. Introduction $\quad 5$

1.1 Urban Greenhouse Gas Measurements - Opportunities and Challenges 7

1.2 Workshop Objectives, Scope and Format 8

2. Overview of Current Research Activities and Capabilities 10

2.1 Plenary Lecture: James R. Whetstone, NIST 10

2.2 Plenary Lecture: Philip L. DeCola, GIST.earth 15

3. Panel Discussions 19

3.1 Panel Discussion:

Scientific and Technical Successes, Barriers, Impacts and Knowledge Gaps 19

3.1.1 Ronald Cohen $\quad 21$

3.1.2 Anna Karion 22

3.1.3 Ralph Keeling 25

3.1.4 Thomas Lauvaux 26

3.1.5 Alistair Manning $\quad 27$

3.1.6 Charles (Chip) Miller 28

3.1.7 Felix Vogel 29

3.1.8 Discussion/Questions for Panelists 30

3.2 Panel Discussion on International Stakeholder Experiences 32

3.2.1 Fouzi Benkhelifa $\quad 32$

3.2.2 Alistair Manning 33

3.2.3 Jocelyn Turnbull 34

3.2.4 Alex Vermeulen 35

3.2.5 Felix Vogel $\quad 37$

3.2.6 James Whetstone 38

3.2.7 Discussion/Questions for Panelists: 39

3.3 Panel Discussion on Domestic Stakeholder Experiences/Broader Impacts 43

3.3.1 Joseph Rudek $\quad 43$

3.3.2 Eric Kort 44

3.3.3 Riley Duren $\quad 45$

3.3.4 Russ Dickerson $\quad 47$ 
3.3.5 Paul Shepson $\quad 48$

3.3.6 Kevin Gurney

3.3.7 Ronald Cohen $\quad 50$

3.3.8 Discussion/Questions for Panelists $\quad 51$

3.4 Wrap up Discussion: Mapping Technical Capabilities to Stakeholder Needs 53

4. Looking Forward - Research Needs and Challenges $\quad 55$

4.1 Summary and Synthesis of Themes

4.2 Circling back to Science/Technology Challenges 61

4.3 Future Planning for Science to Serve Stakeholders 65

4.4 Breakout Group $1-\mathrm{IG}^{3} \mathrm{IS}$ Focused $\quad 69$

4.5 Breakout Group 2 - Urban Focused 72

5. General Conclusions and Recommendations $\quad 75$

$\begin{array}{ll}\text { Appendix A: Acronyms } & 78\end{array}$

$\begin{array}{lr}\text { Appendix B: Workshop Attendees } & 80\end{array}$

$\begin{array}{ll}\text { Appendix C: Agenda } & 81\end{array}$

Appendix D: Power Point Presentations by Plenary Lecturers 83 


\title{
Workshop on \\ Urban Greenhouse Gas Measurements Urban Testbed Systems and International Cooperation \\ January 30-31, 2020 NIST, Gaithersburg, MD
}

\begin{abstract}
Executive Summary
"For more than a century, we have been aware that changes in the composition of the atmosphere could affect its ability to trap the sun's energy for our benefit. We now have incontrovertible evidence that the atmosphere is indeed changing and that we ourselves contribute to that change. Atmospheric concentrations of carbon dioxide are steadily increasing, and these changes are linked with man's use of fossil fuels and exploitation of the land. Since carbon dioxide plays a significant role in the heat budget of the atmosphere, it is reasonable to suppose that continued increases would affect climate". This statement is from the foreword of a 1979 National Academies report; ${ }^{1}$ the question is how much progress have we made since then?

Accurate and precise atmospheric measurements of greenhouse gas (GHG) concentrations have revealed the rapid and unceasing rise of global GHG concentrations due to human socioeconomic activity. ${ }^{2}$ In 2010, a National Academies report ${ }^{3}$ stated that "independent verification of the self-reported fossil $\mathrm{CO}_{2}$ emissions of individual countries will require additional atmospheric measurements and improved tracer-transport estimates of emissions. The density and coverage of measurements would be improved ...by establishing new stations near cities and other large local sources and in sparsely sampled regions..."

Cities contribute over $70 \%$ of energy-related $\mathrm{CO}_{2}$ emissions and account for around two-thirds of global energy demand. If current trends continue, global urban primary energy use would grow by about $70 \%$ and global urban $\mathrm{CO}_{2}$ emissions by about 50\% between 2013 and 2050. ${ }^{4}$ Cities and regions also have a unique capacity to address climate change compared with national governments. It is widely argued that cities are both part of the problem and part of the solution to addressing climate change. ${ }^{5}$ Cities are attracting increasingly larger proportions of the global population, wealth and productivity. More than half of the world's population (54.5\% in 2016) lives in cities, and the number is projected to reach $70 \%$
\end{abstract}

\footnotetext{
"Carbon Dioxide and Climate: A Scientific Assessment", National Academies Press, Washington, DC (1979)

2 https://scripps.ucsd.edu/programs/keelingcurve/

"Verifying Greenhouse Gas Emissions - Methods to support international climate agreements", National Research Council,

Washington, DC (2010) https://www.nap.edu/catalog/12883/verifying-greenhouse-gas-emissions-methods-to-support-internationalclimate-agreements

4 Energy Technology Perspectives 2016, OECD Publishing, Paris, http://dx.doi.org/10.1787/energy_tech-2016-en

5 Tadashi Matsumoto, et al., "An integrated approach to the Paris Climate Agreement: The role of regions and cities", OECD Regional Development Working Papers 2019/13, 2019.
} 
- 6.7 billion people - by $2050 ;{ }^{6}$ cities also generate more than $80 \%$ of global Gross Domestic Product (GDP). ${ }^{7}$

On January 30-31, 2020, a workshop was held at NIST in Gaithersburg, MD to review recent developments in measurement capabilities and technologies addressing urban GHG emissions, to assess the state of the art and remaining scientific challenges, and to identify ways to serve the needs of the specific stakeholders, including large municipalities where mitigation actions are planned or underway. Plenary lectures provided an overview of current research activities and capabilities. Panel discussions were held on scientific and technical successes, and knowledge gaps, on researchers' experiences with domestic and international stakeholders, and on ways to map technical capabilities to stakeholder needs. During the discussions over the two-day workshop, there were several themes that workshop participants emphasized about the scientific accomplishments of the community and the remaining technical challenges.

\section{Scientific Accomplishments:}

Participants agreed that:

a. Tremendous methodological progress had been made in the last few years of research in the area of quantifying greenhouse gas emissions. We have an increased understanding of the challenges associated with atmospheric measurements, background problems (i.e. isolating concentration enhancements from the region of interest), biogenic sources and sinks, and emission models; these have become more tractable problems.

b. There has been a growing body of scientific work on emission models (historically referred to as "bottom-up" approaches) such as Vulcan, Hestia, ACES, ODIAC, EDGAR, etc., that represent practical tools for mitigation efforts; these models have different spatial and temporal resolutions, and some provide global coverage. Detailed inventories based on emission models for several cities already exist and are available for use by others. Accurate municipal or regional emissions models are needed as tools for mitigation efforts. Recent literature suggests that a sampling of self-reported city inventories under-estimate emissions.

c. Atmospheric measurements of GHGs are extremely valuable for validation of emissions models. The accuracy of methods relying on atmospheric measurements (top-down approaches) has been shown to approach $3 \%$ on an annual basis. Uncertainty in meteorological parameters affects the accuracy of such emissions estimates, especially on shorter time scales for which random errors do not cancel.

d. Atmospheric transport is a key link between atmospheric measurements of GHG concentrations and the sources and sinks. Understanding the transport models and any associated uncertainties and systematic errors (biases) is fundamental for improving the estimation of emissions.

e. Biospheric fluxes of $\mathrm{CO}_{2}$ are seasonally large compared to anthropogenic emissions, making topdown estimates of $\mathrm{CO}_{2}$ emissions more difficult than for methane or other trace gases. Efforts to estimate $\mathrm{CO}_{2}$ fluxes using atmospheric monitoring systems will require increased emphasis, as biogenic sinks/sources can confound the signal of GHG emissions; winter studies alone, when the biosphere signal is weaker in non-tropical areas, are not sufficient. Current capabilities of biogenic

\footnotetext{
6 "World Urbanization Prospects: The 2018 Revision", New York, United Nations, Department of Economic and Social Affairs, Populations Division, 2018. https://population.un.org/wup/Download/

7 "Climate Emergency, Urban Opportunity: How National Government Can Secure Economic Prosperity and Avert Climate Catastrophie by Transforming Cities", Coalition for Urban Transitions (CUT), 2019 https:///www.globalcovenantofmayors.org/wpcontent/uploads/2019/09/Climate-Emergency-Urban-Opportunity-report.pdf
} 
models are not sufficient; there is much uncertainty in predictions of biogenic effects. Other trace gas measurements (e.g., $\mathrm{CO},{ }^{14} \mathrm{CO}_{2}$ ) should continue to be used to isolate contributions the anthropogenic emission signals from the total.

f. There has been an increased emphasis on meeting stakeholders' needs. Some stakeholders (e.g., city governments) may not be interested in constructing inventories; they are more focused on taking mitigation actions and following trends, and on related issues such as air quality and social equity. However, good historical baselines are critical to assess trends. Working with stakeholders requires persistence, especially when officials in city, state and national governments change frequently and new policies are implemented. Specific interests of stakeholders may not always align with the scientists' research goals, but it is fruitful to engage stakeholders in exchanges that could guide the research. In some areas, such as energy related activities, there is more interest from stakeholders in using atmospheric measurements to understand and quantify $\mathrm{CH}_{4}$ emissions, since $\mathrm{CH}_{4}$ emissions modeling and inventories are less accurate compared to $\mathrm{CO}_{2}$.

g. NIST GHG Measurements Program has catalyzed several Urban GHG Testbeds around the globe (including China) and promoted an international effort toward development of systematic measurement approaches for GHG emissions.

h. The IG ${ }^{3} \mathrm{IS}$ (Integrated Global Greenhouse Gas Information System) program of the WMO benefited from the NIST urban testbeds work; it was successful in articulating more directly the operational need and developing an institutional foundation.

Research and Implementation Challenges:

There was also agreement that much remains to be accomplished in the coming years:

a. Several improvements are needed in analysis of atmospheric measurements.

- Improvements are needed in atmospheric transport models and assessment of biases and how these biases translate into uncertainties in emissions estimates derived from measurements and inverse models. Comparison and performance assessment of emissions estimation methods and transport models will provide confidence for the results of GHG emission estimates.

- Increased integration is needed between tower, aircraft and satellite observations to ensure full utilization of studies and take advantage of their complementary features.

- Measurement of additional trace gases and investigating emissions ratios can shed light on sectoral attribution of emissions, which remains a significant challenge for atmospheric methods.

b. Better integration between GHG emissions research and air quality efforts is expected to benefit both communities, first because pollutants are usually expressed per unit of $\mathrm{CO}_{2}$, but also because air quality is an important issue at the city-scale and directly connected to public health. Any argument that reducing GHGs would also reduce air pollutants is more likely to gain traction.

c. Progress is needed on modeling the biosphere, at urban and broader regional scales. More accurate predictions of $\mathrm{CO}_{2}$ uptake and emissions will help separate biogenic and anthropogenic processes in the atmosphere at short time scales, improving quantification of emissions, but will also help quantify annual net land sinks, which is a topic of interest to various policy makers.

d. Comparison and performance assessment of different emissions models (Vulcan, Hestia, ACES, ODIAC, EDGAR, etc.) will provide confidence for their performance, reliability, and transparency.

e. Currently established Urban GHG Emission Testbeds should continue to be used as laboratories to monitor long-term changes, as well as to determine the impact of local mitigation efforts. 
Decisions on establishment of new test beds should be based on new features, characteristics, and challenges a new city offers, such as topography, weather patterns, diversity of emissions sources, diversity of biogenic features, etc. and the interest of local stakeholders.

f. Increased stakeholder participation is needed in future meetings to continue the efforts initiated by the CO2-USA Conferences; a strategy needs to be developed to increase stakeholder engagement at all levels. Engagement with politically savvy stakeholders is a must. Engagement with NGOs to articulate the impact of our work would also be beneficial.

- To encourage efficient development of new methods and tools that will meet stakeholder needs, it is recommended to have a follow up meeting within the next year to discuss tangible goals/objectives for which the community could strive (e.g., papers, marketing, more organization, etc.)

- Better communication tools need to be developed to keep the public informed of developments and to engage wide range of stakeholders. For example, visualization of emissions model outputs and direct engagement with the public (e.g. through a web platform) could generate enthusiasm and may have the potential to provide city sustainability managers easy access to higher-quality information in addition to the simpler city inventories constructed by consultants.

- UNFCCC (United Nations Framework Convention on Climate Chante) reporting is done on national levels; however, many of the mitigation efforts will be implemented on a local/regional level. Appropriate stakeholders must be entrained in these efforts, made aware of the tools being developed by this community, and jointly develop dissemination approaches for their use.

g. Continued international coordination and data sharing is required for effective research and development efforts, for the purpose of eventual development of best practices and standards.

- Continued efforts by $\mathbf{I G}^{3} \mathbf{I S}$ are needed for international coordination and validation of test methods. Organizational uncertainties within WMO should be overcome; the IG IS mission and objectives should be better defined; IG $^{3} I S$ communications with the science community, stakeholders and the private sector should be improved; future $\mathrm{IG}^{3} \mathrm{IS}$ stakeholder meetings can be used for these purposes.

- Establishing best practices, which may eventually lead to development and adoption of international standards, will be critical for the use of atmospheric emission estimation systems to guide implementation of mitigation efforts by the private sector as well as governments at all levels. 


\section{Workshop on \\ Urban Greenhouse Gas Measurements: Urban Testbed Systems and International Cooperation}

\section{Introduction}

"For more than a century, we have been aware that changes in the composition of the atmosphere could affect its ability to trap the sun's energy for our benefit. We now have incontrovertible evidence that the atmosphere is indeed changing and that we ourselves contribute to that change. Atmospheric concentrations of carbon dioxide are steadily increasing, and these changes are linked with man's use of fossil fuels and exploitation of the land. Since carbon dioxide plays a significant role in the heat budget of the atmosphere, it is reasonable to suppose that continued increases would affect climate". This statement is from the foreword of a 1979 National Academies report; ${ }^{8}$ the question is how much progress have we made since then?

The year 2018 was the fourth warmest on record and the past four years - 2015 to 2018 - were the top four warmest years in the global temperature record. The year 2018 was the coolest of the four. In contrast to the two warmest years (2016 and 2017), 2018 began with weak La Niña conditions, typically associated with lower global temperatures. ${ }^{9}$

Accurate and precise atmospheric measurements of greenhouse gas (GHG) concentrations have revealed the rapid and unceasing rise of global GHG concentrations due to human socioeconomic activity. ${ }^{10}$ Accurate and precise long-term observations also show a resulting rise in global temperatures and evidence of negative impacts on society. In response to this mounting evidence, nations, sub-national governments, private enterprises and individuals are establishing and accelerating efforts to reduce GHG emissions while meeting the needs for global development and increasing energy access. ${ }^{11}$

The Global Atmosphere Watch (GAW) Program of WMO was established in 1989 in recognition of the need for improved scientific understanding of the increasing influence of human activities on atmospheric composition and subsequent environmental impacts. GAW measurements of ozonedepleting gases have played and continue to play a critical role in the successful response of the Montreal Protocol to stratospheric ozone depletion. Historically, GHG measurements have been made in remote locations that optimized the sampling frequency of global background concentrations of greenhouse gases. ${ }^{12}$ To identify sources of major GHG emissions and to assess the impact of mitigation efforts, spatially and temporally resolved GHG measurements need to be performed in and near major cities of the globe.

In 2010, a National Academies report stated that "independent verification of the self-reported fossil $\mathrm{CO}_{2}$ emissions of individual countries will require additional atmospheric measurements and improved tracer-transport estimates of emissions. The density and coverage of measurements would

\footnotetext{
8 “Carbon Dioxide and Climate: A Scientific Assessment", National Academies Press, Washington, DC (1979)

${ }^{9}$ WMO Statement on the State of the Global Climate in 2018, WMO-No.1233

https://library.wmo.int/doc_num.php?explnum_id=5789

${ }_{10} \mathrm{https://scripps.ucsd.edu/programs/keelingcurve/}$

${ }_{11} \mathrm{https://www.wmo.int/pages/prog/arep/gaw/documents/IG3ISImplementationPlanEC70.pdf}$

12 https://public.wmo.int/en/resources/bulletin/integrated-global-greenhouse-gas-information-system-ig3is
} 
be improved ...by establishing new stations near cities and other large local sources and in sparsely sampled regions..."13

Cities and regions have a unique capacity to address climate change compared with national governments. It is widely argued that cities are both part of the problem and part of the solution to addressing climate change. ${ }^{14}$ Cities are attracting increasingly larger proportions of the global population, wealth and productivity. More than half of the world's population $(54.5 \%$ in 2016) lives in cities, and the number is projected to reach $70 \%-6.7$ billion people - by $2050 .{ }^{15}$ Cities generate more than $80 \%$ of global GDP, ${ }^{16,17}$ and the largest metropolitan areas are often as economically powerful as major countries: Tokyo's economic output is comparable to that of Korea, the world's 15th largest economy; New York's is comparable to Canada's; Los Angeles's to Australia's; and London's to that of the Netherlands. ${ }^{18}$

Regarding the issue of climate change, cities account for disproportionate percentages of global GHG emissions and primary energy use, while they are also vulnerable to climate change impacts:

- Cities contribute over $70 \%$ of energy-related $\mathrm{CO}_{2}$ emissions and account for around two-thirds of global energy demand. If current trends continue, global urban primary energy use would grow by about $70 \%$ and global urban $\mathrm{CO}_{2}$ emissions by about $50 \%$ between 2013 and $2050 .{ }^{19}$

- Lifestyles of urban dwellers including how they move around, how they use energy at home, and how buildings are heated, and how they retain that heat, influence the amount of GHG emissions. It has been widely documented that $\mathrm{CO}_{2}$ emissions from transport tend to be higher in low-density urban areas without effective public transport network. ${ }^{20}$ For instance, North American countries with high personal vehicle use produce $50 \%$ more $\mathrm{CO}_{2}$ emissions than European countries. In terms of the generation of GHG emissions, it is not only the amount of energy consumed, but also the source of energy that matters.

- Local urban heat island can increase local temperatures, alter small-scale processes (e.g., landsea breeze effect) and modify meteorology. ${ }^{21}$ These effects, coupled with extreme storm and heat impacts, can damage physical and social infrastructure, which is the basis of productivity and competitiveness. The increased temperatures in urban areas due to heat island effects may

13 "Verifying Greenhouse Gas Emissions - Methods to support international climate agreements", National Research Council, Washington, DC (2010) https://www.nap.edu/catalog/12883/verifying-greenhouse-gas-emissions-methods-to-supportinternational-climate-agreements

14 Tadashi Matsumoto, et al., "An integrated approach to the Paris Climate Agreement: The role of regions and cities", OECD Regional Development Working Papers 2019/13, 2019.

15 "World Urbanization Prospects: The 2018 Revision", New York, United Nations, Department of Economic and Social Affairs, Populations Division, 2018. https://population.un.org/wup/Download/

16 "Climate Emergency, Urban Opportunity: How National Government Can Secure Economic Prosperity and Avert Climate Catastrophe by Transforming Cities", Coalition for Urban Transitions (CUT), 2019 https:///www.globalcovenantofmayors.org/wp-content/uploads/2019/09/Climate-Emergency-Urban-Opportunity-report.pdf

17 R. Dobbs, S. Smit, J. Remes, J. Manyika, C. Roxburgh and A. Restrep, "Urban World: Mapping the Economic Power of Cities", McKinsey Global Institute, 2011, https://www.mckinsey.com/ /media/McKinsey/Featured\%20Insights/Urbanization/Urban\%20world/MGI urban world mapping economic power of cities full report.ashx

18 OECD Regional Outlook 2019: Leveraging Megatrends for Cities and Rural Areas, OECD, Publishing, Paris, https://doi.org/10.1787/9789264312838-en .

19 Energy Technology Perspectives 2016, OECD Publishing, Paris, http://dx.doi.org/10.1787/energy_tech-2016-en

20 Climate Action in Megacities: C40 Cities Baseline and Opportunities, 2011 available at https://www.c40.org/researches/arupc40-baseline-report

21 Climate Change 2014: Synthesis Report. Contribution of Working Groups I, II and III to the Fifth Assessment Report of the Intergovernmental Panel on Climate Change, Intergovernmental Panel on Climate Change, Geneva, http://dx.doi.org/10.1017/CBO9781107415324 
increase energy demand for space cooling, further driving up energy demand during higher peak load periods. ${ }^{22}$

Based on this background information, it is expected that most effective mitigation efforts would be in megacities; assessment of the impact of mitigation efforts will require direct measurements of GHG emissions and attribution of these emissions to specific sources, such as a power plant, or to broader sectors such as transportation, buildings, industry, waste treatment areas, etc. GHG emission measurements have gained additional importance as carbon credits and related policies are being implemented in megacities around the globe, such as the European Emissions Trading System. $^{23,24}$

The NIST Greenhouse Gas (GHG) Measurement Program was established in 2009. Program objectives are to advance measurements and standards capabilities for greenhouse gas emissions, to develop mitigation tools, and to improve data accuracy and that of remote sensing observations taken from satellites, aircraft, and the Earth's surface. Advancing the accuracy of U.S. national GHG emissions data that feed national reporting procedures is a central program theme. This highvisibility effort seeks to improve emissions data transparency and consistency through improved measurement data quality (accuracy, reliability, and verifiability), reduced uncertainties in predictive models, and development and evaluation of advanced measurement technologies for anthropogenic and biogenic GHG flow quantification to and from the atmosphere. Through an interdisciplinary approach, NIST and external expertise advances measurement capabilities to improve emission source/sink differentiation in space and time, and standards supporting satellite instrument performance evaluation. NIST efforts are coordinated with others in the U.S., ${ }^{25}$ Europe (UK, France, Switzerland, etc.), Canada, Brazil, China and other countries to contribute to a global effort.

\subsection{Urban Greenhouse Gas Measurements - Opportunities and Challenges}

The NIST sponsored Urban Greenhouse Gas Measurements Testbed Systems program was established in 2010 to develop and demonstrate urban GHG measurement tools and methods. The system has grown from its initial testbed located in Indianapolis, Indiana, ${ }^{26,27}$ to include two additional testbed sites, Los Angeles and the Northeast Corridor, beginning in the Baltimore/Washington, DC region and extending northeast. Significant accomplishments have resulted that have advanced urban greenhouse gas quantification capabilities and skills. Since the inception of the urban test-bed concept, policy measures focused on GHG emissions mitigation in the urban domain have also seen considerable change. This workshop focused on discussions of current capabilities and future needs and plans, informed by presentations about the three U.S. testbeds, reviewing current status of research and assessment of progress toward urban GHG

22 World Energy Outlook 2018, IEA, Paris, https://doi.org/10.1787/weo-2018-en

23 https://ec.europa.eu/clima/policies/ets en

24 P. Bayer and M. Aklin, "The European Union Emissions Trading System reduced CO2 emissions despite low prices", https://www.pnas.org/content/pnas/early/2020/04/01/1918128117.full.pdf

$25 \mathrm{CO} 2$ - Urban Synthesis and Analysis Network http://sites.bu.edu/co2usa/

26 J.R. Whetstone, "Advances in urban greenhouse gas flux quantification: The Indianapolis Flux Experiment (INFLUX)", Elem. Sci. Anth., 6 (1), p. 24 (2018), DOI: http://doi.org/10.1525/elementa.282

27 K.J. Davis, A. Deng, T. Lauvaux, N.L. Miles, S.J. Richardson, D.P. Sarmiento, K.R. Gurney, R.M. Hardesty, T.A. Bonin, W.A. Brewer, B.K. Lamb, P.B. Shepson, R.M. Harvey, M.O. Cambaliza, C. Sweeney, J.C. Turnbull, J.R. Whetstone, and A. Karion, "The Indianapolis Flux Experiment (INFLUX): A test-bed for developing urban greenhouse gas emission measurements", Elem. Sci. Anth. 5, p. 21 (2017) DOI: https://doi.org/10.1525/elementa.188 
quantification tools, method development and demonstration. The agenda also included presentations on the status and results of other U.S. and international urban GHG monitoring research efforts.

In light of these recent results and the maturity and reliability of newly developed skills, a second phase of discussion focused on the challenges and opportunities associated with likely needs for delivering information services supportive of urban GHG mitigation efforts. This discussion focused on implementing delivery of GHG measurement-based capabilities in the context of international and intergovernmental coordination efforts. The Paris Agreement, ${ }^{28}$ the WMO Integrated Global Greenhouse Gas Information System $\left(\mathrm{IG}^{3} \mathrm{IS}\right),{ }^{29}$ and the Intergovernmental Panel on Climate Change (IPCC) Task Force on National GHG Inventories (TFI) ${ }^{30}$ represent interfacial areas where new or modified coordination structures are needed to more strongly link the research and stakeholder communities. This is particularly the case with respect to the increasing interest and role of the private sector as both users and providers of emissions data and information services, as well as the role of private foundations and Non-Governmental Organizations (NGOs) to assist with the transition between a research orientation and an operational or GHG measurement tool utilization scenario.

Urban Testbeds are needed to develop and demonstrate GHG measurement and analysis capabilities, assess the level of convergence between advancements in traditional emissions determination methods (bottom-up) and atmospheric measurements and analysis (top-down) approaches, as well as satellite observations. These can provide policy makers and GHG mitigation implementors with practical tools to monitor the progress and the effectiveness of mitigation activities, and potentially make interim adjustments to improve policy approaches as they manage such efforts toward emission reduction goals.

\subsection{Workshop Objectives, Scope and Format}

The objective of the workshop was to assess the state of the art of GHG emission measurements and remaining scientific challenges and identify ways to serve the needs (data and scientific tools) of specific stakeholders, including large municipalities where mitigation actions are planned or underway. Another objective was to identify actionable items and to organize follow-up activities. The workshop agenda was arranged to emphasize opportunities for discussion among the participants.

Discussion topics included opportunities and challenges for application of research results by both the research community and a wide range of stakeholders; identification of research gaps; roles for international collaborative opportunities; structural challenges and gaps in national and international activities; developmental opportunities and needs for urban emissions quantification; mechanisms for cultivating private sector participation; workforce development issues; improving communications with policy makers and stakeholders; markets and financial issues driving the need for robust GHG measurements; and the wide range and scale of governmental jurisdiction interested in this topic.

\footnotetext{
https://unfccc.int/process-and-meetings/the-paris-agreement/the-paris-agreement

9 https://ig3is.wmo.int/

https://www.ipcc-nggip.iges.or.jp/
} 
The workshop was primarily focused on U.S. efforts; however, participants were invited from the EU, New Zealand, and Canada who provided a much wider perspective in the discussions and overviews of other global research efforts.

The workshop was organized by NIST and $\mathrm{IG}^{3} \mathrm{IS}$ researchers. There were relatively few (2) plenary lectures. There were several panel discussions to share views on current state of the art, technology gaps, the role of international collaborations, and the needs of stakeholders, especially those local or national governmental organizations that are in the process of implementing mitigation efforts to reduce their GHG emissions. This topic was of utmost importance for the workshop participants, and a significant effort was made to identify mechanisms to improve communications between research and user communities and to facilitate the application of research results to real world problems. 


\section{Overview of Current Research Activities and Capabilities}

\subsection{Plenary Lecture: James R. Whetstone, NIST \\ Urban Greenhouse Gas (GHG) Measurements Program at NIST}

(See Appendix D for a complete PowerPoint presentation)

The NIST Greenhouse Gas Measurements Program aims to improve emission measurement tools to better equip decision makers and mitigation managers with capabilities to chart progress in GHG emissions mitigation. It is generally agreed that mitigation actions by municipal, regional and state governments, and by private sector institutions will be the main focus of implementation measures. Policy approaches are likely to be market based or regulatory in nature (or a combination) facilitated by technology advances. Widely recognized and accepted emissions quantification tools are needed for effective mitigation policy implementation. Such policy implementation is most likely to occur at local levels relying upon actions taken by municipal and regional governments. Reliable identification of source locations, and those responsible for them, and the amount of GHG emitted is critical to effective management and an essential component underpinning science-based decision making. Since reduction of atmospheric

GHG concentrations is the end goal of reducing atmospheric warming, the incorporation of atmospheric measurement results in emissions inventories will play an essential mitigation role in tracking progress in emission

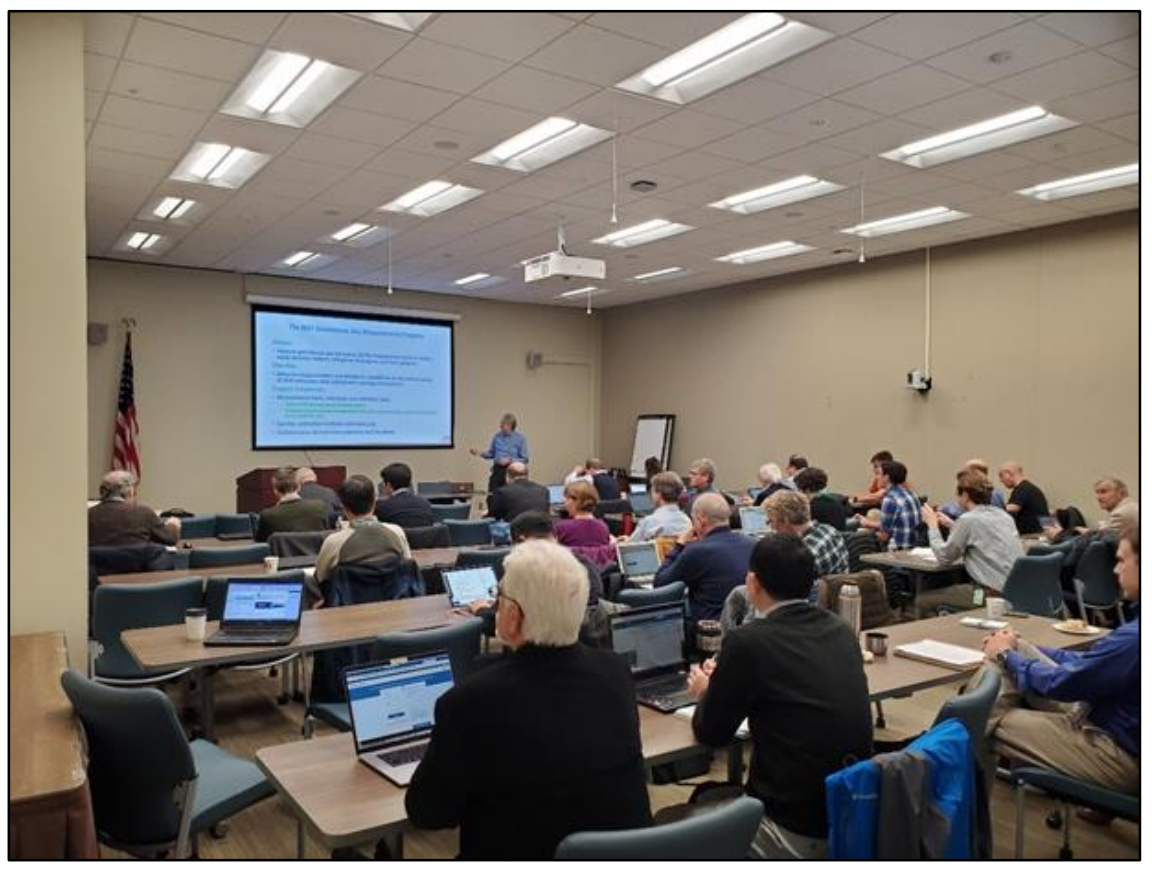
reduction efforts.

NIST's Greenhouse Gas Measurements Program develops and demonstrates measurement tools, standards and reference data in the areas of:

- Urban GHG Measurement Testbed System,

- Stationary/point source (smokestack) emission measurements, and

- Optical radiocarbon measurements.

Similar research efforts address improved satellite calibration methods and standards and those for carbonaceous aerosols.

Market-driven approaches, supported by emissions caps, are expected to augment emissions trading markets resulting in expanded access to credits for those needing emissions offsets. Confidence in emission credit quantification based on advancing measurement capabilities will be foundational 
for support of orderly markets. For certain sectors of emitters, such as power plants and large industrial plants, direct measurements of flue gas composition and flow rate are widely applied in the U.S. Recent NIST efforts have demonstrated accuracy capabilities at the few percent level. ${ }^{31}$ For other point and non-point sources, such as vehicle transportation, residential and commercial buildings, landfills, and agricultural operations, indirect methods that use various proxy data are used to estimate emissions. Validity of such usage can be verified with appropriate atmospheric measurements to provide confidence in inventory data and emissions credits. NIST GHG measurements program was established to advance these measurement methods and standards thereby enhancing accuracy and confidence in emissions and uptake quantities. The remaining key question is: What level of accuracy and standardization provide sufficient confidence within the international climate finance community to provide meaningful resources for municipal and state mitigation efforts?

The proposed U.S. House of Representatives bill CLEAN (Climate Leadership and Environmental Action for our Nation's) Future Act ${ }^{32}$ identifies several sectors of the economy where advances must be made to achieve a $100 \%$ clean economy by 2050 , in concert with recommendations of the IPCC. It emphasizes the role states and local jurisdictions have to play and establishes a National Climate Bank "to help states, cities, communities and companies in the transition to a clean economy".

\section{Advancing Greenhouse Measurements in Cities}

A proposal by K. Gurney, P. Shepson and C. Sweeney for funding from NIST's ARRA ${ }^{33}$ funds catalyzed the start of NIST's Urban Greenhouse Gas Measurements Testbed Program established in 2009. The Testbed Program's objective is to support comparative experiments among atmospheric observations and analyses and emission modeling information. The research project, the Program's first testbed, was established in 2010 in the city of Indianapolis, IN and is known as the Indianapolis Flux Experiment (INFLUX).

INFLUX research initially focused on comparing three emissions measurement methods, an airborne mass balance method ${ }^{34}$, analysis methods using data taken from a two-node surface observing network, ${ }^{35}$ and the Hestia spatiotemporal emissions modeling system. ${ }^{36}$ (Hestia's spatial resolution is sub-kilometer with hourly temporal resolution.) The surface network is based on 24/7 atmospheric concentration measurements of samples drawn from sampling points located at several heights on communications towers located in and around the metropolitan area. At that time Indianapolis was the only city in the U. S. with an extensive emissions data product of sufficient spatiotemporal resolution to directly compare with the other methods based on atmospheric observations and analysis. The emissions monitoring network nodes were located on existing

31 A. Johnson1, I. Shinder, M. Moldover, J. Boyd, and J. Filla, "Progress Towards Accurate Monitoring of Flue Gas Emissions" 10th International Symposium on Fluid Flow Measurement (ISFFM), Querétaro, Mexico, March 2018

32 https://energycommerce.house.gov/newsroom/press-releases/ec-leaders-release-framework-of-the-clean-future-act-a-bold-newplan-to

33 American Re-investment and Recovery Act, 2009

34 K.L. Mays, P.B. Shepson, B.H. Stirm, A. Karion, C. Sweeney, and K.R. Gurney, "Aircraft-Based Measurements of the Carbon Footprint of Indianapolis”, Envir. Sci. \& Tech., 43, pp. 7816-7823 (2009). http://doi.org/10.1021/es901326b

35 S.J. Richardson, N.L. Miles, K.J. Davis, T. Lauvaux, D.K. Martins, J.C. Turnbull, K. McKain, C. Sweeney, C and M.O.L. Cambaliza, "Tower measurement network of in-situ CO2, CH4, and CO in support of the Indianapolis FLUX (INFLUX) Experiment", Elem. Sci, Anth., 5, p. 59 (2017). DOI: https://doi.org/10.1525/elementa.140

36 K.R. Gurney, I. Razlivanov, Y. Song, Y. Zhou, B. Benes, and M. Abdul-Massih, M, "Quantification of Fossil Fuel CO2 Emissions on the Building/Street Scale for a Large U.S. City", Envir. Sci. \& Tech. 46, pp. 12194-12202 (2012). DOI: https://doi.org/10.1021/es3011282 
communication towers. INFLUX was expanded in 2010 and 2011 to test atmospheric inverse analysis methods. A main objective was to determine whether a dense observing network coupled with appropriate analyses had the ability to produce spatially resolved results (at the $1 \mathrm{~km}^{2}$ to $3 \mathrm{~km}^{2}$ scale), with reduced uncertainty, and the role dense networks could play in providing emissions data. Ten additional surface-based observing nodes were added to the INFLUX network for a total of 12 nodes along with atmospheric inversion analysis. The latter uses meteorological models to simulate atmospheric transport of emissions from their source to network measurement points. A city with little sharply varying terrain, Indianapolis is a location where models such as the Weather Research and Forecasting (WRF) model $^{37}$ provide their best performance simulating atmospheric transport.

Additional NIST investments in 2013 enabled the establishment of the second testbed city, the LA Basin. Whereas Indianapolis has little impact from surrounding terrain on the dynamics of the atmosphere and moderate size, Los Angeles has significant terrain and the Pacific Ocean as one boundary with strong terraininduced atmospheric effects and is approximately 10 times the size of Indianapolis. It is truly a megacity. Inclusion of the LA basin in the testbed system provided the opportunity to extend measurement

methodologies over the

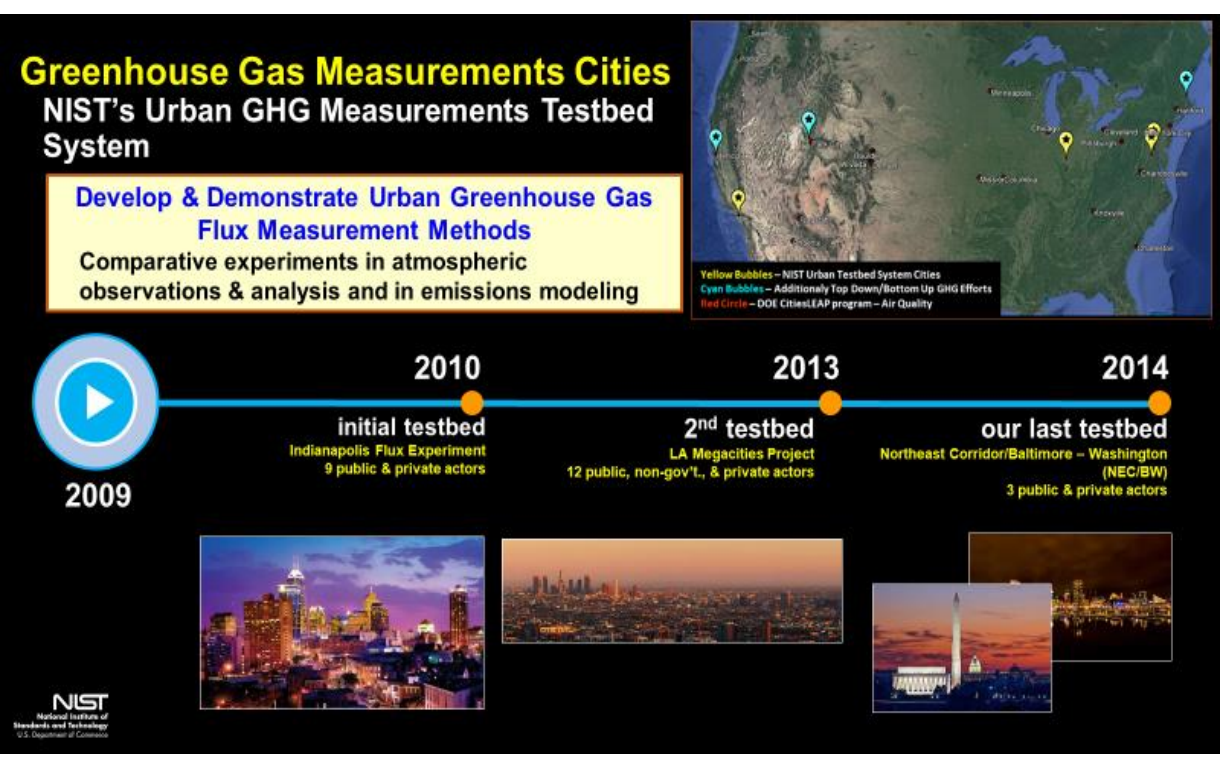
range of terrains and weather patterns.

To develop a testbed that would extend testing capabilities and methodologies from the urban to the regional scale, the U.S. Northeast Corridor (NEC) was chosen as the third and potentially last testbed of the System. Begun in the Baltimore/Washington D.C. metropolitan area in 2014 and denoted the NEC/BW project, this testbed applies the technology of high-density, surface-based observing networks within the heavily populated and industrialized NEC corridor. The as yet unrealized ambition for this project is to extend surface-based observing networks to the major cities of the NEC, and to combine these observations with integrated column measurements available from various satellite and airborne platforms. Located on the Eastern edge of the U.S., the NEC Testbed has the distinction of being that region of the continental U.S. into which much of the air from the industrialized mid-west and the southeast pass. This passage provides another measurement challenge, that of properly characterizing the GHG burden of the incoming atmosphere. Such characterization is needed at accuracy levels sufficient to separate emissions from NEC regions from

37 W.C. Skamarock, J. B. Klemp, J. Dudhia, D. O. Gill, D. M. Barker, M. Duda, X.-Y. Huang, W. Wang, and J. G. Powers, “A description of the advanced research WRF version 3", NCAR Tech. Note NCAR/TN-475+STR, 113 p., Natl. Cent. for Atmos. Res., Boulder, CO (2008) 
that of the incoming atmospheric burden. The NEC/BW has also supported the development of internal measurement and analysis capabilities within NIST and has continued to strengthen engagement with private sector stakeholders.

\section{Results of Comparative Experiments - Whole City Emissions}

Recent results for the entire city of Indianapolis, demonstrated capabilities of methods used in INFLUX ${ }^{38}$ research. This experiment compared multiple, whole city emissions estimates involving two airborne $\mathrm{CO}_{2}$ mass balance measurements, an atmospheric inversion analysis based on data from the INFLUX surface observing network, and results of the Hestia emissions model. This is often referred to as a comparison of bottom-up (Hestia results) and top-down (atmospheric observation and analyses) methods. These results agreed within $\pm 7 \%$ of one another and represent a significant advance in capability relative to previous experimental results ${ }^{\text {that }}$ varied by $30 \%$ to $50 \%$ relative to adjusted national emissions reporting data. It should be noted that these results were obtained from data taken in the winter of 2013 recognizing that the biospheric emissions are much suppressed in winter. This combination of measurements, inversion analysis, and emissions modeling give us confidence that the methods under development are achieving the desired results.

A second analysis involved atmospheric inversion and Hestia emissions modeling over a 3-year period. Over this period emissions and uptake from the biosphere cannot be ignored as these emissions can have a magnitude that is similar to that of anthropogenic combustion emissions. To account for these the Vegetation Photosynthesis and Respiration Model $(\text { VPRM })^{39}$ was used to estimate biospheric emissions and uptake over the 3-year period. These, coupled with Hestia results, were the initial emissions estimate used in the Bayesian

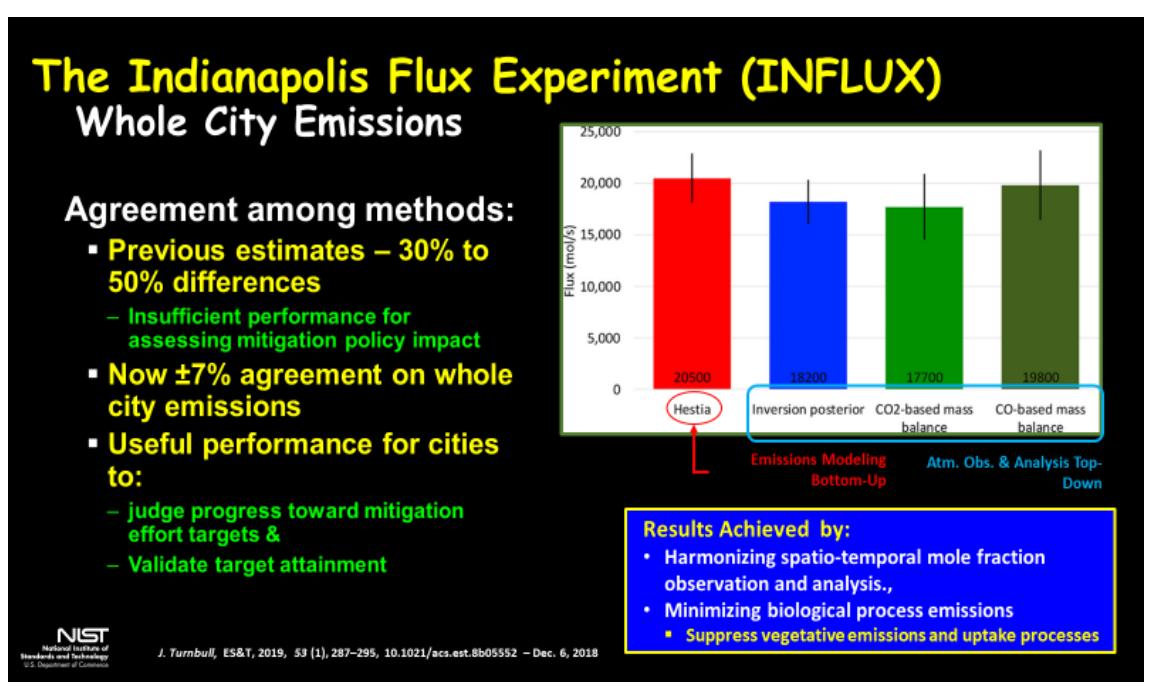
inversion analysis. The results show remarkable consistency and stability over the 3-year analysis. Inclusion of biospheric emissions compensate for some emissions variability, contributing substantially to the ability to separate the anthropogenic components represented by Hestia from biospheric emissions. Error bars represent variability estimates of each method.

As a test of the ability of the Bayesian analysis to use the observations to correct inaccuracies in the initial emissions estimate of Hestia, its values were intentionally offset by $15 \%$. A re-analysis with this incorrect initial estimate results in a corrected value of $-14.2 \%$. This is an excellent result for

38 J.C. Turnbull, A. Karion, K.J. Davis, T. Lauvaux, N.L. Miles, S.J. Richardson, C. Sweeney, K. McKain, S.J. Lehman, K.R. Gurney, R. Patarasuk, J. Liang, P.B. Shepson, A. Heimburger, R. Harvey, and J Whetstone "Synthesis of Urban $\mathrm{CO}_{2}$ Emission Estimates from Multiple Methods from the Indianapolis Flux Project (INFLUX)”, Environ. Sci. \& Tech., 53, pp. 287-295 (2019)

39 P. Mahadevan, S.C. Wofsy, D.M. Matross, X.M. Xiao, A.L. Dunn, J.C. Lin, C. Gerbig, J.W. Munger, V.Y. Chow and E.W. Gottlieb, "A satellite-based biosphere parameterization for net ecosystem CO2 exchange: Vegetation Photosynthesis and Respiration Model (VPRM). global biogeochemical cycles”, 22(2), GB2005 (2008) 
whole city emissions. However, the agreement is exceptionally close, much more so than previous results. Certainly, replication of the methodology in differing settings is needed. However, these methods hold promise for further investigation of the sensitivity of the method for estimation of emissions from various sectors, e.g., the transportation and housing sectors. These also hold implications for greater stakeholder engagement. One of the topics we wanted to discuss during the workshop was how we communicate these results to the stakeholders and make them useful for them.

\section{Engaging Stakeholders, Knowing Their Needs}

As part of NIST efforts to interact with and assist local governments in their efforts to reduce GHG emissions, it is working with the government of Montgomery County, Maryland, home to NIST's Gaithersburg campus with 578 acres along a major arterial link in metropolitan Washington, DC. Challenges of climate change have mobilized many economic, technical, and community groups within the County, and the Office of County Executive is leading the charge with aggressive GHG reduction targets and action plans towards net-zero emissions ${ }^{40}$ To achieve this ambitious goal, the County government has implemented various policies and initiatives, and their new Climate Action and Resiliency Plan has played a critical role in extending their community-wide engagement process. The plan provides specific GHG reduction strategies for major sectors such as building efficiency, transportation, adaptation, land use, sequestration, and public engagement. Montgomery County's Climate Planning Team is in dialog with various NIST experts in building efficiency, community resilience planning, GHG emissions measurements and monitoring. More information on their Climate Action planning process is available from their website.

40 https://www.montgomerycountymd.gov/climate 


\subsection{Plenary Lecture: Philip L. DeCola, GIST.earth Overview of Integrated Global GHG Information System (IG ${ }^{3}$ IS)}

(See Appendix D for a complete PowerPoint presentation)

DeCola opened his remarks identifying three areas of concern that should be emphasized during this workshop:

1. Stakeholder involvement - We got a taste of what user/stakeholder entrainment might look like at the $2^{\text {nd }} \mathrm{IG}^{3} \mathrm{IS}$ workshop in Paris in October 2019. He felt that we have made some progress in this regard, but would have to do a better job articulating the value proposition to get stakeholder involvement

2. Financial support - So far support has come only from the U.S. federal government (NIST, NOAA, NASA, etc.) and other government organizations. How do we bring in support from the private sector, in order to scale up the current efforts, and bring involvement by new players? This is critical to scale up the effort and grow the market.

3. Institutional Infrastructure - $\mathrm{IG}^{3} \mathrm{IS}$ was successful in

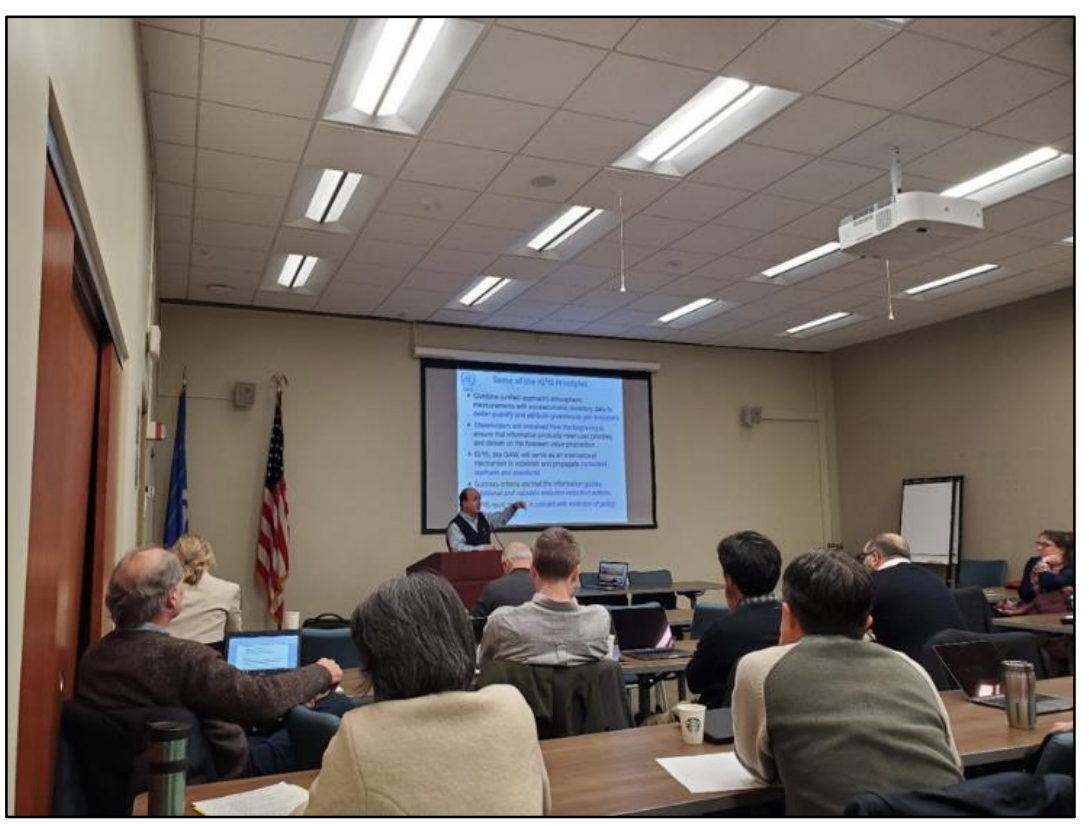
getting this community a standing in the international community; WMO has played an important role in getting $\mathrm{IG}^{3} \mathrm{IS}$ going but there are also drawbacks. In fact, WMO has focused attention on issues of urban environments, such as air quality, emissions, meteorology, but has not been able to help in entraining other stakeholders, such as ICLEI, ${ }^{41} \mathrm{C} 40 \mathrm{Cities},{ }^{42} \mathrm{Global}$ Covenant of Mayors for Climate and Energy, ${ }^{43}$ etc. This is of course not surprising since WMO is an organization of national representatives. Then the question remaining to be answered was how do we connect with other institutions and other stakeholders at subnational levels?

DeCola provided a historical context for evolution of $\mathrm{IG}^{3} \mathrm{IS}$, and an overview of the principals involved, accomplishments, and some seeds for discussion. The idea of a Global GHG Information System was put forth in 2008 by Jim Butler of NOAA, who was a member of the WMO Commission for Atmospheric Sciences (CAS), and Oystein Hov of the Norwegian Meteorological Institute. The original vision was to create a grand system to verify that countries were achieving the targets they had pledged in terms of GHG reductions, but the white paper did not go far. At COP 20 in Lima, Peru, the concept of Nationally Determined Contributions (NDCs), an aspirational view toward

\footnotetext{
Local Governments for Sustainability https://icleiusa.org/

C40 Cities https://www.c40.org/

https://www.globalcovenantofmayors.org/
} 
GHG emission reductions, was established. In the meantime, there were number of activities related to GHG measurements, both at national level (in UK, Alistair Manning's work), at urban level (NIST Urban Testbeds), as well as identification of point sources (methane hotspot detection, stack gas monitoring, etc.). There were several seminal reports published about the importance of

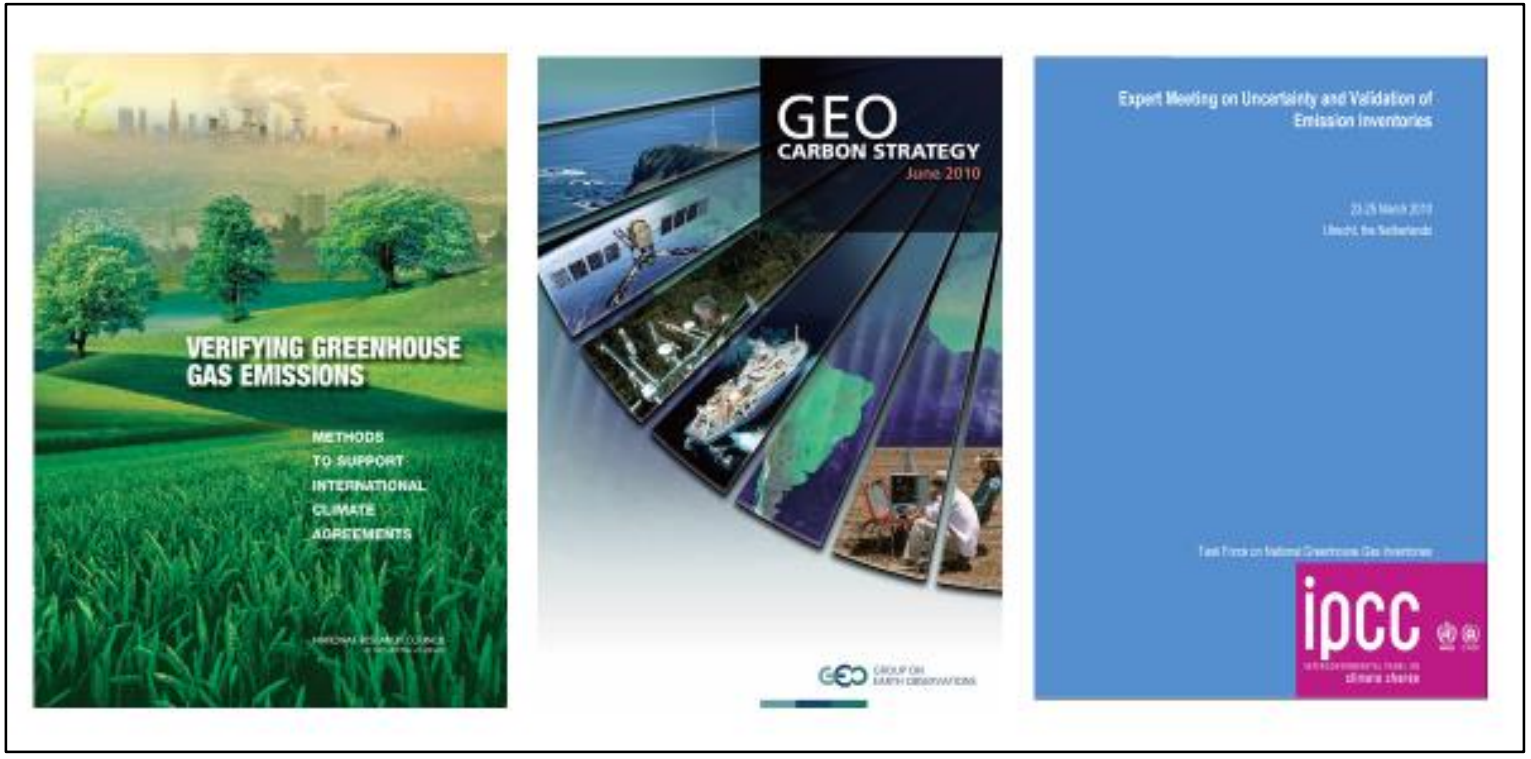

verifying greenhouse gas emissions. ${ }^{44,45,46}$ Encouraged by these activities, Butler and Hov rejuvenated their idea to establish an Integrated Global Greenhouse Gas Information System ( $\mathrm{IG}^{3} \mathrm{IS}$ ); their proposal was discussed at the 2015 WMO Congress. A Steering Committee started work on a Science Implementation Plan and met before the GGMT meeting held at the Scripps Institute in 2015. ${ }^{47}$ The $\mathrm{IG}^{3}$ IS proposal was approved by WMO Executive Council in 2016; the Implementation Plan was approved by EC-70 in 2018, and WMO $18^{\text {th }}$ Congress adopted it in June 2019.

At COP15 in Copenhagen, the agreement was on "Binding Multinational Treaty Commitments"; the approach was on "verifying reported national emissions". This involved a grand top-down GHG information system, advocated by the science community.

By the time COP25 came about, the approach had changed quite a bit. Now the focus was on Nationally Determined Contributions (NDCs); a "federation of focused monitoring systems" were being put in place to "help improve the quality of GHG emissions data". This aspirational approach was supported by WMO (representing meteorological services of 191 countries), UNEP, organizations representing cities (e.g., C40), NGOs, and industry (e.g., oil and gas companies).

At the time, based on Keeling's observations, it was widely accepted that atmospheric carbon dioxide concentrations were increasing along with global temperatures. It was realized that telling people their inventories were all wrong and atmospheric measurements would give them the right answers was counterproductive. $\mathrm{IG}^{3} \mathrm{IS}$ put forth the concept that atmospheric measurements could identify some of the solutions and perhaps where the major sources of GHGs were. This way, IG $^{3} I_{S}$ became part of the solution and was accepted more readily.

44 Verifying Greenhouse Gas Emissions, National Academies, Washington, DC (2010)

45 GEO Carbon Strategy, Group on Earth Observations

46 Experts Meeting on Uncertainty and Validation of Emission Inventories, IPCC

$4718^{\text {th }}$ WMO/IAEA Meeting on Carbon Dioxide, Other Greenhouse Gases, and Related Measurement Techniques, La Jolla, CA, September 13-17, 2015 http://ggmt-2015.com/ 


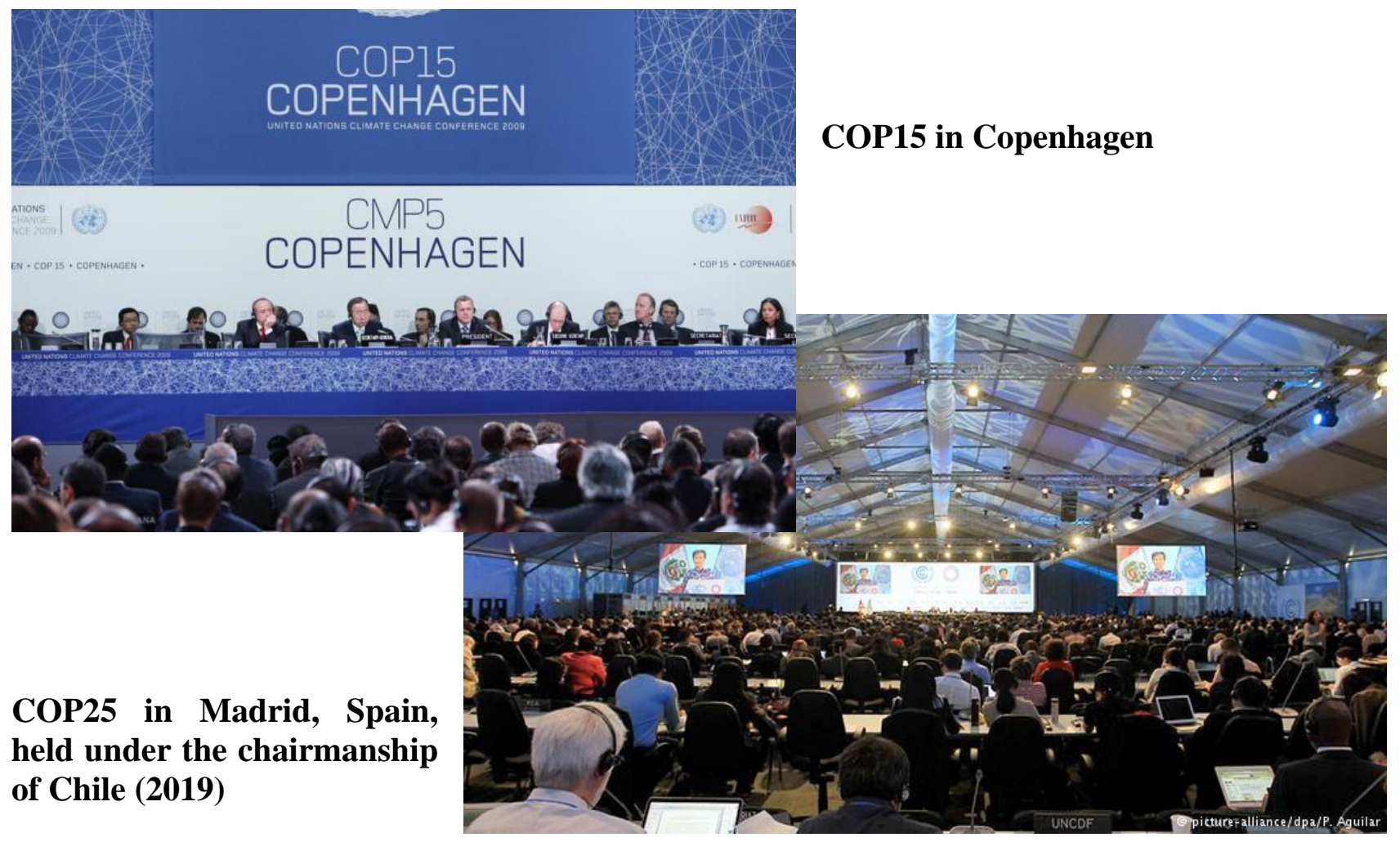

$\mathrm{IG}^{3} \mathrm{IS}$ contributed to these developments by establishing the following principles:

- Combine (unified approach) atmospheric measurements with socioeconomic inventory data to better quantify and attribute greenhouse gas emissions.

- Stakeholders are entrained from the beginning to ensure that information products meet user priorities and deliver on the foreseen value proposition.

- $\mathrm{IG}^{3} \mathrm{IS}$, like GAW, will serve as an international mechanism to establish and propagate consistent methods and standards.

- Success-criteria are that the information guides additional and valuable emission-reduction actions.

- $\mathrm{IG}^{3} \mathrm{IS}$ must mature in concert with evolution of policy and technology.

Some of the actions $\mathrm{IG}^{3} \mathrm{IS}$ has taken include promoting projects to build up a user base and document best practices. These were aimed at supporting national inventory reporting and countries' efforts in NDC tracking and global stocktaking. $\mathrm{IG}^{3} \mathrm{IS}$ has also encouraged atmospheric based solutions at various spatial and temporal scales, specifically in two areas: a) developing standards for atmospheric measurements, data analysis, and practical tools, and b) extend these efforts beyond national to regional/local applications.

Among the accomplishments of $\mathrm{IG}^{3} \mathrm{IS}$, DeCola mentioned the MOU that was signed between WMO and UNEP Secretariat, which was helpful in opening doors for $\mathrm{IG}^{3} \mathrm{IS}$ into Ministries of member countries for high level discussions. Another success was the recognition by the Subsidiary Body for Scientific and Technological Advice (SBSTA) of UNFCCC that in situ and satellite information on atmospheric concentrations of $\mathrm{CO}_{2}$ would be helpful for implementing the Paris Agreement. Discussions were held with $\mathrm{IG}^{3} \mathrm{IS}$ which lead to the changes in the IPCC Guidelines. 
By highlighting and promoting the role of atmospheric measurements in validating GHG emissions inventories, IG ${ }^{3}$ IS was instrumental in 2019 refinement of the 2006 TFI Guidance by IPCC which will now improve guidance to countries:

Will include assessment of methods for using atmospheric measurements \& analyses to improve inventory estimates and certainties.

The Guidance also "established a link with WMO/IG ${ }^{3} I S$ effort to propagate methods and standards to both developed and developing countries."

This language was developed by Shamil Maksyutov, lead author of Volume 1, Chapter 1, in the section on Comparison with Atmospheric Measurements, which provided a well-referenced, detailed protocol that could be used for quality control, under the heading 6.10.2.1 Introduction to Emission

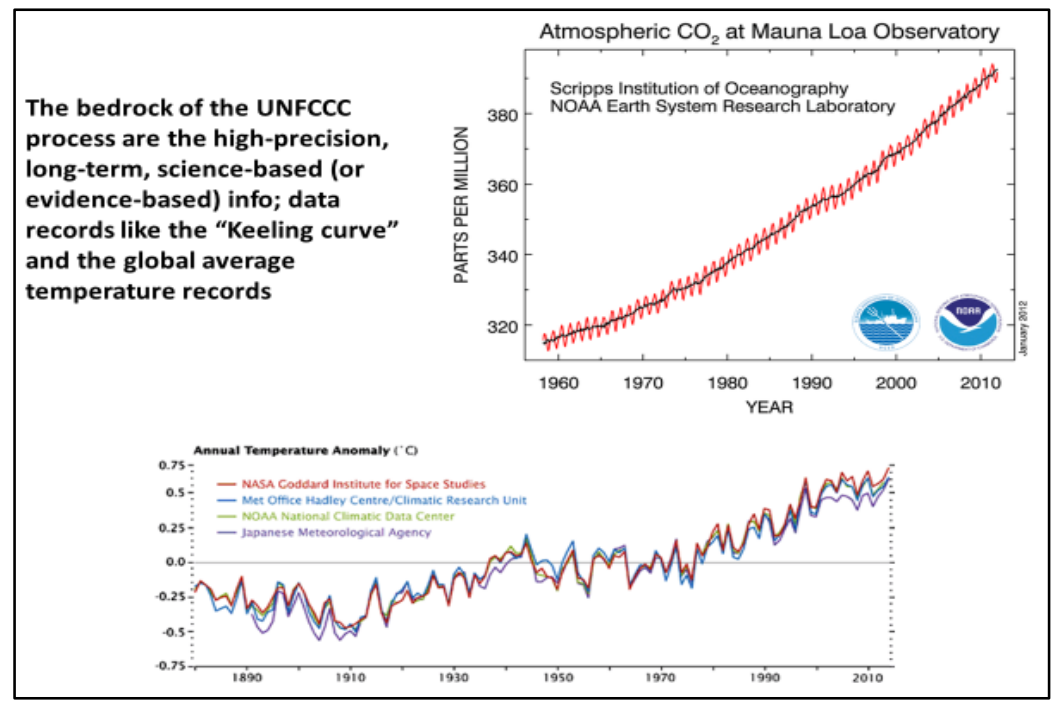
Estimates based on Atmospheric Concentration Measurements.

Another recognition of the importance of atmospheric measurements was the adoption of $\mathrm{IG}^{3} \mathrm{IS}$ approach by the Committee on Earth Observation Satellites ${ }^{48}$ in their report on $A$ Constellation Architecture for Monitoring Carbon Dioxide and Methane from Space, making sure that all the information is integrated in with the satellite observations. This recognition was important to getting EU constellation funding.

$\mathrm{IG}^{3} \mathrm{IS}$ has also facilitated interactions between the TRANSCOM and IG3IS communities through joint meetings. ${ }^{49}$ The latest of these was the meeting held in Paris at Cité Universitaire (October 2019). One of the main topics of discussion was the Inverse Modeling Crosscut Case Studies: Urban and National Scales, to identify the skill sets needed and to develop a benchmark to assess those capabilities to predict, for example, total $\mathrm{CO}_{2}$ and $\mathrm{CH}_{4}$ for a given urban environment.

Finally, DeCola talked about the reorganization process WMO is going through that will impact $\mathrm{IG}^{3} \mathrm{IS}$. It is decided that existing 8 commissions will be replaced by two commissions (Services, Infrastructure) and a Research Board. GAW and IG3IS activities will be under the Research Commission. IG $\mathrm{IG}^{3} \mathrm{IS}$ has proposed terms of references; similar to Air Quality and Deposition (chaired by Ariel Stein) Committees. Announcement are expected to go out calling for nominations for membership; 15 members will be in the "Steering Committee" of IG $^{3} I S$; geographic and gender balance will be an important factor in the makeup of the SC. The other item DeCola mentioned was the $2^{\text {nd }} \mathrm{IG}^{3} \mathrm{IS}$ Users Summit that is planned to be held in Geneva, during the week of October 26, $2020^{50}$.

48 Committee on Earth Observation Satellites https://ceos.org/wp-content/uploads/2020/02/Item-5CEOS_CGMS_GHG_Constellation_Roadmap_-V2.3_cleaned.pdf

49 https://ig3is.wmo.int/en/events/ig3is-transcom-workshop-and-ig3is-science-team-meeting

50 IG3IS Consultation Series, Towards an International standard for Urban GHG Monitoring and assessment, https://ig3is.wmo.int/en/events/towards-international-standard-urban-ghg-monitoring-and-assessment 


\section{Panel Discussions}

3.1 Panel Discussion: Scientific and Technical Successes, Barriers, Impacts and Knowledge Gaps
Moderators: Paul Shepson, Stony Brook University SUNY
Kenneth Davis, Pennsylvania State University
Panelists: $\quad$ Ronald Cohen, University of California at Berkeley
Anna Karion, NIST
Ralph Keeling, Scripps Institution of Oceanography, UCSD
Thomas Lauvaux, LSCE, France
Alistair Manning, UK Met Office
Charles (Chip) Miller, Jet Propulsion Laboratory, NASA
Felix Vogel, Environment Canada

Prior to the workshop, the moderators asked panel members to provide comments on current progress; community needs to provide useful urban-scale GHG emission data to stakeholders; what temporal resolution in flux quantification was needed; what improvements were needed to reduce bias / increase accuracy in urban-scale GHG emission quantification; how to improve GHG emissions inventories; what was needed to make our research products more operational and easier to use, and other technical challenges? The input provided by panel members was collated by Ken Davis and organized into three categories, successes, challenges and needs.

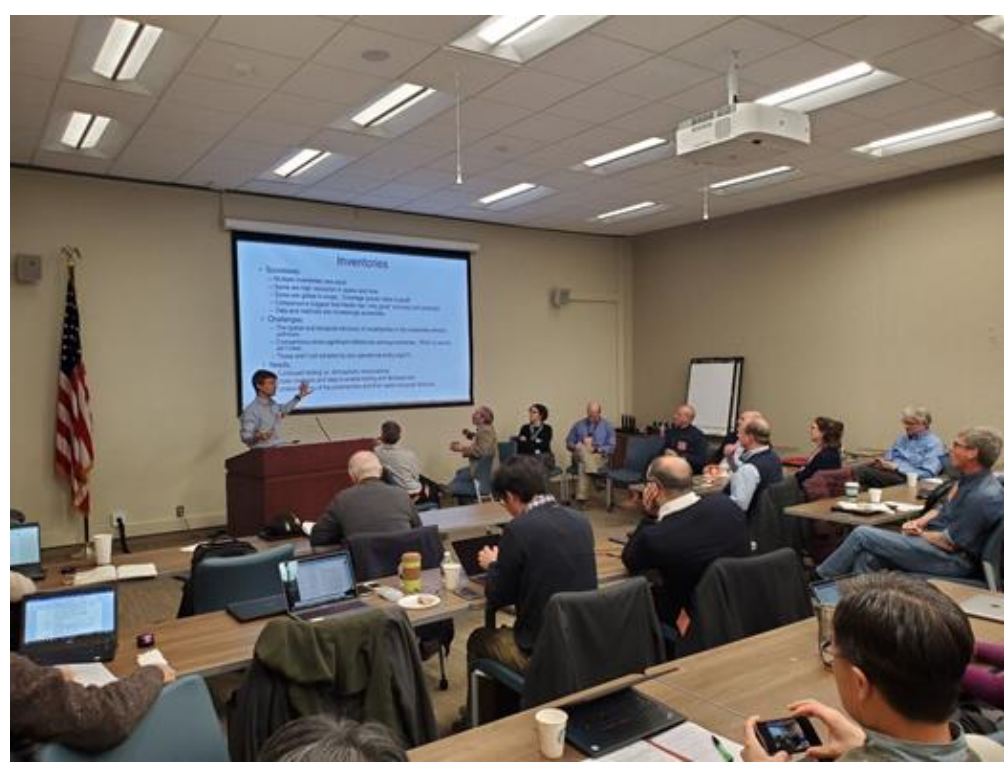

\section{Emission Inventories}

- Successes.

- Multiple inventories now exist; some are providing high resolution in space and time.

- Some are global in scope. Coverage across cities is good!

- Comparisons suggest that Hestia has "very good" accuracy and precision.

- Data and methods are increasingly accessible.

- Challenges.

- The spatial and temporal structure of uncertainties in the inventories remain unknown.

- Comparisons show significant differences among inventories. Which is correct isn't clear.

- These are not yet adopted by any operational entities.

- Needs.

- Continued testing is needed vs. atmospheric observations.

- Open methods and data to enable testing and development.

- Understanding of the uncertainties and their spatio-temporal structure. 


\section{Urban GHG Flux Estimates}

- Successes

- Aircraft have successfully provided quick whole-city quantification with "useful" accuracy and precision.

- Tower-based atmospheric inversions have been demonstrated in a few cities. Accuracy and inter-annual precision are improving.

- Inventories exist for many cities.

- We have made progress in understanding the urban background.

- We have made progress understanding the impact of biospheric fluxes.

- Eddy covariance has proven useful for multiple purposes in the urban environment.

- Estimation of emissions of purely anthropogenic trace gases has been very successful

- Trace gases $\left(\mathrm{CO},{ }^{14} \mathrm{C}\right)$ are being used to inform urban $\mathrm{GHG}$ fluxes

- Divergence between $\mathrm{CH}_{4}$ inventories and atmospheric fluxes has been identified.

- Inversion methods have become increasingly sophisticated, and were applied to multiple types of observations

- Embedding inversion within a regional simulation looks promising

- Challenges

- Biases in flux estimates may still be significant

- Inversions remain difficult to construct; these are complex and expensive methods

- Satellite-based estimates have proven challenging

- The biosphere and complex background conditions remain challenges and degrade the accuracy and precision of atmospheric methods

- Space and time resolution of inverse flux estimates remains limited

- Sectors are difficult to separate using atmospheric measurements

- Atmospheric transport biases remain, and aren't readily / commonly quantified

- Low level winds and near-surface dispersion are a challenge for atmospheric transport systems

- Intermittent sources not captured in prior are tough for atmospheric methods to quantify

- Atmospheric model resolution in urban areas is limited; they may not match well to the scale of atmospheric observations.

- Needs

- Open, portable methodology of urban inversions; a) for experimentation, b) for "users"

- More experimentation with inversion methods.

- Evaluation of results across multiple cities.

- Pursuit of sources of bias in flux estimates

- Better quantification of urban meteorology and transport model biases; development of transport ensembles that are not biased

- Urban tracer release experiment to quantify biases

- Time filtering of data to separate near-field from whole-city signals

- Integrate multiple atmospheric observations, including satellites

- Definition of spatio-temporal structure, and magnitude of uncertainties in inventories

- Options for atmospheric observations in cities without towers.

After this summary of findings, Panel members were asked to make brief presentations about their research programs. Brief summaries are presented on the following pages. 


\subsubsection{Ronald Cohen}

\section{University of California at Berkeley}

$\mathrm{BEACO}_{2} \mathrm{~N}$ (Berkeley Environmental, Air Quality and $\mathrm{CO}_{2}$ Observation Network) is a new approach to observing atmospheric gases over an urban area. Instead of using a small number of extremely sensitive instruments to measure a large area, we blanket interesting locations with a high-density network of instruments, with each instrument representing a network "node". Individually, measurements from these nodes are of moderate quality, but when taken together as a network produce an accurate, highly resolved picture of real-time pollutant concentrations. Some 70 locations are monitored in the Bay area. Each node measures $\mathrm{CO}_{2}$, a major anthropogenic contributor to climate change, and reports back to this site where the collected data including temperature, pressure, and relative humidity is publicly available for viewing and download. The nodes also collect data on nitrogen dioxide $\left(\mathrm{NO}_{2}\right)$, ozone $\left(\mathrm{O}_{3}\right)$, and carbon monoxide $(\mathrm{CO})$ which are indicators for the overall air quality of an area and may be useful for tracing the origins of $\mathrm{CO}_{2}$ emissions.

$\mathrm{BEACO}_{2} \mathrm{~N}$ is also a novel approach to scientific outreach. A science curriculum for $\mathrm{K}-12$ teachers using the BEACON sensors has been developed by scientists and educators at the Chabot Space and Science Center in Oakland, CA. To the extent possible, nodes are being placed on the rooftops of local area schools, so that students may see for themselves the greenhouse gas (GHG) pollution in their area. They also have plans to place nodes on other local science museums and will be working with staff to facilitate displays of the $\mathrm{BEACO}_{2} \mathrm{~N}$ data. Similar systems are being deployed in New York City and Huston, TX; these will be extended to Pasadena, CA and Glasgow, UK, where 20 monitoring locations will be established.

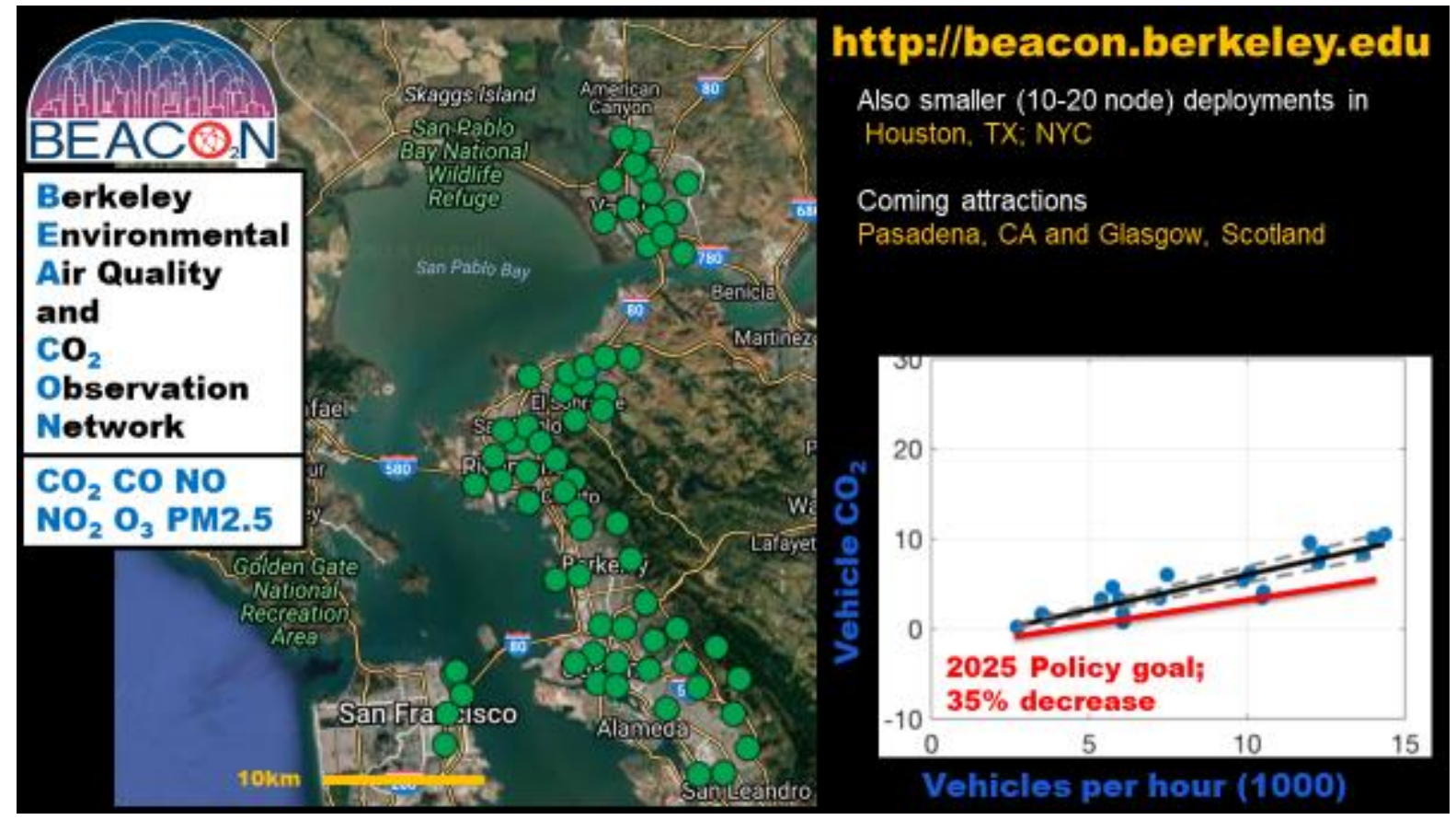




\subsubsection{Anna Karion}

\section{NIST}

The Northeast Corridor (NEC) project was established in 2015 as the third NIST urban testbed, after Indianapolis and Los Angeles. The goals for this project are:

- To demonstrate that top-down atmospheric emissions estimation methods can be used in a domain that is complicated by many upwind and nearby emissions sources in surrounding urban areas. The objective is to isolate the anthropogenic GHG emissions from urban areas along the U.S. East Coast from many confounding sources upwind (cities, oil\& gas development, coal mines, and powerplants).

- To use both ground-based and airborne measurements to understand the large biological $\mathrm{CO}_{2}$ signal from the highly productive agricultural areas and forests nearby and within the cities. The presence of highly vegetated areas such as urban parks, local agriculture, and managed lawns is expected to dominate the $\mathrm{CO}_{2}$ signal in summertime.

- To demonstrate the use of multiple inverse model constructions using both tower-based and aircraft-based observations to infer emissions of anthropogenic $\mathrm{CO}_{2}$ and $\mathrm{CH}_{4}$ from urban regions in the Northeast US.

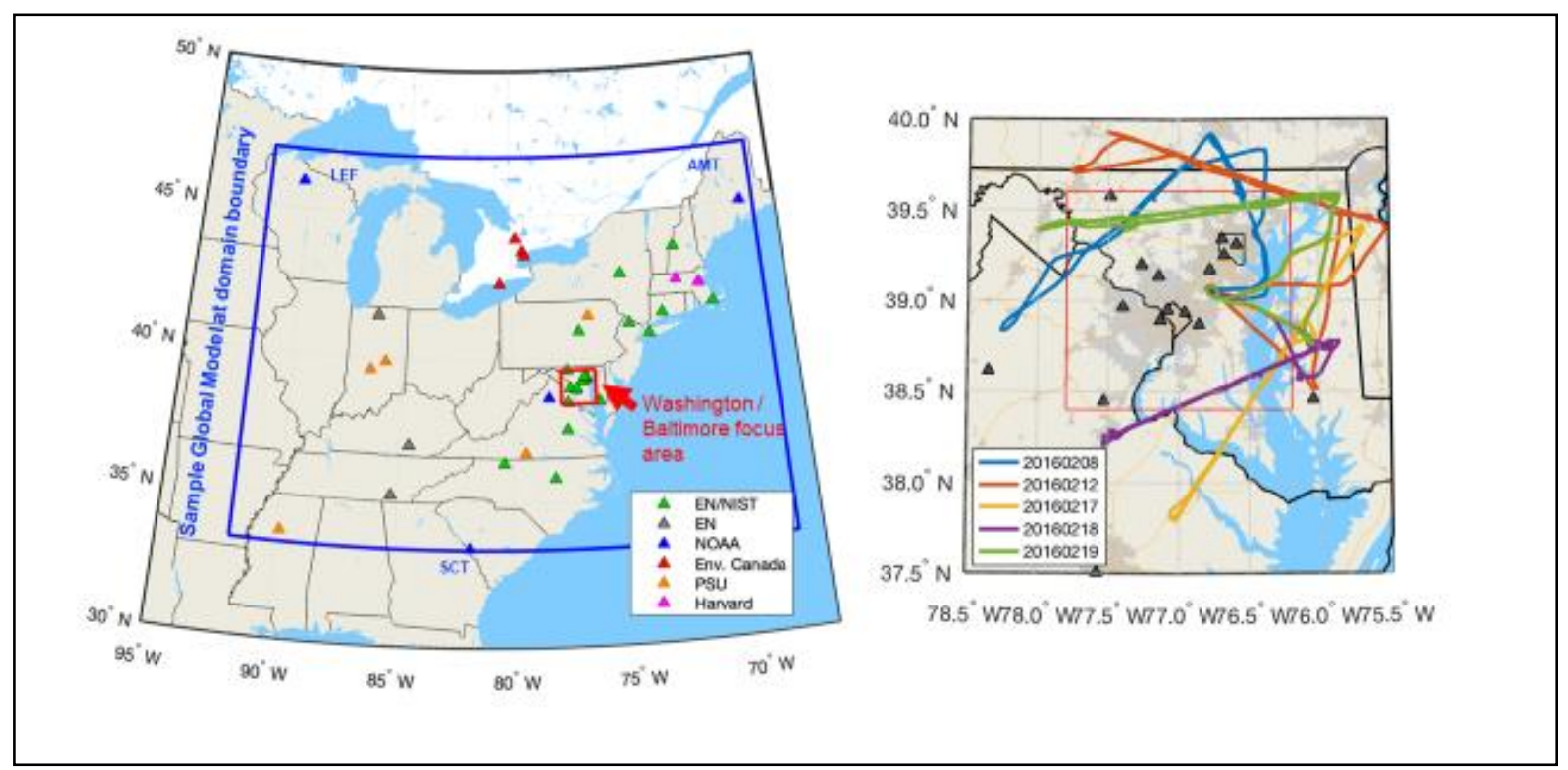

Some successes achieved so far include:

- It was found that nesting our urban domain in a larger regional domain for modeling purposes has helped us define a better background. It also has allowed us to evaluate regional biospheric $\mathrm{CO}_{2}$ and methane flux models/inventories. ${ }^{51}$

- Significant success achieved (along with various publications out) using aircraft campaign data (from UMD and Purdue), both using mass balance and inversion modeling. ${ }^{52}$

- Tower-based analysis has quantified methane emissions in DC/Baltimore (U. Michigan).

51 A. Karion, W. Callahan, M. Stock, S. Prinzivalli, K.R. Verhulst, J. Kim, P.K. Salameh, I. Lopez-Coto, and J. Whetstone, "Greenhouse gas observations from the Northeast Corridor tower network", Earth Syst. Sci. Data, 12, pp. 699-717 (2020) https://doi.org/10.5194/essd-12-699-2020.

52 I. Lopez-Coto, X. Ren, O.E. Salmon, A. Karion, P.B. Shepson, R.R. Dickerson, A. Stein, K. Prasad, and J.R. Whetstone, "Wintertime CO2, CH4, and CO Emissions Estimation for the Washington, DC-Baltimore Metropolitan Area Using an Inverse Modeling Technique”, Environ. Sci. \& Tech., 54 (5), pp. 2606-2614 (2020). https://doi.org/10.1021/acs.est.9b06619 
The signal of biological $\mathrm{CO}_{2}$ flux can be many times larger than the signal of anthropogenic $\mathrm{CO}_{2}$ flux from fossil fuel emissions during the growing season, especially in rural areas upwind of urban centers, but also in suburban and urban fringe locations. This complicates the ability to monitor urban fossil fuel emissions using the atmospheric data alone, which in urban areas reflects the integrated signal of both biological and anthropogenic $\mathrm{CO}_{2}$ fluxes in near-field and upwind locations. During the afternoon hours when $\mathrm{CO}_{2}$ measurements are typically used in inversions, the biological drawdown and fossil fuel emission signals can largely offset one another during the growing season. Also, the specification of urban region background conditions is complicated by upwind variability in biospheric $\mathrm{CO}_{2}$ fluxes, particularly in the Northeast Corridor which is downwind of deciduous forests and Midwestern cropping areas.

To help address these concerns, NIST is collaborating with others in the carbon cycle community, evaluating and improving biospheric models of $\mathrm{CO}_{2}$ flux. NIST researchers are currently running the Vegetation Photosynthesis and Respiration Model (VPRM), ${ }^{53}$ a fully diagnostic model, optimizing parameters using flux towers situated in the eastern US and Canada upwind of the DC/ Baltimore region and improving the process-based representation of respiration in the model. ${ }^{54}$ NIST researchers are also collaborating with partners at other institutions who have been running different biosphere models and comparing them with customized VPRM results. Modeled fluxes are coupled to a transport model (WRF-STILT) to simulate concentrations at tower locations throughout the Eastern U.S. and Canada, allowing for the models to be evaluated against observations.

The modeled contribution (from VPRM) of biosphere fluxes (green) and fossil fuel fluxes (orange) to July afternoon $\mathrm{CO}_{2}$ enhancements at two Northeast corridor towers (HAL in Halethorpe, MD and

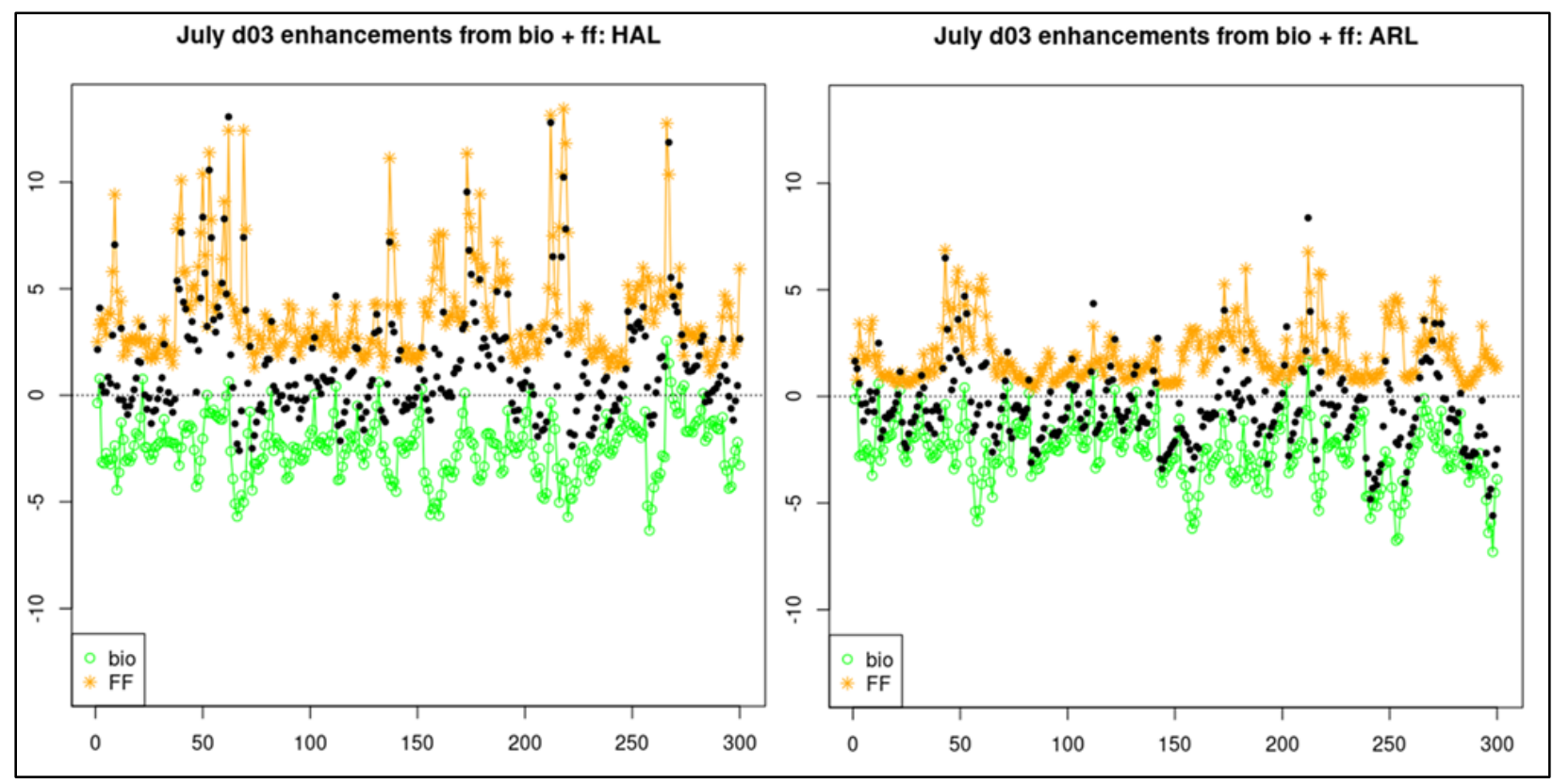

53 P. Mahadevan, S Wofsy, D. Matross, X. Xiao, A. Dunn, J. Lin, C. Gerbig, W. Munger, V. Chow and E. Gottlieb, “A satellitebased biosphere parameterization for net ecosystem CO2 exchange: Vegetation Photosynthesis and Respiration Model (VPRM)", Global Biogeochemical Cycles, 22, no. GB2005 (2008)

54 S. Gourdji, I. Lopez-Coto, A. Karion, I. Baker, C. Williams, Y. Zhou, S. Ghosh and K. Mueller, "An evaluation of terrestrial biospheric model performance in eastern USA and Canada using atmospheric CO2 observations from a network of surface towers," Presentation - ACT-America Workshop (2020) 
ARL in Arlington, VA), with the sum indicated in black. The depletion of $\mathrm{CO}_{2}$ due to biospheric influence cancels out or exceeds the magnitude of fossil fuel enhancements for this month.

The NIST Headquarters in Gaithersburg, MD also provides a convenient testbed to evaluate the current state of knowledge relating optical remote sensing to biophysiological measurements of vegetative land cover. The mixed deciduous forest at NIST, with some specimens well over 100 years old, has a network of sensors deployed over a 1-hectare area within the larger 40-hectare

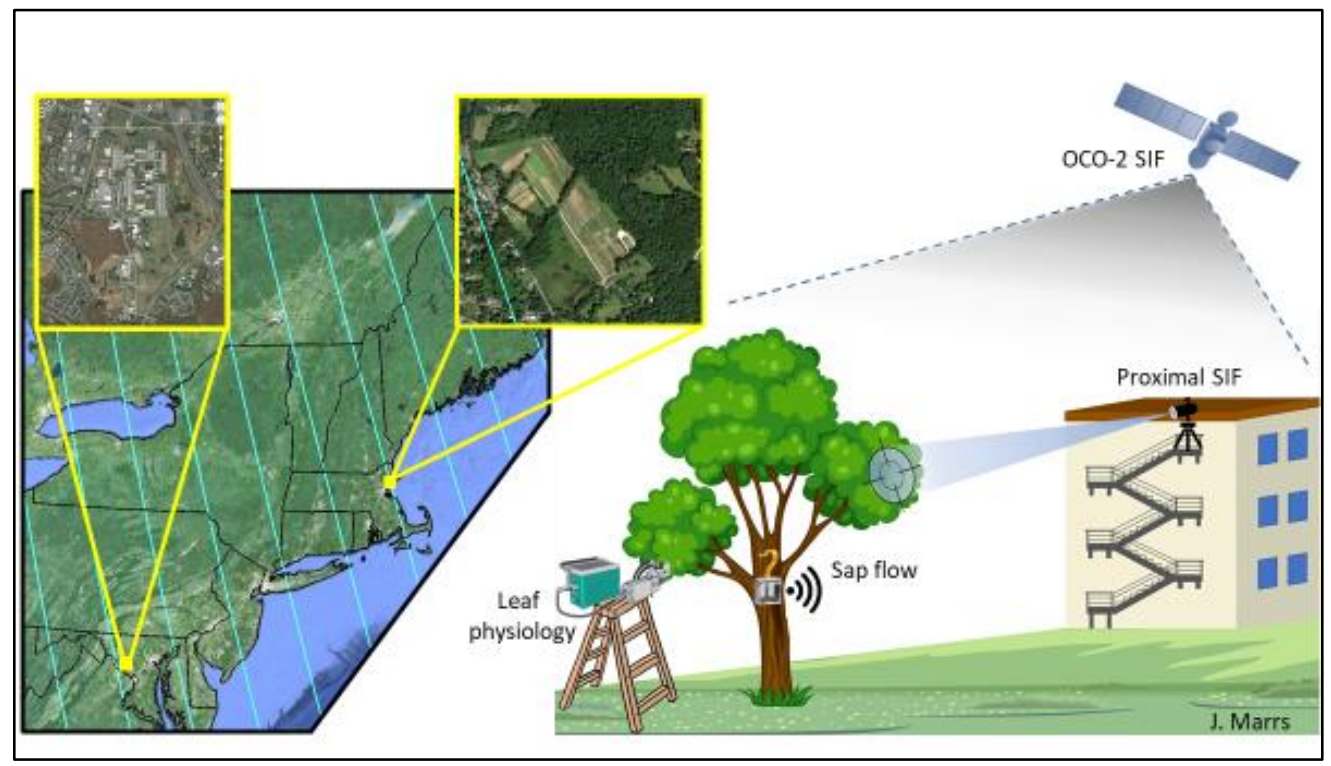

forest. These sensors include respiration measurements, sap flow sensors on trees, and meteorology to provide ground truth to model simulations and optical observations. Optical remote sensing observations of vegetation can help constrain ecosystem models used to estimate carbon fluxes. Optical observations provide the advantage of sampling up to the global scale. However, linking a satellite scale footprint to the patch and leaflevel observations is an ongoing area of research. The goals of the research are to:

- Provide a testbed (Forested Optical Reference for Evaluating Sensor Technology, FOREST) for ecophysiological and optical sensors with well-established reference points

- Investigate ecosystem phenomenology that will allow for better estimates of carbon flux

- Improve estimates of carbon flux of fragmented urban landscapes

- Link leaf level to satellite footprint scale observations

Some challenges faced in this project include:

- Although regional nesting helps, uncertainty on background is large due to large uncertainty in the emissions of $\mathrm{CH}_{4}$ and biospheric $\mathrm{CO}_{2}$ fluxes upwind. The location of Washington, DC and Baltimore, MD domain downwind of large fluxes makes this problem more difficult than in other cities.

- Currently we do not have a handle on methane emissions attribution - because it is less wellknown from the bottom-up, our priors are less certain, and our background is less certain.

Other publications from this project can be found on: https://www.nist.gov/topics/northeast-corridor-urban-test-bed/publications 


\subsubsection{Ralph Keeling}

\section{Scripps Institution of Oceanography, UC San Diego}

Keeling expressed his concerns about the accuracy of GHG flux measurements, especially in light of the uncertainties of atmospheric transport models; he felt that these models still need a lot of work and their uncertainties need to be evaluated. Given their relatively large uncertainties, can we claim uncertainty levels of around 3\% for GHG measurements and inversions? His main concern was about evaluation of meteorological uncertainties and resulting uncertainties of the inversions. We want to make sure that the resulting inversions are not "fake inversions" and don't give us false confidence. Also, just because different models give similar results, does that mean they are correct? Assessment of uncertainties of atmospheric transport models will require additional tracer experiments and talked about some of the experiments they have carried out with methane emissions. ${ }^{55}$

\section{Need for due-diligence in transport modeling}

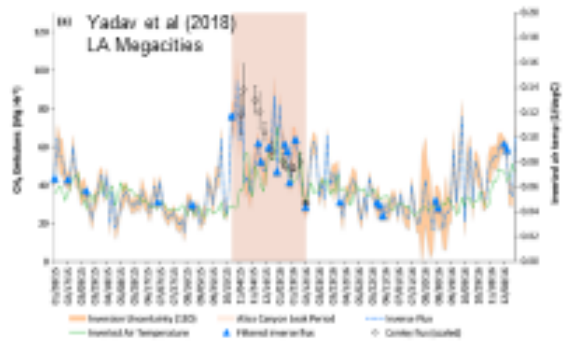

Flow-through system

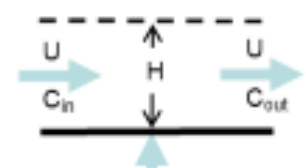

Flux $=U^{*} H^{*}\left(C_{o u t}-C_{i n}\right)$

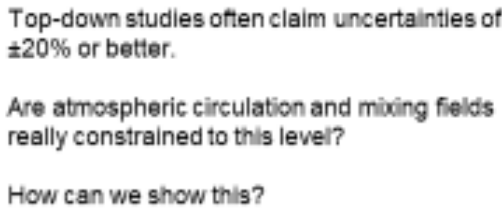

How can we show this?

Static box

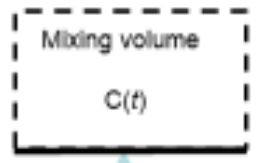

Flux $=(\text { Volume })^{*} \mathrm{dC} / \mathrm{dt}$

55 V. Yadav, R. Duren, K. Mueller, K.R. Verhulst, T. Nehrkorn, J. Kim, R.F. Weiss, R. Keeling, S. Sander, M.L. Fischer, S. Newman, M. Falk, T. Kuwayama, F. Hopkins, T. Rafiq, J. Whetstone, and C. Miller, "Spatio-temporally Resolved Methane Fluxes From the Los Angeles Megacity", Journal of Geophysical Research: Atmospheres, 124, pp. 5131-5148 (2019) https://doi.org/10.1029/2018JD030062 


\subsubsection{Thomas Lauvaux}

\section{Laboratoire des Sciences du Climat et de l'Environnement (LSCE), France}

Lauvaux spoke about some of the recent advances demonstrated with INFLUX data analysis over a 3-year period; these results showed significant improvements in GHG flux measurements. ${ }^{56,57} \mathrm{He}$ shared concerns expressed by Keeling about the accuracy of atmospheric transport models. He agreed that, after demonstrations performed in Indianapolis, we need to demonstrate the techniques for other cities with different meteorologies and topographies. The predictions made for Indianapolis were meant to be only the starting point for demonstration of capabilities. That's why experiments are being expanded from Indianapolis to LA Megacity and the North East Corridor where significantly different conditions exist.

\section{Recent Advance in INFLUX Data Analyses}

Combined emission modeling and atm. obs. \& analysis

- Urban measurement result convergence

- Results of atmospheric obs. \& analysis results are highly consistent.

- Results over a 3-year period

- The methodology corrects an intentional input data offset of $+15 \%$ by $-14.2 \%$.

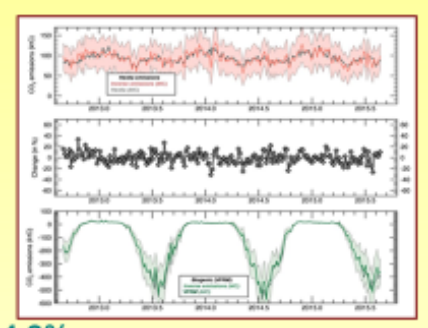

- These results increase our confidence that it is possible to detect a 3 to $5 \%$ change over periods of 1 to 3 years for Indianapolis.

- These tools hold the potential to investigate sectoral mitigation efforts, but require replication and refinement to determine and demonstrate their extensibility to other urban areas.

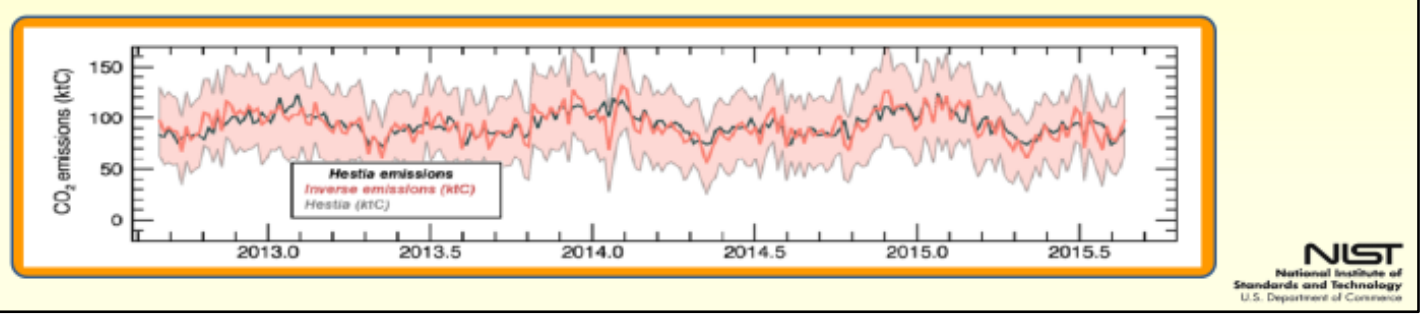

56 J.C. Turnbull, A. Karion, K.J. Davis, T. Lauvaux, N.L. Miles, S.J. Richardson, C. Sweeney, K. McKain, S.J. Lehman, K.R. Gurney, R. Patarasuk, J. Liang, P.B. Shepson, A. Heimburger, R. Harvey, and J. Whetstone "Synthesis of Urban CO2 Emission Estimates from Multiple Methods from the Indianapolis Flux Project (INFLUX)”, Environ. Sci. \& Tech., 53, pp. 287-295 (2019)

57 T. Lauvaux, K.R. Gurney, N.L. Miles, K.J. Davis, S.J. Richardson, A. Deng, B. Nathan, T. Oda, J. Wang, L. Hutyra, and J. Turnbull, "Policy-relevant assessment of urban greenhouse gas emissions", Environ. Sci. Technol. 54 (16), pp. 1023710245 (2020) https://doi.org/10.1021/acs.est.0c00343 


\subsubsection{Alistair Manning United Kingdom Met Office}

Manning described UK DECC Network established for monitoring GHG emissions. ${ }^{58,59} \mathrm{He}$ felt that the $\mathrm{CO}_{2}$ measurements are still in research mode, especially because of difficulties with background measurements and small enhancements. Non-CO2 measurements are already in delivery mode, e.g., hydrofluorocarbons (HFC's). He described some of the early successes they have had with measurements for HFC's. ${ }^{60}$ These measurements have shown emissions seem to be about half of the inventories. They are working on evaluating biases in the inversions and uncertainties in the inventories. There is for hope for closer convergence in coming years. He also mentioned some of the CFC-11 inversions in Europe, such as those in the UK and Switzerland.

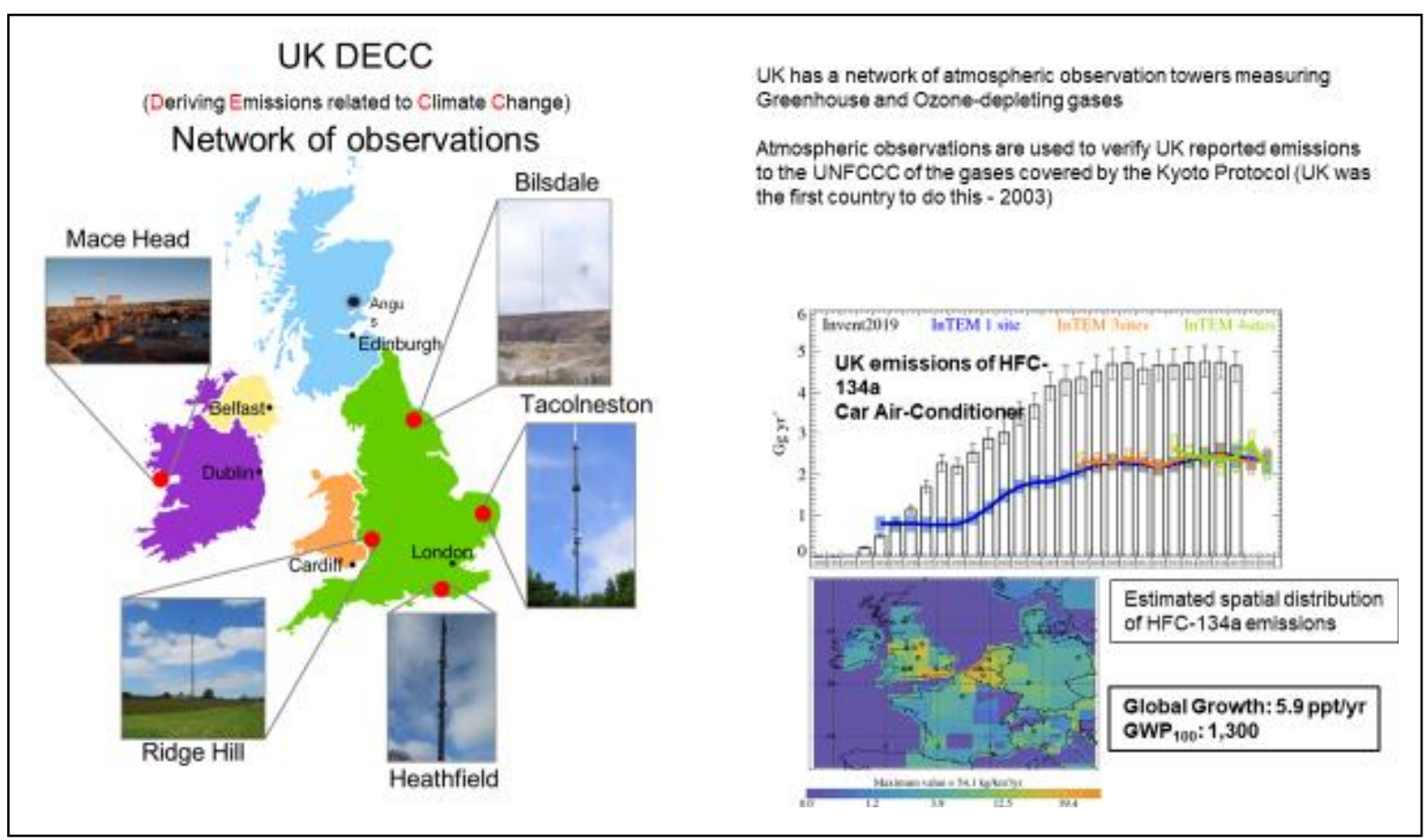

58 P.I. Palmer, S. O'Doherty, G. Allen, K. Bower, H. Bosch, M.P. Chipperfield, S. Connors, S. Dhomse, L. Feng, D.P. Finch, M.W. Gallagher, E. Gloor, S. Gonzi, N.R.P. Harris, C. Helfter, N. Humpage, B. Kerridge, D. Knappett, R.L. Jones, M. Le Breton, M.F. Lunt, A.J. Manning, S. Matthiesen, J.B.A. Muller, N. Mullinger, E. Nemitz, S. O'Shea, R.J. Parker, C.J. Percival, J. Pitt, S.N. Riddick, M. Rigby, H. Sembhi, R. Siddans, R.L. Skelton, P. Smith, H. Sonderfeld, K. Stanley, A.R. Stavert, A. Wenger, E. White, C. Wilson, and D. Young, "A measurement-based verification framework for UK greenhouse gas emissions: an overview of the Greenhouse gAs Uk and Global Emissions (GAUGE) project”, Atmospheric Chemistry and Physics, 18, pp. 11753-11777 (2018) 10.5194/acp-18-11753-2018, 2018.

59 K.M. Stanley, A. Grant, S. O'Doherty, D. Young, A,J, Manning, A.R. Stavert, T.G. Spain, P.K. Salameh, C.M. Harth, P.G. Simmonds, W.T. Sturges, D.E. Oram, and R.G. Derwent, "Greenhouse gas measurements from a UK network of tall towers: technical description and first results", Atmospheric Measurement Techniques, 11, pp. 1437-1458 (2018) 10.5194/amt-11$\underline{1437-2018}$

60 D. Say, A.J. Manning, S. O'Doherty, M. Rigby, D. Young, and A. Grant, "Re-Evaluation of the UK's HFC-134a Emissions Inventory Based on Atmospheric Observations”, Environ. Sci. Technol., 50, pp. 11129-11136 (2016) 10.1021/acs.est.6b03630, 2016. 


\subsubsection{Charles (Chip) Miller}

\section{Jet Propulsion Laboratory, NASA}

Miller described the network of 13 surface measurement sites within and around the Los Angeles basin that provides the backbone of the Megacities Carbon Project monitoring system. These sites are equipped with in-situ greenhouse gas analyzers that continuously sample the air; they are on radio towers and tall buildings. All of the sites measure $\mathrm{CO}_{2}$, some also measure methane $\left(\mathrm{CH}_{4}\right)$, and Carbon Monoxide (CO). Some of the sites have been operating for over 10 years; the current network installation was completed in August 2015. ${ }^{61}$ The site locations were carefully selected to ensure the network provides complete coverage of the basin and to avoid "contamination" of known nearby pollution sources. In addition to the sites located within the basin focused on measuring urban air, there are 3 sites outside the LA basin (Victorville, San Clemente Island and La Jolla) that provide a relatively clean "background" reference measurement as well as (sometimes, when the winds shift) measurements of outflowing air from the basin. The network is currently undergoing commissioning and checkout. The network was instrumental in capturing the Aliso Canyon blowout; methane emissions from other sources have also been identified. ${ }^{62}$ Results have also been published on $\mathrm{CO} 2$ and methane emissions, ${ }^{63,64}$ and other papers are forthcoming. Data from OCO2 and $\mathrm{OCO} 3$ satellites will also be utilized. Carbon Dioxide results from Hestia and other tools have been published; results for $\mathrm{CH} 4$ emissions are expected soon. A major effort is being made to transition from research to real world applications.

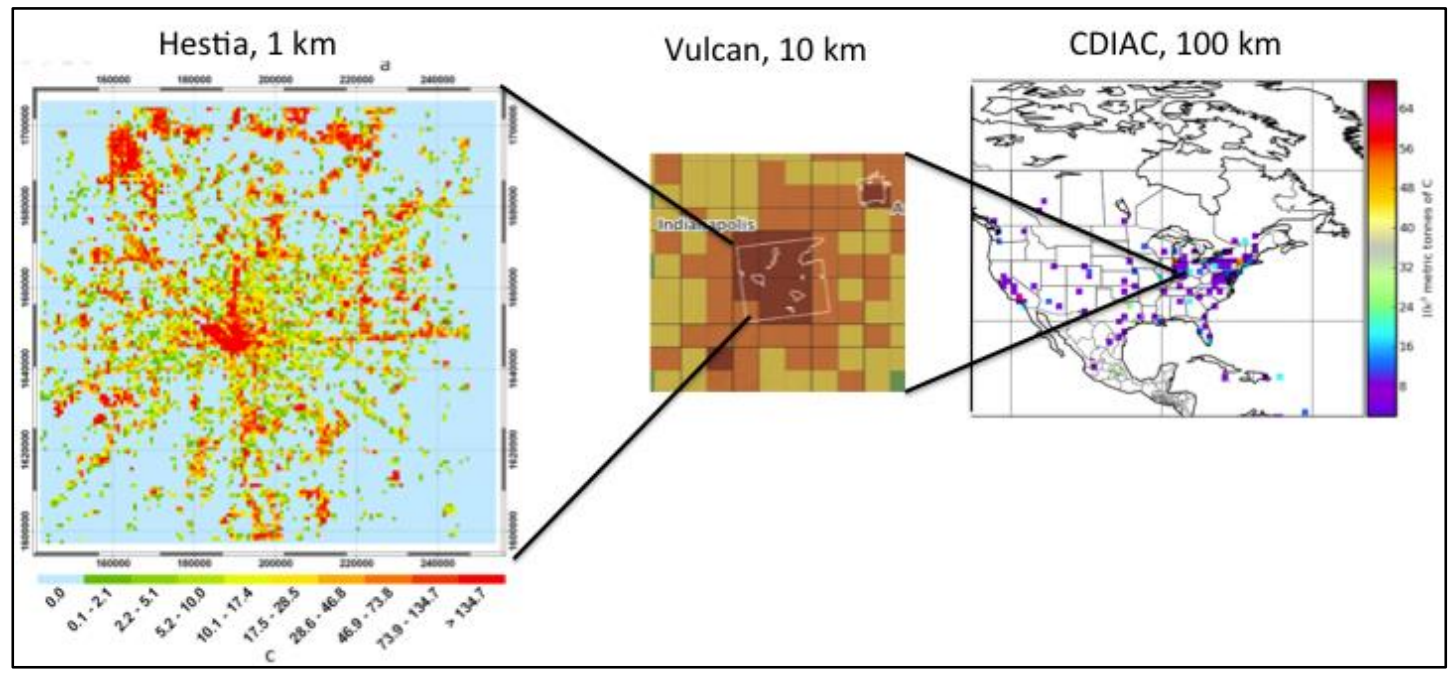

${ }^{61}$ https://megacities.jpl.nasa.gov/portal/about/

${ }^{62}$ Viatte, C., Lauvaux, T., Hedelius, J. K., Parker, H., Chen, J., Jones, T., Franklin, J. E., Deng, A. J., Gaudet, B., Verhulst, K., Duren, R., Wunch, D., Roehl, C., Dubey, M. K., Wofsy, S., and Wennberg, P. O. (2017): Methane emissions from dairies in the Los Angeles Basin, Atmos. Chem. Phys., 17, pp. 7509-7528 (2017), doi: 10.5194/acp-17-7509-2017. https://www.atmos-chemphys.net/17/7509/2017/

${ }^{63}$ K.R. Verhulst, A. Karion, J. Kim, P.K. Salameh, R.F. Keeling, S. Newman, J. Miller, C. Sloop, T. Pongetti, P. Rao, C. Wong, F.M. Hopkins, V. Yadav, R.F. Weiss, R.M. Duren, and C.E. Miller, "Carbon dioxide and methane measurements from the Los Angeles Megacity Carbon Project - Part 1: calibration, urban enhancements, and uncertainty estimates”, Atmos. Chem. Phys., 17, pp. 8313-8341 (2017)

${ }^{64}$ S. Newman, X. Xu, K.R. Gurney, Y.K. Hsu, K.F. Li, X. Jiang, R. Keeling, S. Feng, D. O’Keefe, R. Patarasuk, K.W. Wong, P. Rao, M.L. Fischer, and Y.L. Yung, "Toward consistency between trends in bottom-up CO2 emissions and top-down atmospheric measurements in the Los Angeles megacity", Atmos. Chem. Phys., 16, pp. 3843-3863 (2016) 


\subsubsection{Felix Vogel}

\section{Environment and Climate Change - Canada}

Vogel described efforts of Environment and Climate Change - Canada to monitor GHGs to improve understanding of regulated and non-regulated sources and provide insights as to the effectiveness of regulatory actions taken (both domestically and internationally). This should lead to the improved characterization of current and past concentrations of greenhouse gases, their sources and sinks, and the climate response (including carbon-cycle feedbacks). Improved characterization based on an expanded atmospheric GHG measurement network, combined with climate and GHG modelling approaches to determine baselines from which environmental impacts can be established, will be used to determine progress on the implementation of regulations.

Research on enhanced GHG monitoring networks and climate modelling is utilized to develop methodologies for independent estimation of GHG emissions (carbon sources and sinks) based on observations and the Canadian Earth System Model (CanESM). New monitoring sites are planned for the northwest Arctic and western Canada to achieve regional-scale information and supplement the existing network. A new monitoring network is also being established around the city of Toronto that includes 4 Picarro instruments. They are also developing models to account for biogenic effects, as well as guidelines for different types of urban observations.

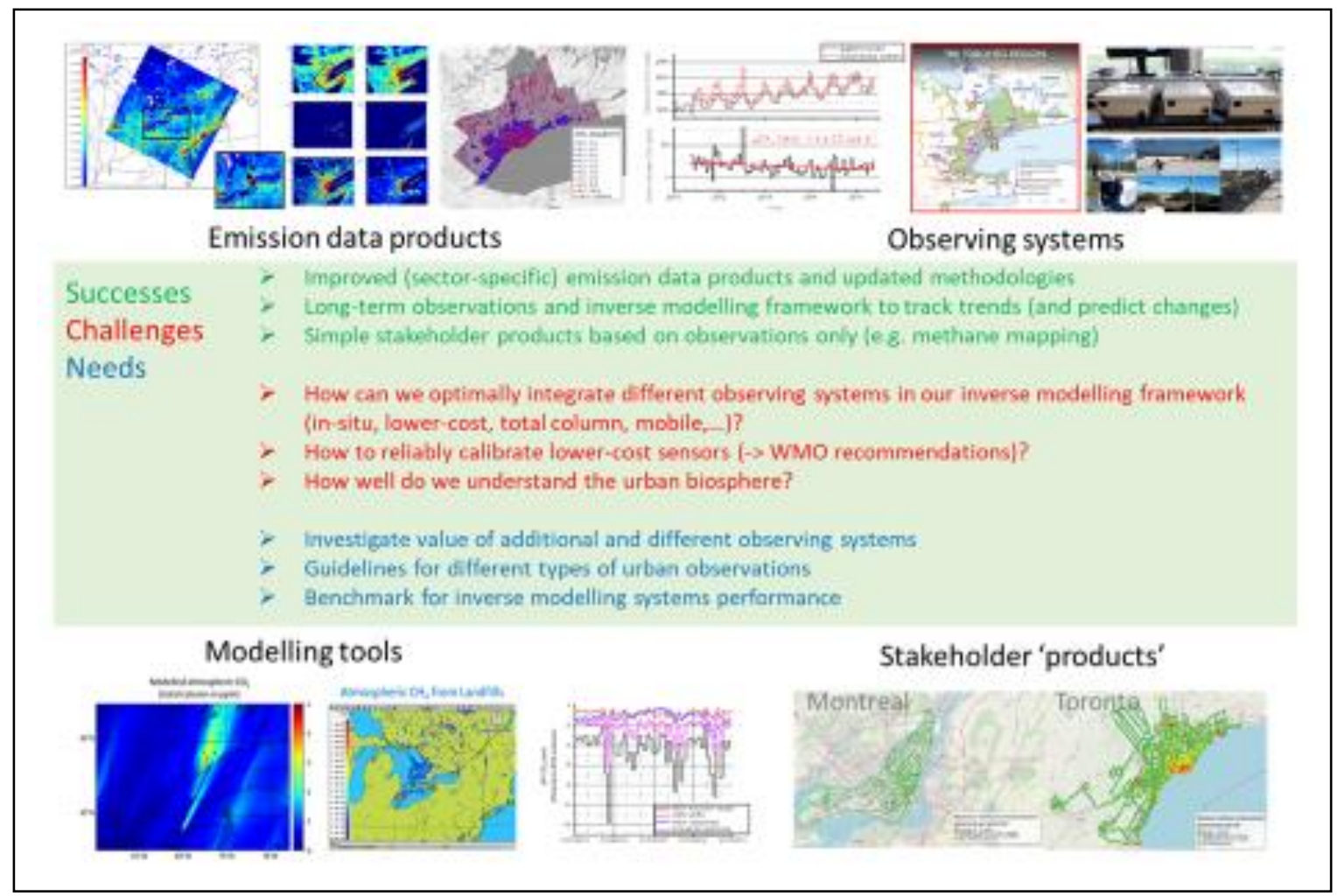




\subsubsection{Discussion/Questions for Panelists}

Duren asked if we were at the point of applying these capabilities to challenges in developing countries? It was pointed out that so far, all data was from industrialized regions in mid latitudes, northern hemisphere. How about the southern hemisphere? How about countries doing a lot of biomass burning for heating and other purposes? Do they represent other challenges?

Rudek noted that there were many more differences between developed and developing economies; biomass burning is used for heating; farming economies are quite different with more livestock and use of fertilizers; these areas will require additional methods. It was also mentioned that there was a lot to be learned from smart city efforts and those efforts should be tracked. Lin mentioned that there are many more city projects are underway, such as in LA, Boston, SLC, Portland, and the data are available on Oak Ridge DAC. There is a lot of other data on the cities; e.g., impact of changes in cities to electric generation grid, or conversion from coal to NG. Dickerson added that the inventories for cities are improving; can provide more accurate baselines to determine trends especially for states that have regulatory infrastructures. We need to work more closely with city governments.

DeCola stated that many investments are being made number of cities like Zengzhou, Beijing, Seoul, Tokyo. How useful would a system like BEACON be useful? How much progress had they made with inversions of BEACON data? Cohen responded that they have not done inversions. They are focusing on individual sectors.

Sweeney pointed out the fact that aircraft measurements were not mentioned much in the presentations. Network of aircraft may be useful and complementary to surface based networks. Shepson agreed. They are mobile and quickly deployed; inversions of aircraft data are becoming available generating useful data.

Kort mentioned the need to be more explicit and precise in establishing objectives, goals and articulating capabilities. It was felt that the discussion was too slanted toward tower experiments. Aircraft data without inversions would also be useful by themselves as well as satellite data. In fact, the current usage of satellite data may have been understated. The audience were reminded that atmospheric measurements are done basically to validate emissions modelling and FE models.

Lin wanted to make a point about terminology and to touch on the linkage to AQ issues. He cautioned about the use of the term "Inversion"; in some places like Utah, where he works, it has a very different meaning and has linkage to air quality issues. There is a Utah Roadmap legislation currently being discussed and it is primarily about AQ issues. Karion wanted to explore ways to engage with the AQ issue; for example, how to articulate co-benefits of AQ vs GHG measurements, short lived vs long lived species, GHG data acquired at higher elevations vs AQ data at $10 \mathrm{~m}$. Do we need two different networks? Dickerson injected that it was very important to emphasize cobenefits; ratioing might be useful; states are open to these approaches. AQ regulations have teeth. AQ efforts may be linkable to reducing GHGs and may go hand in hand with improving AQ improvements and benefits for human health effects. Cohen pointed out that AQ pollutants are usually expressed in terms of quantities per grams of $\mathrm{CO}_{2}$. A single inventory framework for both GHGs and AQ may be more useful; otherwise we have a duplication of effort.

S. Miller, in a related point to duplication of networks, mentioned that NIST has a tower network in Baltimore; JHU has a network of low-cost sensors for AQ at lower heights. Baltimore port is outside of the city but how do you separate emissions? The situation presents a jurisdictional issue. 
It was mentioned that similar jurisdictional issues exist in Paris, but we need to remember that AQ is for monitoring the health of people; similar boundary issues come up with wastewater.

Cohen was asked if he has had any contacts from the climate activists or from the social science community? They have had interactions with people from across the spectrum; many of them are looking for particular issues; e.g., how all the shipping of coal through San Francisco is affecting aerosols?

J. Kim stated that species that have only anthropogenic sources (like HFCs) may be easier for testing analytical methods. They have simpler emission patterns; could use AGAGE data to test inversion methods. Trying to address the $\mathrm{CO}_{2}$ question, are we trying to run before we can walk? Keeling concurred and added that $\mathrm{CO}_{2}$ may be a bag of worms. Should we be addressing these challenges? $\mathrm{CO}_{2}$ is not what people care about, and it is not a low hanging fruit. Shepson added that $\mathrm{CO} 2$ is the driver and still the elephant in the room.

Some concerns were expressed that there was too much emphasis on "inversions". Turnbull stated that simpler tools and results may be more useful for stakeholders and can gain their trust. Others agreed that we need to establish confidence in the system before moving forward.

Gurney mentioned that city inventories are including all Scope 1, 2 and 3 emissions. Reading their inventories is a useful exercise. Ways are needed to use atmospheric measurements within this context. Stakeholder interests are much broader than just GHGs; they are interested in planning, marketing, etc. They have no mandate, but just want to do the right thing. We have a bit of a disconnect; a hammer and nail problem; this is really a communication problem. Karion said we are talking about Scope 2 and 3, but can we do Scope 1 right, given transport and urban biosphere challenges? Gurney reiterated that Scopes 1-3 include all emissions, but what are we getting from BEACON, towers, Inversions? There seems to exist a bit of an inconsistency.

C. Miller wanted to bring to the attention of the community new methods such as imaging spectroscopy (with IR or near-IR sensors) which provide data with resolution down to scale of a few meters. Such imaging methods are very effective in communicating with lay people. Source ID is very clear and visceral communication means. The question is how do we exploit it?

Weiss had the last word of the session, stating that there are no easy solutions to a complex problem like monitoring $\mathrm{CO}_{2}$ emissions. 


\subsection{Panel Discussion on International Stakeholder Experiences \\ Moderator: Kimberly Mueller, NIST \\ Panelists: Fouzi Benkhelifa, Origins Earth, France \\ Alistair Manning, United Kingdom Met Office \\ Jocelyne Turnbull, GNS Science, New Zealand \\ Alex Vermeulen, ICOS, Europe \\ Felix Vogel, Environment \& Climate Change Canada \\ James Whetstone, NIST}

The moderator asked the panel members to articulate their experiences in interactions/engagement with stakeholder(s), how/if they fit into a larger structure (e.g. city/regional stakeholder works in context of a state regulatory system or national impacting subnational entities), how important were atmospheric research topics (e.g. observations, emissions modeling, etc.) in these interactions; were the stakeholder needs changing, and how these interactions impacted their perspective of atmospheric research, future research, and stakeholder engagement? Each panel member was asked to make a brief statement about their experiences, which are summarized below.

\subsubsection{Fouzi Benkhelifa \\ Origins Earth, France}

Benkhalifa talked about lessons learned from the pilot project in Paris. He loves what this community is doing! He thinks the climate scientist is the new hero! But at the local level, no one asks the scientists for their opinion or what we do.... As scientists, we love what we do, but also have to love the problems of the stakeholders. Local community doesn't always need accurate data. How can we help city planners manage the carbon budget of their city? They are not necessarily interested in technical details and scientific accuracy! What city planners need: awareness, responsiveness, efficiency, transparency, opportunities. In Paris, some people interested in GHG monitoring system, but there are also political opponents. Have to create a shared agenda with stakeholders with "design thinking" process. Even opponents expressed buy-in after the stakeholder interactions. But we need a common standard across cities. It helps to create trust, perhaps through the use of an international standard, e.g. ISO 14064. People using it as a standard, even if not perfect. Publicity is very important for the successful projects and their impact; confidence in the scientific community still means a lot. There was lots of press coverage after announcement of the Paris project (> 100 articles in 3 weeks for work in Paris!) 


\subsubsection{Alistair Manning UK Met Office}

Manning works for the Department of Environment (changes names often) on non- $\mathrm{CO}_{2}$ inversions $\left(\mathrm{CO}_{2}\right.$ is more difficult). They fund inventory work and inversions to evaluate inventories, which helps to facilitate working together more effectively. They also see a lot of personnel turnover at his organization, which makes the work difficult. The UK Climate Change Act, a 5-year plan, has targets to reduce GHG's every 5 years. Also, NDC's for UK are a driver for this work. Manning started talking to government agencies 20 years ago; it took a long evolution to gain their confidence as well as building confidence in one's own work and reducing uncertainties. There are still many biases in the system (discrepancies between atmospheric data and inventories?) Hard to look at trends for historical periods when data didn't exist. ${ }^{65,66,67}$ Four administrative divisions in UK (Scotland, N. Ireland, Wales, England) have their own targets and inventories. Manning also stated that it is important to get uncertainties right in order to properly interpret model results. Also, there are concerns about natural gas pipeline leaks; since there are $\mathrm{CH}_{4}$ emissions from landfills and agriculture, it is difficult to figure out the contribution of different sectors. This knowledge will help in adjusting emission factors in inventories. They are setting up isotope measurements across the network to tease apart sectoral contribution.

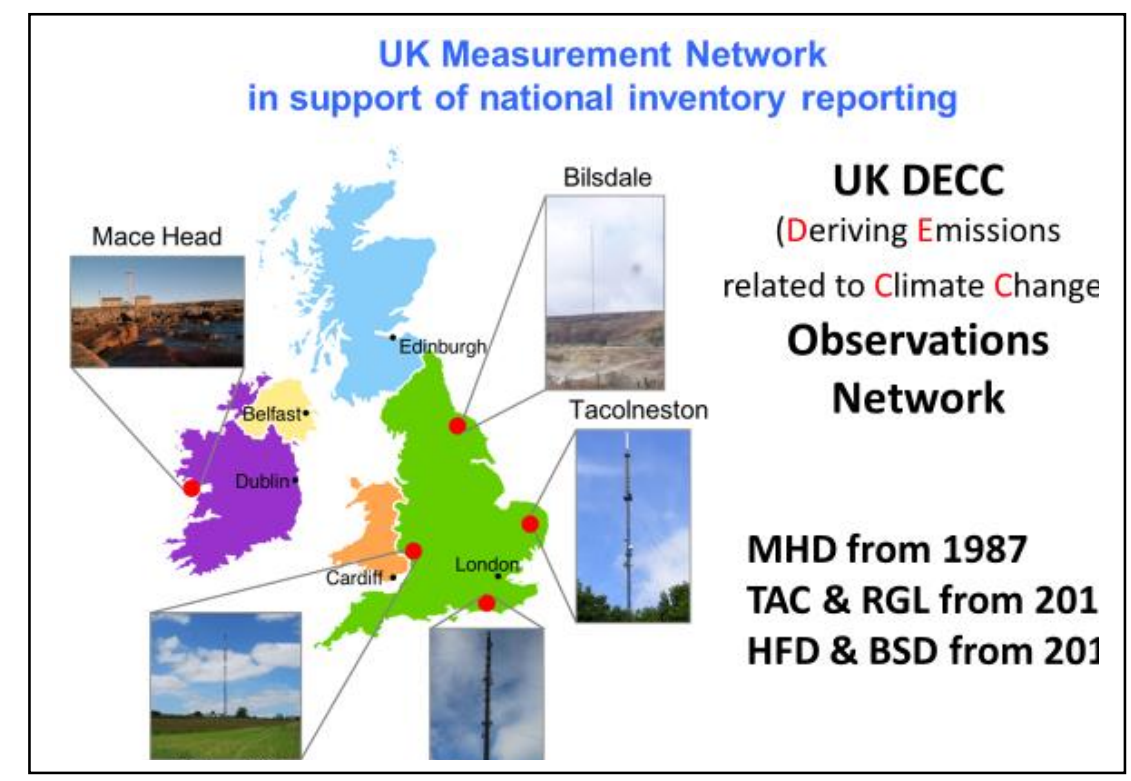

65 A.R. Stavert, S. O'Doherty, K. Stanley, D. Young, A.J. Manning, M.F. Lunt, C. Rennick, and T. Arnold, "UK greenhouse gas measurements at two new tall towers for aiding emissions verification”, Atmospheric Measurement Techniques, 12, pp. 44954518 (2019) 10.5194/amt-12-4495-2019

66 A. Wenger, K. Pugsley, S. O'Doherty, M. Rigby, A.J. Manning, M.F. Lunt and E.D. White, “Atmospheric radiocarbon measurements to quantify $\mathrm{CO}_{2}$ emissions in the UK from 2014 to 2015", Atmospheric Chemistry and Physics, 19, pp. 1405714070 (2019), 10.5194/acp-19-14057-2019

67 E.D. White, M. Rigby, M.F. Lunt, T.L. Smallman, E. Comyn-Platt, A.J. Manning, A.L. Ganesan, S. O'Doherty, A.R. Stavert, K. Stanley, M. Williams, P. Levy, M. Ramonet, G.L. Forster, A.C. Manning and P.I. Palmer, "Quantifying the UK's carbon dioxide flux: an atmospheric inverse modelling approach using a regional measurement network", Atmospheric Chemistry and Physics, 19, pp. 4345-4365 (2019) 10.5194/acp-19-4345-2019. 


\subsubsection{Jocelyn Turnbull}

\section{GNS Science, New Zealand}

Turnbull works in the city of Auckland and also at national scale, with those involved in preparing the inventories. CarbonWatch New Zealand, a full carbon budget for the country in $\mathrm{CO}_{2}$ and $\mathrm{CH}_{4}$, is focusing on forestry (natural and plantation), farmland and urban areas. Started with engagement with scientists in government agencies, who have some grasp of what we're doing. She is also working with the Ministry of Environment, who does the National Inventory Reporting (NIR). Established contacts with the NZ Transportation Authority. Also working with Climate Change Commission. After lots of meetings and discussions over a 2-year period, they started to understand what you're doing and what they could do with it. Frustration is that bureaucrats changing every 2 years in national government! At city scale, worked through existing air quality relationships. Also established relationship with scientists who developed inventory for Auckland. They know fossil emissions and want more info on the biogenics and advice on traffic related emissions. She has also had engagement with indigenous groups in NZ, which was difficult but rewarding. They consider themselves as caretakers of the land, and maintain a long-term view of what we should be doing... Surprising thing is what stakeholders want is not what she thought they might want. It has been enjoyable as a scientist to see how you can adapt your work. ${ }^{68}$

$\mathrm{CO}_{2}$ inversion for NZ indicates larger land carbon uptake than expected

- Atmospheric measurement and analysis shows

2011-2013 mean CO2 flux distribution in $\mathrm{kg} \mathrm{CO2} \mathrm{m}-2 \mathrm{yr}-1$

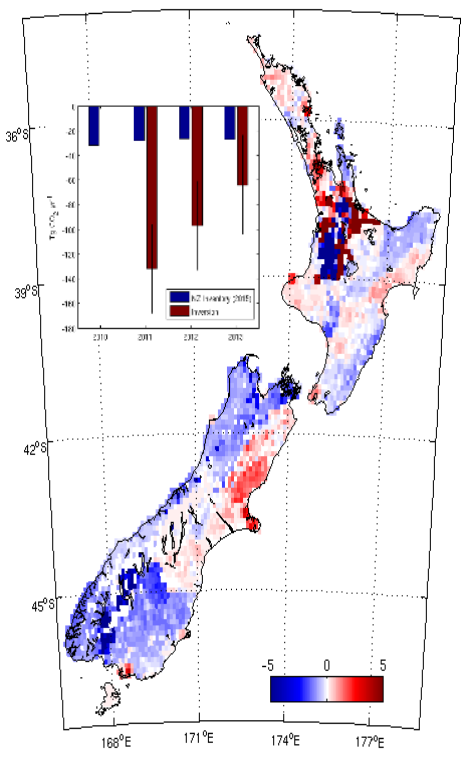

30 to $60 \%$ more $\mathrm{CO}_{2}$ land uptake than

expected from the NIR and the land model

(when accounting differences are resolved)

- Interannual variability in the land carbon sink not present in NIR

- Much of this additional $\mathrm{CO}_{2}$ uptake apparently occurs in Fiordland - old growth forested wilderness

New NZ National and Auckland Projects Initiated

- Process studies of natural, plantation, pasture, and urban biosphere

- Detailed emission modelling and atmospheric inversions at national and regional scales

- Combine atmospheric observations and bottom-up information to refine both and provide best national estimates

Atmospheric $\mathrm{CO} 2$ observations and models suggest strong carbon uptake by forests in New Zealand Steinkamp et al, Atmos. Chem. Phys., 17, 47-76, 2017, doi:10.5194/acp-17-47-2017

68 Stephens "Atmospheric CO2 observations and models suggest strong carbon uptake by forests in New Zealand", Atmos. Chem. Phys., 17, pp. 47-76 (2017) doi:10.5194/acp-17-47-2017 


\subsubsection{Alex Vermeulen}

\section{Integrated Carbon Observation System (ICOS) of Europe}

(See Appendix D for a complete PowerPoint presentation)

Vermeulen provided a brief overview of the Integrated Carbon Observation System (ICOS) in Europe. ICOS is a pan-European research infrastructure founded in 2008, with the Head Office located in Helsinki, Finland. ICOS Research Infrastructure (ICOS RI) provides data on greenhouse gas concentrations and is thus part of the European environmental Research Infrastructure landscape.

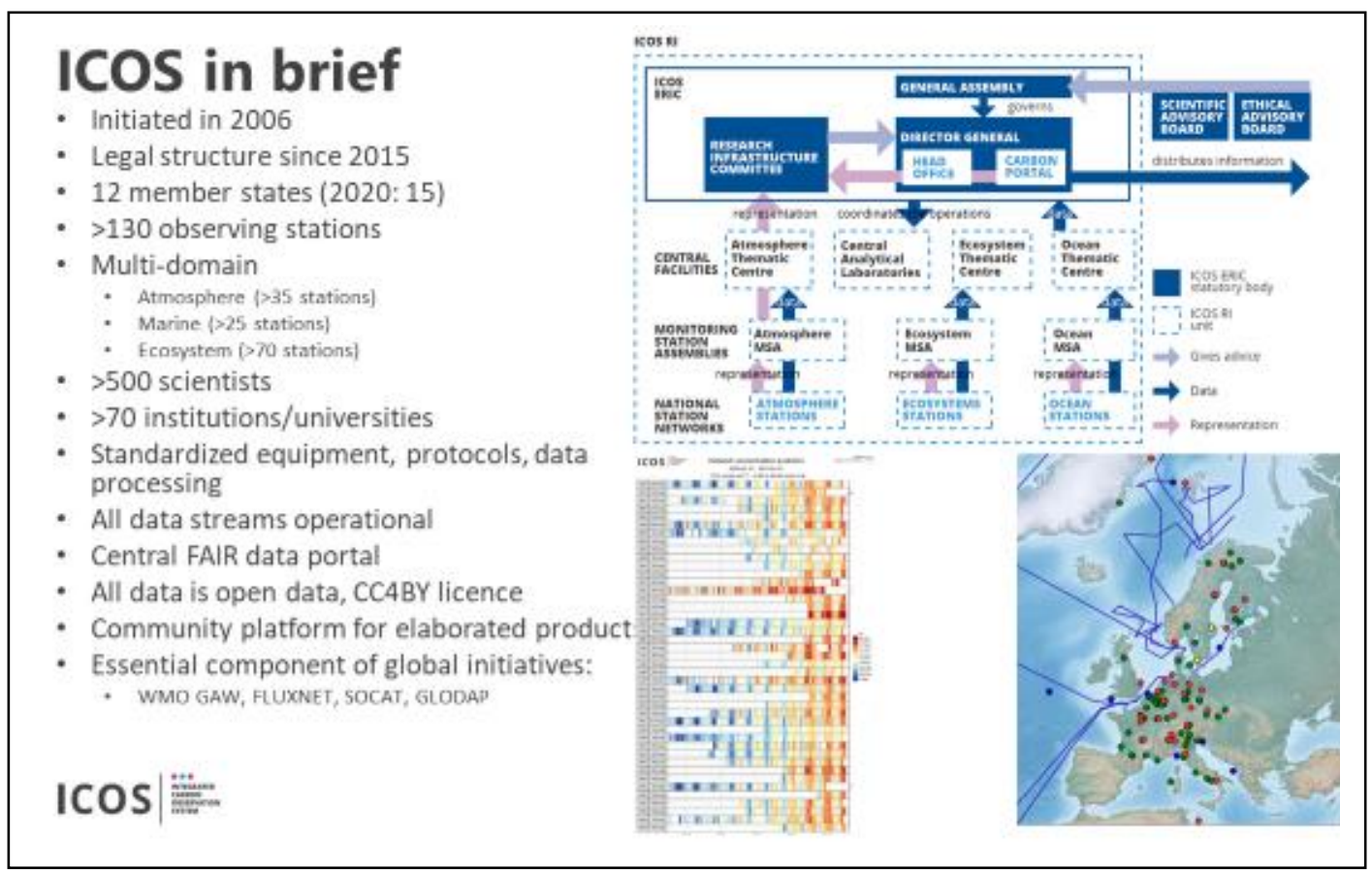

ICOS Research Infrastructure is coordinated and integrated by the ICOS European Research Infrastructure Consortium (ERIC). ICOS ERIC was established by the decision of the European Commission in November 2015. ICOS is an international organization of twelve European member countries (three more countries expected to be joining soon) and over 130 greenhouse gas measurement stations aimed at quantifying and understanding the greenhouse gas balance of Europe and neighboring regions.

ICOS research infrastructure provides long-term, continuous observations of concentrations and fluxes of the greenhouse gases (GHGs) carbon dioxide, methane, nitrous oxide, and water vapor. ${ }^{69}$ One of the benefits of this activity is that it permits evaluating GHG emissions and their regional dynamics, and thus the efficiency of the mitigation undertaken by national and regional organizations.

69 G. Monteil, G. Broquet, M. Scholze, M. Lang, U. Karstens, C. Gerbig, F-T. Koch, N.E Smith, R.L. Thompson, I.T. van der Laan-Luijkx, E. White, A. Meesters, P. Ciais, A.L. Ganesan, A. Manning, M. Mischurow, W. Peters, P. Peylin, J. Tarniewicz, M. Rigby, C. Rödenbeck, A. Vermeulen, and E.M. Walton, "The regional EUROpean atmospheric transport inversion COMparison, EUROCOM: first results on European wide terrestrial carbon fluxes for the period 2006-2015", Atmospheric Chemistry and Physics, December 2019 https://doi.org/10.5194/acp-2019-1008 
Many GHGs occur naturally in the atmosphere, such as water vapor, carbon dioxide, methane, and nitrous oxide, while others are synthetic, man-made. The latter include, for example, chlorofluorocarbons (CFCs), hydrofluorocarbons (HFCs), perfluorocarbons (PFCs), and sulfur hexafluoride $\left(\mathrm{SF}_{6}\right)$. Human activities increase atmospheric concentrations of both natural and synthetic GHGs. Greenhouse Gases remain in the atmosphere for different amounts of time and some of them are more effective than others at warming the atmosphere. ICOS provides in-situ measurements of GHGs gases, with standardized equipment and protocols to maintain precision of measurements. It represents a complimentary component of a total monitoring system along with the Copernicus satellite program, which will have three consecutive satellites.

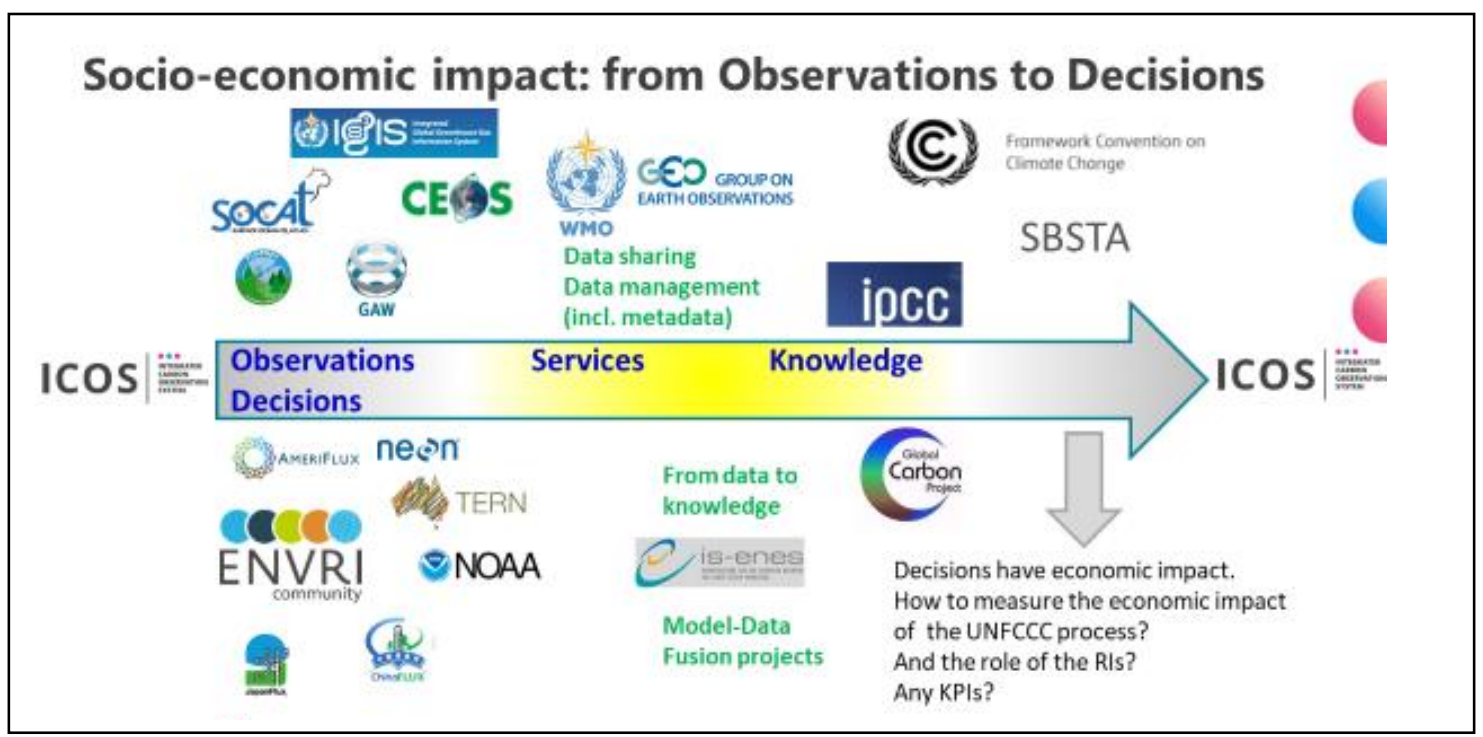

ICOS data is made available at the Carbon Portal, a one-stop shop for all ICOS data products, which is available to the scientific community and to policymakers. ${ }^{70}$ Data is acquired from bottom-up emission estimates and monitoring stations. Level of activity depends on each member state, since each country decides on their own annual budgets. There is increased discussion about extending the program to cities, but this will have to be approved by member states. ICOS strives to increase the relevance of observations to societal needs, and products are developed to increase the socioeconomic impact of the program. ICOS is also working on development of tools to articulate the economic impact of such research programs, which will, to a certain extent, depend on the type of stakeholder utilizing the information provided by ICOS. To facilitate this process, stakeholders are mapped out as users, practitioners, enablers, frame-makers and general public, and their level of influence and level of interest is evaluated. This exercise is utilized to decide where to focus ICOS interactions. Based on these assessments, ICOS has generally concentrated on "operators", i.e., people who work on inventories, climate-sensitive businesses, and standards making activities.

70 https://data.icos-cp.eu/portal/ 


\subsubsection{Felix Vogel}

\section{Environment \& Climate Change - Canada}

Environment \& Climate Change - Canada, which is Canada's Department of the Environment, is in charge of preparing GHG inventories for Canada. It has branches for research, air quality, enforcement, etc.; many of these activities occur under the same umbrella. There is interest on the part of Federal and local governments and the private sector to reduce GHG impacts. Ottawa government is interested in emission reductions of short-lived climate pollutants, especially $\mathrm{CH} 4$; they are targeting for $40 \%$ reduction in 5 years. Vogel has been talking to enforcement people about what information would be helpful in tracking these changes. Air Quality division at Federal level provides daily data with $10 \mathrm{~km} \times 10 \mathrm{~km}$ resolution. They are starting to use products to estimate emissions; they also want to repurpose these inventories for $\mathrm{CO}$. Improved emission inventories are expected to help with forecasts. The City of Toronto and communities around it have ambitious emission reduction goals of $35 \%$ in 10 years. They are working with universities, who are working on priors. Vogel has been in touch with the city; discussions about uncertainties does not seem to be of interest to city stakeholders. Interested in visual, straightforward products and/or trends. He is also working with the city of Montreal. Their interests are driven by the transport sector and they want to know the impact of extending subway lines to reduce emissions in specific neighborhoods. It is tricky to come up with good flux estimates at small scales (with inversions); it represents a difficult technical problem. Companies in the oil/gas sectors and those running landfills are concerned about $\mathrm{CH} 4$ regulations. To find out what their emissions are, they have vans driving around monitoring emissions; they have done a 10,000 km of mobile campaign across Toronto and Montreal $^{71}$. Not exciting science but it provides enough data of statistical significance! These kinds of activities do not generate publications but get good feedback from stakeholders. They provide simple ways to check for $\mathrm{CH} 4$ leaks, at $1 \mathrm{ppm}$ level, but also provide added value from detecting leaks at earlier stage with higher precision. From federal level, compared to US cities, Canada has put less focus on natural gas and more focus on the waste sector. A big waste management company has approached them to conduct a study of landfills in the Toronto area. They think inventories are overestimating landfill emissions compared to atmospheric measurements; the study is still in primary stage of trying to answer these questions. Canada's focus seems to be shifting from combustion products and $\mathrm{CO} 2$ to VOC's and CH4. At Environment Canada, they have a 2-way strategy to have people working on the "boring" production side of collecting data, another part of group involved in research questions. For example, the government is planting 2 million new trees, and is planning additional research on the urban biosphere.

71 S.C. Pugliese, J.G. Murphy, F.R. Vogel, M.D. Moran, J. Zhang, Q. Zheng, C.A. Stroud, S. Ren, D. Worthy4 , and G. Broquet, "High-resolution quantification of atmospheric CO2 mixing ratios in the Greater Toronto Area, Canada", Atmos. Chem. Phys., Vol. 18, pp. 3387-3401 (2018) https://doi.org/10.5194/acp-18-3387-2018 


\subsubsection{James Whetstone \\ NIST}

Greenhouse gas measurements and climate change are not only important for the U.S. but the entire world; hence, the solutions have to come from the international community. NIST has supported IG $^{3}$ IS to promote international activities and cooperation. There are significant efforts, in addition to those NIST has undertaken within the U.S., in the U.K., New Zealand, France, Switzerland, and more recently in China. Whetstone noted that meeting Fouzi Benkhelifa resulted in learning that the business community was worried about the lack of standards. This was surprising since he felt that ISO 9000 had been more of a burden on the business community rather than a benefit! It was expensive to implement. Whetstone cited one example where a senior company manager estimated that ISO 9000 compliance had an estimated cost of about $15 \%$ of operating costs. However documentary standards are important because they provide the means to put techniques developed by this community into a form that can be used in mitigation efforts and in contracts that could support these efforts.

Cities don't necessarily have the capacity to use the tools being developed now. There is usually a combination of universities, NGOs and consulting businesses that can help cities develop inventories. At the moment, these are not of very high quality. An important point for this community is "How do we deliver this message without annoying people?" Sometimes cities hire people who don't know much about this topic, but this new standard would give those people an established tool. Documentary standards could also be used as a performance metric in development and award of contracts, and in judging the results appropriately. Benkhelifa and Whetstone have been engaging with documentary standards community in this country and abroad. Their focus has been on ISO and related organizations (ANSI, CEN, etc.). They are trying to develop a long-term strategy and output mechanisms. They are also trying to engage organizations like OSA and AGU to provide scientific support. These represent just the preliminary stages of thinking this through. They hold promise for providing technical standards that would have to be met for GHG emission assessments. They would be even more effective if they could be connected with Air Quality related efforts.

Whetstone also mentioned that the National Institute of Metrology (NIM) of China was another institution that was participating in these international collaborative efforts. They have sent several researchers to NIST for training and have established testbeds in Beijing and Zhengzhou. The testbed at Zhengzhou is already producing useful data on urban GHG emissions. 


\subsubsection{Discussion/Questions for Panelists:}

Vermeulen was asked about the scatter plot (see slides in Appendix D), and how points were located in the "interest vs. influence" spectrum. This assessment was done by experts, mostly scientists from ICOS. Another question was about why climate-sensitive businesses were in the low interest/influence quadrant, especially given that investment companies are increasingly more concerned about climate risks now. It was pointed out that this is still a work in progress and perhaps some of these assessments would change in the future. Some were amazed that EU was able to put together this monitoring system. It was agreed that the network provided valuable information on local atmospheric conditions, but how was that used to validate inventories? It was pointed out that inverse modelers and biosphere modelers were using the data in their scientific products. Inventory developers are not yet involved with these efforts. But European Commission is considering this problem and trying to connect inverse modelers and inventory developers. By the time of the 2028 stock-take, the community should have prototype tools ready. The Copernicus program is a critical piece of the puzzle, and a robust atmospheric monitoring system has to be in place in time for the satellite launch. It was pointed out that originally ICOS was similar to the NOAA network, where stations were located primarily for monitoring the biosphere, but interest is shifting more to monitoring the impact of fossil fuel use. There is now much discussion about how to expand ICOS to urban environments, but interest varies by country. There is of course the question of cost; urban monitoring expenses have to come from national levels, hence much political debate! It was mentioned that stakeholders seem to be more excited about what this community is doing and this excitement is growing rapidly, such as Banque Paribas and business organizations such as WBCSD; however, it was agreed that this community has to create its own market for itself.

Manning was congratulated for successfully establishing a unique relationship with inventory makers in the UK. This relationship is partly responsible for the success of their program. The question was asked about what stakeholders were really interested in, accuracy vs. precision vs. trend detection? It was agreed that monitoring trends is the important point at this time. Inventories considered to be reasonably good, but many coming from unknown sources, therefore the magnitudes may not be right, but the real question is: are the trends okay? In many cases, we are trying to compare atmospheric vs. bottom-up trends; some gases are easier to compare than others. For example, cars are phasing out HFC-134A use; the question is will this be observable in the atmosphere? It was agreed that trends are important, but magnitudes are important too! The Kyoto Protocol was based on the 1990 numbers, but if those numbers are wrong, all the following data may be wrong too. But there were not a lot of measurements in 1990; this may end up being a very flawed approach. Manning's good working relationship with UK inventory developers seems to be a unique situation; the conversation is different in the US and EU. In EU, there has been a good relationship with air quality inventory people but not GHG emission inventory developers who work with IPCC! This seems to be true in other countries such as Japan. Some pointed out that, when talking with people at state or national levels, there is little resonance with the need for verification of inventories with atmospheric measurements; most of them do not see a reason to disbelieve inventories. We may need some bad news to get the attention of the newspapers and then the policy makers! There have been some exceptions, such as the case for Paris which was reported widely.

Benkhelifa pointed out that perhaps the community needs people like Origins.earth to build bridges to city planners. It was also pointed out that scientists sometimes have difficulty using language in their presentations that is clear for non-technical audiences. They need to work harder to clearly communicate directly with city planners. We may need middlemen who know city politics. Also, 
citizens like seeing visual tool, perhaps distribution of $\mathrm{CO}_{2}$ at neighborhood level. We are in Greta Thunberg era! Maps mean a lot. Perhaps we have been talking to the wrong people for a long time! Benkhelifa also emphasized the importance of quantifying magnitudes vs. trends. "Climate emergency" is on the agenda of many cities; we need new ways of communication with these stakeholders. Paris is phasing out diesel in 2024 and gasoline in 2030? Can we detect the impact of these changes? Need to show people where we are now and follow the trends to see if we are on the right path (or not). People will understand that they have to change to meet targets. Sciencebased approaches have value for people. In fact, big companies are using science-based targets. Atmospheric scientists have good products, and don't need to compete with the inventory community. Another issue of concern is the concept of carbon neutrality. What is the exact definition? How do we define emissions vs. offsets; it is assumed that we can be "carbon-neutral" only by offsetting. Some companies are pushing for this definition of neutrality. Don't want to miss this opportunity to influence actual mitigation! Standards community has the opportunity to help define this debate and to define "neutrality". It was pointed out that offsets also need verification which is not being done at the moment.

Turnbull pointed out the difficulties of interacting with the NZ Ministry of Environment. The Ministry staff felt like they were being talked down to and were quite defensive because these activities may have threatened their jobs. But scientists were persistent and kept going back after painful discussions, and eventually had the Ministry's buy-in. It took 3 years for the inventory folks to accept model output in their reporting to IPCC. The community can't give up...She also pointed out that NZ is a small country; scientists know each other; hence, they couldn't review each other's proposals. $\mathrm{IG}^{3} \mathrm{IS}$ played an important role to give their ideas and proposals validity.

Cohen pointed out that the public are stakeholders too! Nightly news could show carbon weather for next day? How do we improve communication to general public? Google can create userfriendly display for emissions estimates... Not just engagement with technocrats. Public-facing websites can create broader exposure for our work.

Gurney stated that the conversation with policy makers at the nation/state level is easier, since states have to turn in reports to UNFCCC. But at a lower level, efforts to prepare city level inventories may be a waste of resources for municipal governments if they are hiring consultants to create inventories. Several in the scientific community are doing the job and the cities should utilize these resources. The real question is; should we have a single system? What cities can contribute to these efforts is by providing more detailed, superior local knowledge on residential, commercial, industrial and vehicular sources of emissions. Municipal resources would be more effectively utilized in mitigation efforts. It was pointed out that perhaps we need multiple sources to reduce uncertainties. We need to be doing things that are more valuable for cities. We need to clarify their needs to facilitate mitigation efforts.

Gourdji asked if it wasn't a good idea to have multiple efforts, such as Vulcan, ACES, ODIAC, etc., to reduce uncertainties? Comparisons between Vulcan and individual city efforts show a lot of differences! But the problem may be that in different models, sectors are split up differently and different data sources and methods are utilized, leading up to differences that may get up to $50 \%$. Most city inventories are persistently lower than Vulcan (80\% of cities). How do we reframe this problem going forward? One possibility is correcting the use of emission factors which are wrong. Another approach may be creating "atmospherically-calibrated" inventories; or using data consistent with radiocarbon measurements. Consulting companies have templates and deliver cities results which use generic information. Cities have a hard time getting petroleum data, causing them 
to potentially leave out parts of industrial sectors, e.g. point sources. Problem approached completely differently. It was also pointed out that cities and industries want to know what they can do to reduce their carbon footprint? City-based inventories may be based on the sectors where they want to focus mitigation efforts (e.g. transit system). Many sources in cities are not captured with emission factor approach. Top-down numbers "the best", but stakeholders want to know what can they do? Perhaps we need to establish Science Based Targets (SBT). We were cautioned against using the word "inventory" for the emissions activity-based model. Urban-scale models need to be able to scale up and be consistent with state-level, or regional-level models, etc. We need to be able to test consistency up and down different scales.

Whetstone was asked how atmospheric measurements might fit in with documentary standards. Atmospheric measurements may become candidates for documentary standards, along with other data sources, but we are not there yet. However, some parts of the technology, for example atmospheric concentration measurements, is probably ready for standardization. In fact, documentation from GGMT practices implemented for the GAW network could be a good starting point; these could form the foundation for atmospheric flux measurements. Also, methods developed for design of monitoring networks, or how to define footprints of monitoring stations, could be established as best practices. As these techniques mature, they can be considered for standards. In many cases we are not there yet, but we need to keep these in mind to establish internationally accepted practices, and perhaps develop a prioritized list.

J. Kim was asked to provide perspectives on related work in S. Korea. He tried to talk to Ministry of Environment during $\mathrm{PhD}$ studies, it was like talking to people on the moon! Different departments have different roles, develop rapport and then staff turnover! Same thing with colleagues in China... The challenge is knowing how to deal with these issues, particularly in developing countries. Government people are looking for a PR opportunity, how will my career benefit if I fund you or support your program? How would I look to voters? They seem to want something catchy, visual, something that can be explained clearly with a good story. These drivers are sometimes contrary to the goals of scientists. Kim was also asked to compare/contrast experiences in US vs. S. Korea. He pointed out that, in Korea, people reviewing proposals had absolutely no idea what you were doing! In US, reviewers would at least be in the general field of atmospheric sciences. In Korea, one must have to explain things from the very beginning in order to justify the need for measurements.

Turnbull agreed that $\mathrm{IG}^{3} \mathrm{IS}$ was important because an international stamp of approval is very helpful to "validate" their efforts, especially because NZ a small country. Only a handful of its people do carbon cycle science. Internal review usually means reviewers know nothing about what you do. The challenge is how do you convince people that you're good at what you do?

Semerjian mentioned that he has drafted a beginning process of standardization for this field. "Best practices" need to be established to encourage the private sector to act and to justify their activities. Discussions have been initiated with committees that participate in ISO standardization. We don't necessarily need to develop a standard right away but could develop a technical report where the state of the art is discussed and where things are in terms of standardization. What do the IPCC guidelines say in this regard? Bottom-up approaches document some of these methods and could represent recommendations best practices. Accurate measurements of atmospheric GHG mole fraction are being performed and inter-comparability of GHG measurements are being checked around the globe. Some of these areas are mature enough to go towards establishment of a standard. An agreed upon approach to estimate the impact of biogenic sources and sinks would be highly 
valuable, given significant commitments/ investments being made for planting large numbers of trees, etc. Best practices for urban platforms implemented in the US, France, UK, NZ, China would be highly desirable. Weiss pointed out that, standards for atmospheric mole fraction measurements are dependent on scales, and the metrology community needs to provide scales that are more precise than absolute values and understand that we need scales; we are better at comparing two values than at knowing the absolute value.

Keeling pointed out that in-situ measurements already have well-defined standards. Network design is still at the R\&D stage but is more mature; atmospheric modeling part still needs more fundamental research. A city is not going to have a resident inverse modeler; they barely have funding to pay for GHG measurements. The city considers itself compliant because it's providing the community with information that allows an audit; this is done by an outside group that's respected and uses the cities' data.

Benkhelifa noted that an understanding of the added value of services provided need to be developed. First level of service, providing a trend, could be very important. Second level, mapping spatial distribution of hotspots, would be very useful. Third level, dashboard by sectors, would be informative. Fourth level, the impact of projects undertaken, would encourage further investments. This community needs to deliver data with a dynamic approach, making comparisons possible. Opportunities based on success stories will define future ecosystem climate science-based services. The Paris City Council vote on near-real time $\mathrm{CO}_{2}$ monitoring is an illustration of this approach. It was pointed out the European economies are already making the transition between climate science and businesses through "climate services". The global market for air quality monitoring in cities is about $\$ 7$ billion per year, including companies that make sensors, deliver and deploy them. More like $\$ 70$ billion is spent for clean-up efforts. Joining forces with those communities makes sense for GHG emissions mitigation efforts. But if we expect this to happen, we have to build a marketplace for the workforce and good practices. Some of the private sector entities will be both suppliers and consumers. Companies like Procter \& Gamble want advice on how to reduce emissions in their supply chain. Very little climate finance has gone to cities to help reduce emissions, to retrofit buildings, etc.

Shepson pointed out that, in New York City, a new Law 97 sets targets for buildings above a certain size $\left(50,000 \mathrm{ft}^{2} ; 4,645 \mathrm{~m}^{2}\right)$; puts a price on carbon for difference between target and current emissions. A fee of \$US 268/metric ton C may be applicable for emissions above the allowed levels ${ }^{72}$. It was mentioned that the current European system for carbon mostly focused on offsets; big companies are putting up tons of money by paying developing countries to plant trees! This allows them to check a box on the regulatory side, but who knows what's actually happening in Tanzania, for example, who received the funds? No one seems to know what the status of that "forest" is!

72 All About Local Law 97, https://www.urbangreencouncil.org/content/projects/all-about-local-law-97 


\title{
3.3 Panel Discussion on Domestic Stakeholder Experiences/Broader Impacts Moderator: Thomas Lauvaux, LSCE, France
}

\author{
Panelists: $\quad$ Ronald Cohen, Univ. California at Berkeley \\ Russ Dickerson, Univ. Maryland \\ Riley Duren, Univ. Arizona \\ Kevin Gurney, Northern Arizona Univ. \\ Eric Kort, Univ. Michigan \\ Joseph Rudek, Environmental Defense Fund \\ Paul Shepson, Stony Brook Univ., SUNY
}

\subsubsection{Joseph Rudek \\ Environmental Defense Fund}

Rudek summarized several EDF projects that are focused on industry to help them meet their methane emission reduction goals along the entire supply chain. One of the projects was a long series of studies on methane leaks from oil and gas fields, $;{ }^{73,74}$ they helped identify locations of leaks and their repair. A more recent study was to detect leaks in city distribution pipelines; EDF and Google Earth Outreach teamed up to build a faster, cheaper way to find and assess leaks under our streets and sidewalks. ${ }^{75}$ In a project run out of West Virginia University, they worked with manufacturers and operators of heavy duty truck fleets of NG vehicles; leaks from crank cases and other locations were identified and fixes were implemented. EDF is also conducting surveys of $\mathrm{NO}_{2}$ emissions from agricultural activities and fertilizer use. ${ }^{76}$ Surveys of ammonia manufacturing plants have indicated 100 times higher $\mathrm{CH}_{4}$ emissions than expected. Protein companies involved with agriculture and livestock have a challenge since many of their emissions are from large landscapes, and emissions from livestock and from agriculture are difficult to monitor. They want to reduce their emissions because of corporate stewardship responsibilities and their relationship with investors. EDF is also interested in reducing emissions from appliances, such as water heaters. Finally, energy companies that are to get offsets are producing biogas (mainly methane) from renewable fuels and landfills. Leakage is a big issue in these systems, and we need to make sure offsets are not having a negative impact.

73 https://www.edf.org/climate/methane-research-series-16-studies

74 D.T. Allen, V.M. Torres, J. Thomas, D.W. Sullivan, M. Harrison, A. Hendler, S.C. Herndon, C.E. Kolb, M.P. Fraser, A.D. Hill, B.K. Lamb, J. Miskimins, R.F. Sawyer, and J.H. Seinfeld, "Measurements of methane emissions at natural gas production sites in the United States”, Proc. Nat. Acad. Sci. 110 (44), pp. 17768-17773 (2013); https://doi.org/10.1073/pnas.1304880110

75 "Local leaks impact global climate", https://www.edf.org/climate/methanemaps

76 _K. Kritee, D. Nair, D. Zavala-Araiza, J. Proville, J. Rudek, et al., "High nitrous oxide fluxes from rice indicate the need to manage water for both long- and short-term climate impacts”, Proc. Nat. Acad. Sci., 115 (39), pp. 9720-9725

(2018); https://doi.org/10.1073/pnas.1809276115 


\subsubsection{Eric Kort \\ University of Michigan}

Kort first wanted to redefine and talk about what we mean by impact. He thinks what we consider as engagement is sometimes too narrow. We usually define the stakeholders (local officials, regulatory or inventory personnel) narrowly; there are many other ones. As a result, successful impact may include making a problem visible to the public, identifying mitigation opportunities, motivating regulatory action, or improving inventories. It is also important just being careful about how to communicate our work.

Kort mentioned two anecdotes of successful engagement:

1. Work on offshore oil and gas platforms: ${ }^{77}$ In discussions with EPA folks doing the inventory, they found activity factor errors in the inventory; EPA will use corrected values in their new inventories. They specifically calculated emission factors to put in the paper, so that EPA can incorporate them directly. They also found that the wells were not accounted correctly.

2. 4-Corners- methane emissions. ${ }^{78}$ Did not engage or have stakeholder goal in mind. Got press attention, was a good picture. Local people got involved and energized, local forum, US politicians got engaged, was used to make the Bureau of Land Management methane rules.

Kort also mentioned his work with a large number of collaborators on emissions from the oil and gas supply chain, ${ }^{79}$ and his more recent work in collaboration with NIST on the Northeast Corridor. ${ }^{80}$ It was mentioned that engaging commercial airplane pilots in emissions measurements would significantly reduce costs of testing and enable acquisition of data over a broader range of conditions.

77 A.M. Gorchov Negron, E.A. Kort, S.A. Conley and M.L. Smith, “Airborne Assessment of Methane Emissions from Offshore Platforms in the U.S. Gulf of Mexico", Environ. Sci. Tech., 54 (8), pp. 5112-5120 (2020)

78 M.L. Smith, A. Gvakharia, E.A. Kort, C. Sweeney, S.A. Conley, I. Faloona, T. Newberger, R. Schnell, S. Schwietzke, S. Wolter, “Airborne Quantification of Methane Emissions over the Four Corners Region”, Environ. Sci. Tech., 51 (10), pp. 58325837 (2017)

79 R.A. Alvarez, et al., "Assessment of methane emissions from the U.S. oil and gas supply chain”, Science, 361 (6398), pp. 186188 (2018); DOI: $10.1126 /$ science.aar7204

80 Y. Huang, E.A. Kort, S. Gourdji, A. Karion, K. Mueller and J. Ware, "Seasonally Resolved Excess Urban Methane Emissions from the Baltimore/Washington, DC Metropolitan Region”, Environ. Sci. Tech. 53 (19), pp. 11285-11293 (2019) 


\subsubsection{Riley Duren \\ University of Arizona}

Duren summarized lessons learned from many interactions including those with GHGIS (20082011); ${ }^{81}$ climate treaty negotiation and verification communities; LA Megacities Carbon Project (2011-present): LA basin municipalities and companies; CMS Understanding User Needs 20122016: US Federal \& California agencies; California Methane Survey 2015-2018: California state \& local agencies, landfill operators, gas utilities, O\&G industry, dairy lobby; CMS multi-scale methane projects (2015-present): CA, NM, CO governments, gas utilities, Oil and Gas industry, waste management industry; "CalCEMS" satellite program (2016-present): foundations, commercial space. He concluded that:

- Stakeholder entrainment (beyond engagement) occurs when data is delivered in a timely fashion and directly addresses problems framed by public- \& private-sector stakeholders who are willing $\&$ able to pay/act.

- Stakeholders may need help a) recognizing problems, b) defining what they need and c) adapting to shifting political and economic landscapes [requires persistent, bi-directional dialogue].

- Most compelling: data that enables "shovel ready" mitigation action at local scale, followed by actionable diagnosis of regional/sectoral accounting errors; this is probably why $\mathrm{CH}_{4}$ is hot and $\mathrm{CO}_{2}$ is not.

- Common stakeholder priorities: Timeliness, attribution, and accurate quantification (in that order).

- Many actors are still "watching and waiting" before committing (some quietly evaluating monitoring capabilities including a growing mix of commercial solutions with a wide range of transparency and credibility)

Success requires clear alignment with the needs of motivated and empowered stakeholders, and data products that are affordable, politically tenable, relevant for action, and within their interest horizon.

Duren emphasized the importance of knowing what problem(s) we trying to solve, because we have a very diverse set of stakeholders, cultures $\&$ applications. The stakeholders include:

- Primary stakeholders (may pay for or act directly on data)

- National, state and local governments

- Regulatory agencies; Local enforcement agencies/oversight boards

- Oil \& Gas companies; Biogas companies

- Executives in big cities

- Operators in rural areas

- Landfill managers

- Waste management companies

- Farmers

- ESG analysts and certification companies

- Commercial/financial data services

- Philanthropic foundations (donors)

- NGOs (including activists and advocates)

${ }^{81}$ https://www.osti.gov/biblio/1033495/ 
- Secondary stakeholders

- Educators; Researchers

- Media

Our stakeholders are also culturally diverse and include urban and rural areas, red and blue states, all economic sectors, public and private entities, climate deniers and acceptors, US and other countries, developed and developing economies, large corporations and small businesses and landowners.

It is also important to realize that our stakeholders have a wide range of scientific and policy expertise, which include blue collar workers, industry executives, policy makers and regulators, scientists and engineers, activists and organizers, and the general public.

Different applications have different data requirements; field operators concerned about leak detection and repairs need exact location of leaks; markets need data on carbon intensity and certification processes; governments need data on GHG inventories and trends.

Their earlier work at Four-Corners motivated CARB to tackle super-emitters. Started their monitoring effort at JPL. Talks to CARB every week. A "tiered observing system" was used for airborne remote sensing of point sources; the data was shared with landfill and local enforcement agency, and mitigation actions were implemented.

Tiered observing system in action: landfill methane emissions mitigation

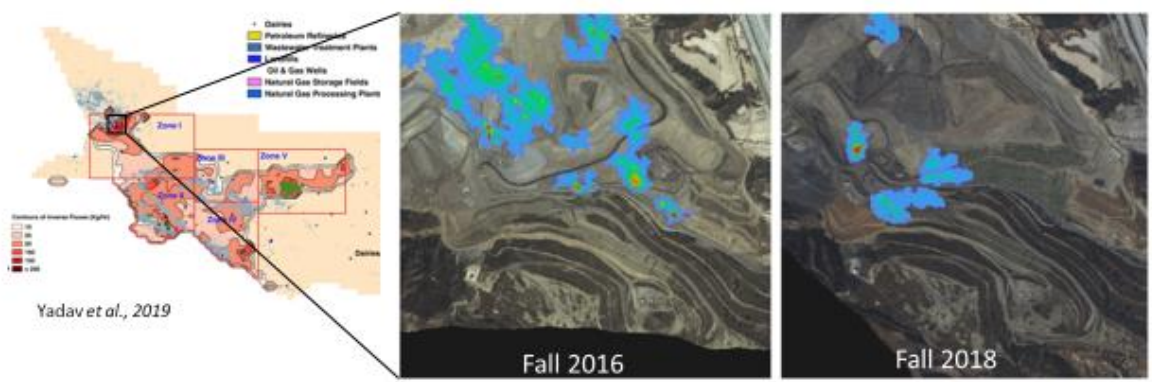

Other entities using our point source data:

-California state \& local agencies (CARB, CEC, BA-AQMD, etc)

-oil companies (Chevron, CRC, etc)

-gas utilities (SoCalGas, PG\&E)

-other landfill operators \& enforcement agencies (Republic, LEA)

-ESG providers (Truevalue Labs, Spherical Analytics)

-City of LA (inventory team)

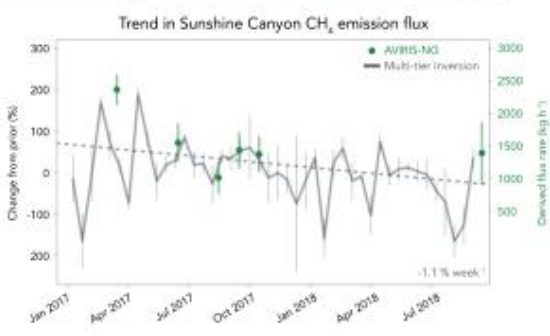




\subsubsection{Russ Dickerson \\ University of Maryland}

Dickerson pointed out that the Univ. of Maryland has had a strong partnership with the Maryland Department of the Environment over a 30-year period. It started with the realization that the city of Baltimore had the worst air quality along the Eastern U.S., based on ozone measurements. The authority and responsibility for fixing the Non-Attainment Area (NAA) problem falls on the State. They came to the university seeking help. Univ. of Maryland provided science fundamentals and measurements that helped identify some of the problem areas and improved air quality; changes from use of coal for power generation to natural gas has helped quite a bit. Now Baltimore is in attainment for particulates and near-attainment for ozone. The Non-Attainment Area has moved from Baltimore up the coast to the New York City and Connecticut area, giving something to do for Shepson at Stony Brook!

Maryland enacted the GHG Reduction Act which requires a reduction of $40 \%$ by 2030, hence the increased emphasis on GHG measurements. The State of Maryland has also become a member of the Regional Greenhouse Gas Initiative (RGGI), which is the first mandatory market-based program in the United States to reduce greenhouse gas emissions. RGGI is a cooperative effort among the states of Connecticut, Delaware, Maine, Maryland, Massachusetts, New Hampshire, New Jersey, New York, Rhode Island, and Vermont to cap and reduce $\mathrm{CO}_{2}$ emissions from the power sector. In fact, Maryland's Secretary of the Environment is now the chair of RGGI. Maryland has also established a Climate Change Commission; Dickerson is serving as one of the Commissioners.

Carbon dioxide measurements indicated an agreement with inventories within about $15 \%$ which was considered acceptable. ${ }^{82}$ Methane measurements indicated a more challenging problem; they were off by a factor of 2-3. ${ }^{83,84}$ The State needed guidance on improving emission models, including the impact of the biosphere. There was a major undertaking to reduce emissions from landfills; the power company BG\&E fixed many of the leaks from their distribution lines and valves, etc. What they would like to see is some evidence that all their hard work fixing pipes has worked in Baltimore.

82 D. Ahn, R.J. Salawitch, I. Lopez-Coto, O. E. Salmon, P. B. Shepson, K. Prasad, X. Ren, R. R. Dickerson and J. R. Whetstone, "Fluxes of Atmospheric Greenhouse-Gases in Maryland (FLAGG-MD): Emissions of Carbon Dioxide in the Baltimore, MDWashington, DC area", J. Geophys. Res.-Atmosheres (15 April 2020) https://doi.org/10.1029/2019JD032004

83 X. Ren, O. E. Salmon, J. R. Hansford, D. Ahn, D. Hall, S. E. Benish, P. R. Stratton, H. He, S. Sahu, C. Grimes, A.M.F. Heimburger, C. R. Martin, M. D. Cohen, B. Stunder, R. J. Salawitch, S. H. Ehrman, P. B. Shepson, and R. R. Dickerson, "Methane Emissions from the Baltimore-Washington Area Based on Airborne Observations: Comparison to Emissions Inventories", J. Geophys. Res.-Atmospheres, 123 (16), pp. 8869-8882 (2018) https://doi.org/10.1029/2018JD028851

84 X. Ren, D. L. Hall, T. Vinciguerra, S. E. Benish, P. R. Stratton, D. Ahn, J. R. Hansford, M. D. Cohen, S. Sahu, Hao He, C. Grimes, J. D. Fuentes, P. B. Shepson, R. J. Salawitch, S. H. Ehrman, and R. R. Dickerson, "Methane Emissions from the Marcellus Shale in Southwestern Pennsylvania and Northern West Virginia Based on Airborne Measurements," J. Geophys. Res.-Atmospheres, 124, pp. 1862-1878 (2019) https://doi.org/10.1029/2018JD029690 


\subsubsection{Paul Shepson \\ Stony Brook University, SUNY}

Shepson reviewed his more recent activities. In the past, he was working in the DC/Baltimore area with NIST and Univ. Maryland colleagues, ${ }^{8586}$ but now working in the New York City (NYC) area as well. NYC has a new law titled "Climate Leadership and Community Protection Act" signed on Dec 31, 2019. It calls for $40 \%$ reduction of GHGs by 2030 and increasing the renewable electric power share to $70 \%$ by 2030. Shepson and Whetstone visited with the NYC Mayor's Office of Sustainability to get an interaction going. They have their own emissions model, based on a spreadsheet, and they don't seem to care much about systematic errors or inaccuracies; their main concern is assessment of the trend. They are also more interested in methane. The law is to be implemented through a 22-person Climate Action Council. (Directory of NY State Energy Research and Development Act (NYSERDA)). They will produce an implementation plan to achieve the goals. Bob Howarth (an ecologist) and Paul Shepson are the two scientists on the group. They will produce a plan that will then go through 1 year of public hearings, leaving 7 years to implement the plan. The State is thinking of large-scale grid-based renewables - wind and solar. This is expected to involve large energy delivery companies and organizations. Implementation could take another decade. In the meantime, what can be done right away? Conservation does not seem to be part of the Americans' psyche and is hard to make a difference. Now Paul is interested in the social sciences. How do you engage people in fundamental day to day

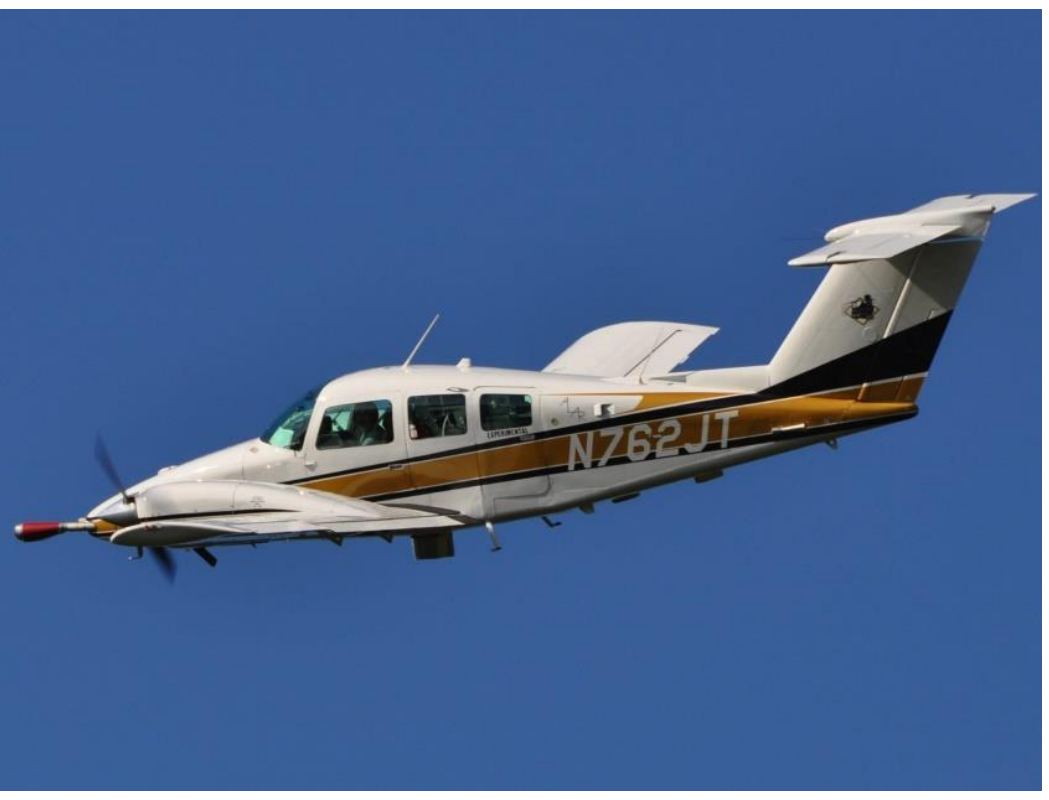
decisions? How do you get people to make these decisions? He is looking forward to acting as a stakeholder which is a new role for him.

85 N. L. Miles, S. J. Richardson, T. Lauvaux, K. J. Davis, N. V. Balashov, A. Deng, J. C. Turnbull, C. Sweeney, K. R. Gurney, R. Patarasuk, I. Razlivanov, M. O. L. CambalizaP and P. B. Shepson, "Quantification of urban atmospheric boundary layer greenhouse gas dry mole fraction enhancements in the dormant season: Results from the Indianapolis Flux Experiment (INFLUX)", Elementa Sci Anth, 5, p. 27 (2017), https://doi.org/10.1525/elementa.127.

86 K.R. Gurney, J. Liang, R. Patarasuk, D. O'Keeffe, J. Huang, M. Hutchins, T. Lauvaux, J. C. Turnbull, and P. B. Shepson, "Reconciling the differences between a bottom-up and inverse-estimated FFCO2 emissions estimate in a large US urban area", Elementa Sci. Anth., 5, p. 44 (2017), DOI: https://doi.org/10.1525/elementa.137 . 


\subsubsection{Kevin Gurney Northern Arizona University}

Gurney stated that most cities are underestimating their GHG emissions, some by as much as $80 \%$. These are findings from a paper they are planning to publish soon, ${ }^{87}$ where they show results comparing city inventories with Vulcan. ${ }^{88}$ IPCC economists and sociologists are pushing for use/consumption-based accounting which explains some of these discrepancies. There is a mandate challenge: there is no regulatory mandate for cities to reduce emissions. City inventories are being used as political instruments and for publicity purposes! The question of interest seems to be: How quickly can they become carbon neutral? There is also a resource challenge: the cities don't have the resources to do a full system analysis and establish a credible baseline. This foundation should be established by a central organization with credibility. The other challenge is the fact that organizations such as ICLEI, WRI, C40 claim to have developed "standards" feel threatened by the current work. We should be "shining a light" on these activities instead of "shaming".

These estimates are also not accounting for Scope 3 emissions; this is difficult to calculate and also verify at local/city scale. National scale is easier. Gurney thought that cities should not be spending resources to do the inventory; they should use them towards achieving their goals and mitigating the problem.

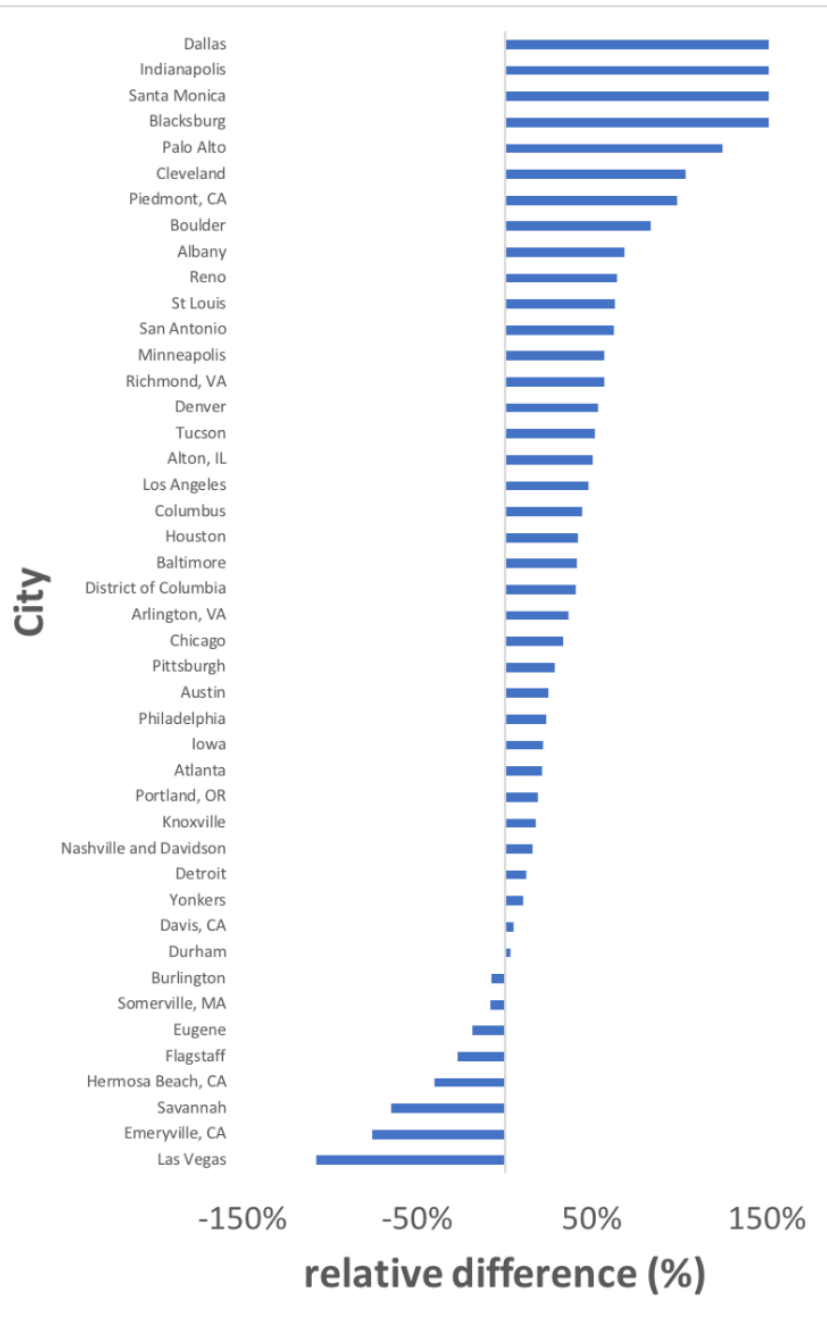

87 K.R. Gurney, J. Liang, G. Roest, Y. Song, K. Mueller, and T. Lauvaux, "Under-reporting of greenhouse gas emissions in U.S. cities", Nat Commun, 12, 553 (2021). https://doi.org/10.1038/s41467-020-20871

88 http://vulcan.rc.nau.edu/ 


\subsubsection{Ronald Cohen University of California at Berkeley}

Cohen was initially interested in $\mathrm{CO}_{2}$ measurements, but the new California law is focused on environmental justice; as a result, their focus has shifted to air quality (AQ) monitoring and lowcost sensor networks. Planning to do an experiment in Glasgow, mostly a public education project, primarily associated with the COP26. Public education is a key part of their engagement in order to showcase how people think about where cities are and how they can contribute to saving the planet by reducing $\mathrm{CO} 2$ emissions. ${ }^{89}$ They are trying to engage the public and enhance their interest. They are doing a project in Pasadena with the schools, engaging the teachers, and putting monitors on top of the schools. They are also working with the Exploratorium to develop a model of the Bay Area.

Retired scientists from LLNL came looking to help and work with students to build instruments in the classroom. They try to scale down complexity of instruments for a classroom of high school students. Engaging students at that level would be very inspiring.

Univ. of California at Berkeley is also providing training for teachers so that teachers can use the measurements in classrooms to talk at about climate or air quality, but also about measurement and data science, and concepts like measurement uncertainty. They are also providing support for high school science curriculum development. Univ. California - Berkeley graduate students do a lot of classroom visits to places where they make measurements and talk about career paths. This is actually what science teachers want to hear most.

They have developed a 5-week summer school for Community College students; the curriculum is built on the observations they are making to bring the undergraduate pipeline into graduate school, including under-represented communities.

89 A.A. Shusterman, J. Kim, K.J. Lieschke, C. Newman, P.J. Wooldridge and R.C. Cohen, Observing local CO2 sources using low-cost, near surface urban monitors", Atmos. Chem. Phys., 18, pp. 13773-13785 (2018) 


\subsubsection{Discussion/Questions for Panelists}

Several participants emphasized the importance of educating the new generation. JPL has tried to stand up a summer school. Cohen said he prepared a new curriculum and the summer school is open for registration. Target audience is community college students who might transfer to UCB, also juniors who may want to transfer. He is using Jupyter notebook as a pilot program; happy to share that with others who might want to scale it up. He was asked what they were specifically teaching. Students are learning about the atmosphere and some programming; the goal of the project at the end is to do some kind of research project with data from their networks. Kim said he talked to an art student at UCSD interested in mapping human activity in cities. There seems to be a general interest in visualizing GHG emissions and engaging people. Cohen added that they are also working with an Exploratorium artist to develop visual tools.

Rudek asked if cities adopted more "standardized" inventories and baselines, how would that affect their earlier claims about emissions reductions, etc.? It was stated that it was important for us to track trends and provide feedback for the stakeholders, and we need to create a feedback loop. Currently it is only aspirational - not regulatory. Rudek said in addition to a standard for setting the baseline, there should be a standard about how to track trends and changes. Shepson asked what was the right thing to do here given the knowledge of the state of the cities' inventories? If it continues the way that it is, when we get closer to 2030, when you integrate over all the cities' calculated change, you'll get a number significantly different from what would be calculated using national-scale Vulcan. We have a responsibility to communicate in a politically helpful way.

Duren said a few years ago there was a gigaton gap in China between reporting at provincial scales and national levels. If we see a large discrepancy - do we say that the national inventory is off? Gurney says there is a difference between Vulcan calibrated to the atmosphere and the EPA (10\% $-11 \%$ ) which is still a lot for a national total. The ${ }^{14} \mathrm{C}$ inversion matches Vulcan very well. Not sure what is going on. Need a system that conserves mass. Current city inventories don't have that, they are not a nested system. Kort says if there is a discrepancy in one year may not be interesting to us. If we tell them that their trends are wrong, or the way they are counting a sector is wrong, that might be more meaningful to a city government.

Duren was asked if the emphasis was on $\mathrm{CH}_{4}$ (instead of $\mathrm{CO}_{2}$ ) because it represents lost money? It was felt that the lost revenue issue was not that important. In many cases, the facility operators were not even aware of the leaked emissions. In some cases, it might also cost more money to fix the leaks. The oil/gas industry usually takes their social license to operate seriously; otherwise, they may lose it. Emissions from waste and agriculture are also not realized in many cases, and they don't have simple solutions. Of course, there is no money implication for $\mathrm{CO}_{2}$ emissions but that does not mean that we can ignore them. Duren also mentioned the low-carbon certificates; we need to establish some kind of certification of low-carbon footprint methane systems for businesses that they can publicize. In many cases, the political cost is re-election for the cities. If you are not meeting your targets, there is a political cost there.

Benkhelifa returned to the issue of financing $\mathrm{CO}_{2}$ mitigation efforts. One part of discussion with Paris was the business model of the CAP. $20 \%$ of their plan is relying on their own buildings (city) and $80 \%$ is working with companies and individuals. Currently, businesses are going for lowhanging fruit and leaving the more difficult part to the city and individuals. There is an increased 
driving force about using offsets within the cities instead of planting trees at remote locations; they are looking for investments in other emissions-reducing projects within the city to get offsets. The city has issued Green Bonds worth 350 M Euros.

Dickerson mentioned the RGGI coalition in the US North East; these states have signed on to very strict GHG reductions. These are in fact stricter than the Paris agreement There are teeth in those agreements; they have to meet the goals for $\mathrm{CO}_{2}$. Gurney was asked if he had done comparisons to the RGGI states; he had not. Sweeney did talk to them and they were not interested. They are relying on CEMS self-reporting; these may not always be accurate. It was pointed out that, until very recently, RGGI only regulated powerplant emissions, which is why there may be a disconnect here.

S. Miller stressed the need to think of strategies to convince cities. He mentioned a personal anecdote; he is tasked with doing the revision of the Baltimore city inventory. Baltimore inventory is $30 \%$ lower than Hestia; he needs to show why and how we need to change it. But they need to know if they met their reduction goal from 2007. But we need to give a number relative to 2007. The consulting company who did the inventory did not include home heating oil. But over time, people are switching to natural gas, which is counted; so it may look like residential emissions are increasing when they are not. Similar corrections have to be made in other cases; EPA AQ inventory not back-corrected, but the GHG inventory is back-corrected.

Benkhelifa felt that we were spending too much time talking about inventories. Markets are more concerned about the quality of the information. How do we know the real quality of the inventory? Why should they pay more for just another inventory if we can't articulate the level of quality? How do we compete with a consultant for this? The money is not in the inventory but in the "smart cities" - actually solving the problem. We need to be part of the new investment plan of the cities, not just improving the reporting of the existing inventories.

Turnbull commented that it makes more sense to do an inventory at national scale and make it available to everyone. How would we get buy-in to do this? Gurney injected that we should not pitch them to use the system, but that we need them as partners to champion the system to stakeholders like Congress, commercial entities, etc. Tell cities this will be useful, and this will save you from doing it, and it's more accurate/precise. Keeling concurred that we need data from the cities themselves, and the partnership could engage the cities on providing something they do anyway better, since they have access to the data we need. Gurney also pointed out that we need to focus on the integration of top-down and bottom-up data as a complete system; the combination is going to deliver the best information. The system needs iterative engagement with localities, states, etc. 


\subsection{Wrap up Discussion: Mapping Technical Capabilities to Stakeholder Needs Moderators: Riley Duren, University of Arizona Phil DeCola, GIST.earth}

The moderators tried to put the entire day's discussions into a form that would highlight the objectives of the wide range of stakeholders and the type of information and data that would be useful for them to meet their objectives. The moderators noted that, in the morning discussion, successes of the system were mentioned. These have to be foundational things that are deliverables at multi-scales; we need to propagate these achievements and identify projects that would promote these foundational elements.

One of the goals of this meeting was to figure out how to generate financial resources. WMO is probably not the right venue for that. We need to clarify the likely role the WMO-IG $\mathrm{IS}^{3}$ platform can play in engaging stakeholders. The World Meteorological Organization (WMO) could help generating interest at national scales but not so sure at sub-national scales. A broader approach has to be adopted to stimulate investments, new partnerships, etc.

A spread sheet was developed to document the type of problems stakeholders may have in the form of "objectives". The group wanted to make sure that we capture how education and successes foster motivation and trust. The next question was how to place science/policy into buckets about carbon intensity? How do cities relate to these issues?

In the case of commercial aircraft, how should we identify and work with stakeholders that are in the process of developing technologies to reduce GHG emissions? They can, in fact, become part of the solution by installing monitoring stations on their aircraft.

Another question was how we should articulate "assessments of carbon offsets, carbon neutrality, credits" etc.? Should they be combined or distinguished from underpinning low carbon certification? How do we promote development of standards/best practices? We clearly have to do more on the delivery side. Should we develop specific "use case" examples and map them to the above to make them more helpful?

There was a long discussion about the heading of Column 3 "Data/Information Requirements". What does that mean in terms of the data requirements? Should this be data requirements or data needs or product requirement (not necessarily what we can do)? This may be a general piece of "knowledge" that can meet a stakeholder need ... specific to stakeholder needs. This could have specific applications for global "stock take" or trend analysis where you need to update the data quarterly or sub-annually. Latency and resolution are different requirements, and both are important.

Inventories are not just emission factor $\mathrm{x}$ activity data; they are more complicated, and they have more constraints especially sub-nationally. They can be tied to another "verifiable" value like the NEI or national totals.

The following spread sheet was developed as a starting point. It was agreed that more thought needs to be put into this topic so that the community can use this as a tool to address the needs of the stakeholders and make sure the necessary capabilities are in place and progress can be tracked in a systematic way. 


\begin{tabular}{|c|c|c|}
\hline Objectives & $\begin{array}{l}\text { Stakeholder types } \\
\text { (examples) }\end{array}$ & Data/information requirements \\
\hline $\begin{array}{l}\text { Identify accounting issues } \\
\text { (inventories and self-reporting) }\end{array}$ & $\begin{array}{l}\text { city/local, state, national agencies; } \\
\text { policy makers; companies; NGOs; } \\
\text { urban federations (C40, ICLEI, U2C) }\end{array}$ & $\begin{array}{l}\text { annual aggregate emissions by sector, } \\
\text { EF's, activity data - covering timespan } \\
\text { of interest (maybe finer scale for } \\
\text { diagnosing issues) }\end{array}$ \\
\hline $\begin{array}{l}\text { Diagnose accounting issues } \\
\text { (inventories and self-reporting) }\end{array}$ & $\begin{array}{l}\text { city/local, state, national agencies; } \\
\text { policy makers; companies; NGOs; } \\
\text { urban federations (C40, ICLEI, U2C) }\end{array}$ & $\begin{array}{l}\text { space-time resolved emissions by } \\
\text { sector, EF's, activity data - covering the } \\
\text { timespan of interest (maybe finer scale } \\
\text { for diagnosing issues) }\end{array}$ \\
\hline $\begin{array}{l}\text { Improve carbon models and } \\
\text { projections }\end{array}$ & $\begin{array}{l}\text { city/local, state, national agencies; } \\
\text { policy makers }\end{array}$ & TBD \\
\hline $\begin{array}{l}\text { Identify mitigation } \\
\text { problems/opportunities } \\
\text { (process specific) }\end{array}$ & $\begin{array}{l}\text { city/local, state, national agencies; } \\
\text { policy makers; companies; NGOs; } \\
\text { urban federations (C40, ICLEI, U2C) }\end{array}$ & $\begin{array}{l}\text { similar to Diagnosing accounting issues } \\
\text { but maybe with improved GIS/mapping }\end{array}$ \\
\hline $\begin{array}{l}\text { Monitor progress of policies } \\
\text { (including NDCs) and ultimate } \\
\text { climate objectives (e.g., stock- } \\
\text { take) }\end{array}$ & $\begin{array}{l}\text { national governments (diplomats, } \\
\text { regulatory agencies) }\end{array}$ & $\begin{array}{l}\text { various policy metrics; (maybe) } \\
\text { emissions data }\end{array}$ \\
\hline $\begin{array}{l}\text { Assess emission trends by } \\
\text { jurisdiction and sectors }\end{array}$ & city/local, state, national agencies & monthly (?) emissions for $10+$ years \\
\hline $\begin{array}{l}\text { Support regulatory enforcement } \\
\text { and compliance (rule/sector } \\
\text { specific) }\end{array}$ & $\begin{array}{l}\text { local, state, national agencies; } \\
\text { companies }\end{array}$ & monthly (?) facility scale monitoring \\
\hline $\begin{array}{l}\text { Direct mitigation guidance } \\
\text { (e.g., leak detection and repair) }\end{array}$ & companies (operators) & $\begin{array}{l}\text { persistent, low-latency plume detection } \\
\text { ( \& coarse binning) }\end{array}$ \\
\hline $\begin{array}{l}\text { Underpin low carbon } \\
\text { certification (markets, ESG } \\
\text { metrics, license to operate) }\end{array}$ & energy producers and consumers & $\begin{array}{l}\text { carbon intensity of individual } \\
\text { companies/activities }\end{array}$ \\
\hline $\begin{array}{l}\text { Co-benefits of GHG } \\
\text { measurements to other } \\
\text { priorities (Air Pollution and } \\
\text { Environmental Justice) }\end{array}$ & $\begin{array}{l}\text { (currently) a few local and state } \\
\text { jurisdictions; public health and } \\
\text { justice advocates }\end{array}$ & $\begin{array}{l}\mathrm{CO}_{2} \text { and } \mathrm{CH}_{4} \text { as proxies/indicators for } \\
\text { VOCs, } \mathrm{BC} \text {, other criteria pollutants; } \\
\text { mapping to communities }\end{array}$ \\
\hline $\begin{array}{l}\text { Improve general education and } \\
\text { awareness }\end{array}$ & $\begin{array}{l}\text { general public; politicians; academic } \\
\text { institutions (capacity building) }\end{array}$ & $\begin{array}{l}\text { simple visualizations; GHG indices; } \\
\text { broader outreach (Google) }\end{array}$ \\
\hline $\begin{array}{l}\text { Urban greenspaces, biogenic } \\
\text { exchange, carbon storage }\end{array}$ & city/local governments & \\
\hline $\begin{array}{l}\text { Verification of carbon offsets, } \\
\text { carbon neutrality, credits? }\end{array}$ & (not just REDD+) & \\
\hline \multicolumn{3}{|l|}{ Other contracting mechanisms? } \\
\hline \multicolumn{3}{|l|}{$\begin{array}{l}\text { Assessment of Negative } \\
\text { Emission Technology }\end{array}$} \\
\hline \multicolumn{3}{|l|}{$\begin{array}{l}\text { Consistency in emission } \\
\text { estimates across scales }\end{array}$} \\
\hline $\begin{array}{l}\text { Voluntary measurement and } \\
\text { mitigation programs }\end{array}$ & $\begin{array}{l}\text { (construction companies, airlines, } \\
\text { etc.) }\end{array}$ & \\
\hline
\end{tabular}




\section{Looking Forward - Research Needs and Challenges}

\subsection{Summary and Synthesis of Themes \\ Kevin Gurney, Northern Arizona University}

At the beginning of the second day of the workshop, Gurney was asked to provide a summary of the first day's discussions. He expressed his hopes that the workshop attendees were able to focus little better than the people in the cartoon and summarized the previous day's presentations and discussions. He said that the NIST program was providing an important context for the need to bring standards to the new (circa late 2000s) urban domain. He summarized some of the recent accomplishments as follows:

- Many of the researchers came into this arena from global/regional measurement, modeling, inverse work (some already were working at mesoscale but often other parts of the problem)

- Stakeholders emerged from lack of international/federal action and now city organizations are playing a more active role. This merged with the science which went from global to national scales to local.

- Increasing efforts are being aimed at testing methods and approaches; initially they were primarily heuristic.

- Multiple domains active with varying mixtures of measurement approaches, models, data products, stakeholder engagement

He concluded that the IG $^{3}$ IS program was a beneficiary of the NIST urban testbeds work but more directly articulating the operational need and developing an institutional foundation. The four pillars of IG $^{3} I S$ were articulated as: urban, nation-state, methane, crosscut. Though there are common methods/ approaches/issues, there are some critical differences. For example, nation-states represent a regulated environment, cities are not; methane policies are heavily top-down, $\mathrm{CO}_{2}$ is an optimal mix, etc. A clear roadmap was provided on IG $^{3} I S$ evolution, with an update on where the effort is at vis a vis the WMO. Remaining challenges and needs mentioned were:

- Enumerating the value proposition and stakeholder entrainment; all agree that they will not come to us; we have to reach out to persuade the stakeholders.

- How to acquire resources needed to initiate projects?

- Will the institutional structure develop within WMO or outside? This is the remaining question.

Gurney observed that tremendous methodological progress had been made compared to where we were a few years ago; we have a much better understanding of background problems, biogenic sources and sinks, bottom-up approaches; these have become more tractable problems. Measurement approaches have expanded (multiple techniques, expanded species, etc.) These efforts have had practical outcomes, such as trend detection capabilities, detection of $\mathrm{CH}_{4}$ hot spots, etc. There have been growing scientific work on bottom-up approaches (as opposed to "self-reported" inventories), showing decent performance. In contrast to our first gathering four years ago, the progress is impressive.

These efforts were well documented in special issues of journals and many peer-reviewed papers. We have what looks to be a "proto-system" entailing integration of top-down/bottom-up approaches, which provide relevant, rich information content with reasonable accuracy. 
Gurney stated that a number of technical issues and challenges still remain to be overcome, such as atmospheric transport bias, complex backgrounds, biosphere, uncertainty estimations, etc. Further observational integration is needed between satellite, ground and aircraft systems, and integration between GHG and air quality monitoring systems, which could provide lots of benefits. We are dealing with very complex systems, with multiple constraints and data assimilation issues. Operational steps still have lots of hurdles in terms of how we get people engaged at a technical level. We need to highlight the relevance of our work, the practical and technological value of our system, especially in terms of different sectors, processes, etc. We need to be sensitive to system element trade-offs and costs; we need to look at different ways of modeling and observations to find an optimal mix. He also emphasized the importance of

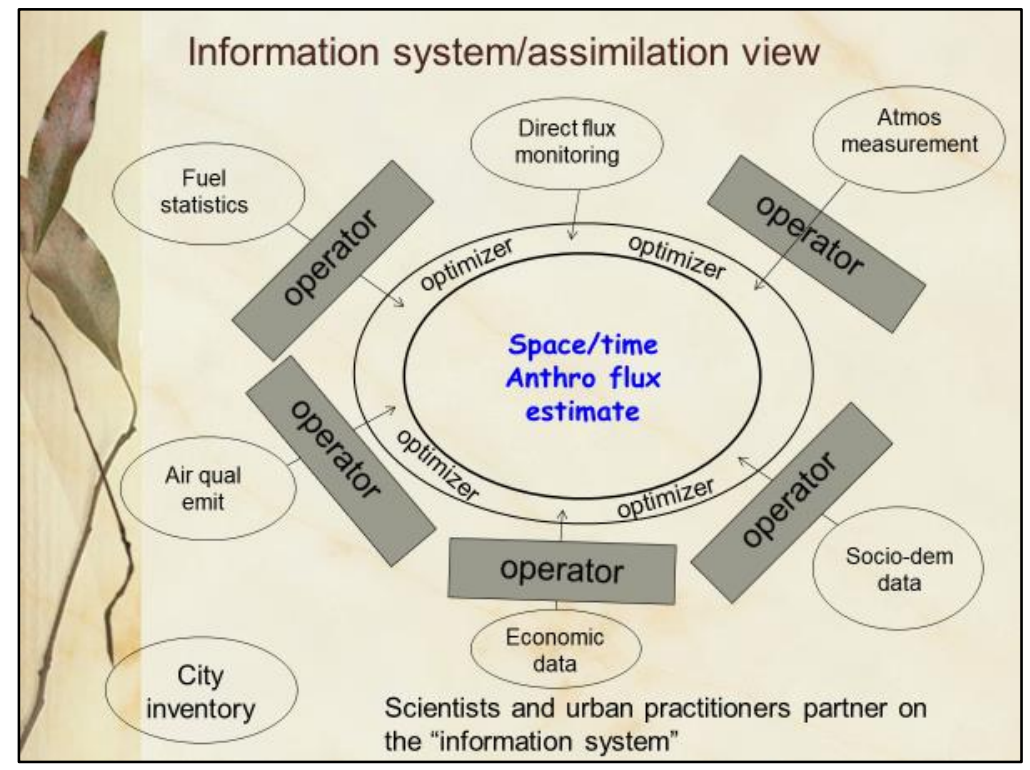
establishing a feedback loop with stakeholders, to develop a better understanding of their needs. We may also need more domains and test the sensitivity of our systems. The scientific community also needs to expand out of industrial north towards the global south. Gurney felt that the community still seems to be resistant to full data assimilation concept of problems; many are still looking at the atmosphere only, or bottom-up approaches only, etc. He illustrated his concepts with this following figure:

Gurney summarized the findings of the panel on "International Stakeholder Experiences/Broader Impacts" as follows:

- What city planners need is awareness, responsiveness, efficiency, transparency, opportunities.

- There is increasing recognition that standards are needed (or best practices and varying evolutionary stages), that could lead to documentary standards.

- Engagement is slow; suffers from human turnover in stakeholder institutions. Persistence can pay off.

- Nation-state setting has a more defined need and seems to have more near-term success, exemplified by successes in the UK, Switzerland and New Zealand.

- Air quality needs and questions come up frequently, emphasizing our need to think forward on GHG/AQ integration.

- The community needs more communication devices (visuals, impact statements); the cities are not so interested in uncertainty statements.

- There are many classes of stakeholders, including the public; their needs may be quite different.

- Capacity/knowledge at the stakeholder end is highly variable and presents challenges.

- The value of the self-reported process is being questioned. We may want to establish a single foundational flux quantification service, freeing cities to focus on what they know - specific mitigation activities. 
- We should promote linkage in scales - from city to nation-state to globe to conserve mass and maintain context.

- Financing discussion - there are analogues where significant resource flows exist (AQ is multibillion $\$$ industry). Workforce needs.

He summarized the discussions on "Domestic Stakeholder Experiences/Broader Impacts" as follows:

- There has been considerable traction and uptake on methane work.

- The most compelling data is that which leads to mitigation.

- Just telling stakeholders their emission estimate is wrong is not enough and will not engage them; there has to be specific improvement paths or links to mitigation.

- There is a wide array of successful educational opportunities - summer schools, museums, etc. Different set of stakeholder requirements are worth outlining.

- Current city "self-reported inventories" are primarily political instruments and take a specific responsibility perspective mostly at-odds with our total emissions approach.

- Without a true mandate at the national level, an ad hoc self-regulated system has emerged.

- City network organizations (such a WRI, ICLEI, etc.) have attempted "standard" development and are threatened by what we are doing.

- There is a resource challenge; city revenue approach will not work; a foundational system should be conceived like the weather service.

- In the case of NYC, the situation may be different; if they tax everyone at $\$ 280 /$ ton C, that may generate significant revenue stream.

Several participants expressed concerns that many people have never heard of the work we are doing. For example, people working on the IPCC urban chapter (Gurney works with them) have never heard of this work at all; part of it is explained by the fact that many of them are economists or sociologists. It takes a long time to socialize new ideas; we also have to realize that it's a large field so we all need to learn about other aspects.

There was an extensive discussion on how to communicate the importance and impact of this work to the wide range of stakeholders. One suggestion was to get public affairs people involved. Another approach could be to utilize the power of "big papers". We have been very productive in paper writing; a lot of methodological work has been published, but we are also on the verge of some big papers. It was agreed that there has been Impressive progress compared to the resource investments; however, it was also mentioned that reports and workshop summaries don't get much visibility (including National Academy reports). Duren suggested that there were couple of pathways to success on connecting with the press. If you write a paper that gets reported in the popular press (especially in NY Times or Washington Post), that gets attention and gets you in the door. Also networking with high-level stakeholders (governor's office, White House, etc., not in the depth of the agencies) would be helpful. The other approach may be connecting with sophisticated commercial entities (e.g. oil and gas companies), who have the scientists and experience to understand the implications of the work.

Gourdji expressed her concern that we don't have a demonstration yet of how atmospheric measurements can be used to "correct" a fine spatial scale product like Vulcan. Most inversion results are reported at whole city-scale now. Also, she was somewhat hesitant about doing a full data assimilation system (the equivalent of an inversion using bottom-up priors in this context). How would observations really help Vulcan and then turn that into something operational and 
remove the human element? How do you automate something like that? Gurney referred to the work on FFDAS ${ }^{90}$ he did to describe what he meant by a full data assimilation system and how was that different from an inversion. He also mentioned the work he did with Peter Rayner ${ }^{91}$ that describes the style of optimization for parameters that can go into Vulcan.

Hutyra reminded the participants that many cities are already beyond worrying about inventories; they are focused on how to evaluate the impact of mitigation actions. She heard this from the urban sustainability directors. She says we know what the inventory is going to tell us, we are not learning anything new. But they were discouraging the development, they should just do policy actions. But they are lacking the ability to see if the policy is working. They are not interested in inventories anymore. At the municipal scale there is political will and they want to make a difference. They don't care what the neighbor cities are doing (they care about their own city and politics). Duren mentioned the example in the city of LA; after many failed attempts to get them engaged, they came to them a month ago. They are tasked with building an inventory for methane.

Rudek pointed out that it was important to have the interaction with stakeholders early on so that they can influence the project direction etc. It is an educational process for them to understand what is available and what they need; if you wait until you are done you may miss the kind of information they need.

Shepson asked if we should consider writing a state of the science concept, and the question was why and for whom? Needs to be an opinion piece in a widely read publication. Vogel also mentioned that he is working on such a "science" paper. It was suggested that publication in Foreign Affairs or in Economist could be desirable.

Whetstone pointed out that NIST public affairs people are often asking what we are doing to publicize the work.

Benkhelifa pointed out the importance of a local urban climate scientist; Lauvaux has played that role for Paris and is partly responsible for the success because people can relate to that local person. He shared his experience from a press conference a few months ago and the launch of the Paris "carbon weather" project. Spoke with French association of environmental journalists. To make sure the message is understood. First, a short draft, a summary; in fact, perhaps a teaser - not all the information. To advertise press conference. Tuesday morning is the best day for a press conference. Choose some angles: now we can assess and have a clear view of what a CAP looks like at city level. Citizens will see effect of action at the city level. So, they engage with this association but also with international correspondents in Paris. Don't publish before, only give a teaser, then have the press conference.

Vogel has been involved in a project with UNEP and EDF on urban methane; they are so good at translating the information into something that will get taken up. So perhaps we should get the NGO's involved because they are good at this kind of thing. Duren: agreed that organizations like EDF and NASA are good at promoting their programs. They actually have an outreach function, with people whose job is to make sure the information gets out, to set up booths at AGU, through

90 P. J. Rayner, M. R. Raupach, M. Paget, P. Peylin, and E. Koffi, “A new global gridded data set of CO2 emissions from fossil fuel combustion: Methodology and evaluation”, J. Geoph. Res., 115, D19306 (2010). doi: 10.1029/2009JD013439, 2010

91 S. Asefi-Najafabady, P. J. Rayner, K. R. Gurney, A. McRobert, Y. Song, K. Coltin, J. Huang, C. Elvidge, and K. Baugh, “A multiyear, global gridded fossil fuel CO2 emission data product: Evaluation and analysis of results", J. Geophys. Res. Atmos., 119, (September 2014) doi:10.1002/2013JD021296 
social media, etc. Perhaps we need a budget for an outreach function; maybe $\mathrm{IG}^{3} \mathrm{IS}$ should have an outreach person or function.

Kort agreed that various engagements through press and media are important to get to larger audiences. But we should be cautious because the EDF methane study had a focus and narrow objectives. Right now, there are a lot of objectives and capabilities to market. We need more clarity and a unified message. It was agreed that we needed an effort to focus our message, perhaps on 2 or 3 things. There is a visibility gap and knowledge gap in what we do. EDF tried to educate and influence the dialog. Forces us to do some work. It was suggested that, to address the gap in communication, it would be helpful to engage authors from the IPCC community in this effort. They will write it better, in language we may not think of, and would also serve the purpose of smoothing over the knowledge gaps with that community. DeCola stressed that this is what he has been trying to get $\mathrm{IG}^{3} \mathrm{IS}$ to focus on from day one, and getting the TFI to include the atmospheric measurements etc. Every fall, the GAW program puts out the GHG Bulletin, publicizing the global $\mathrm{CO}_{2}$ numbers for the year. That usually gets good coverage every year.

Rudek pointed out that EDF has 6 communications people for each scientist in the organization. It is a process between the scientist and communications team to write something that is scientifically robust but also can be communicated to the stakeholders. May also consider bringing in the stakeholders to be educated and influence how the document is written. Also think about engaging them in a plan of action so the report doesn't sit on a shelf but potentially gets commitments from governments (state, city, etc.). They are being pushed to take actions, but they don't know how to get there necessarily. We need to understand their need and for them to know what's available. EDF is volunteering to help with this thinking.

Lin pointed out that EDF has done a good job in this regard and gave the example of the guide on "making the invisible visible". 92

Weiss reminded the importance of accuracy in what is written by reporters. There were reports about the CFC-11 violations in China. There is a new paper on HFC-23; it mentions at the beginning of the paper the Kiagali amendment. ${ }^{93}$ The blogosphere stated that the agreement is not working due to India and China; in fact, they were not yet part of the agreement and may not be in the future because of such press.

Lauvaux mentioned that $\mathrm{IG}^{3} \mathrm{IS}$ in a way has been fulfilling the need for standards. Industry and other stakeholders want the $\mathrm{IG}^{3} \mathrm{IS}$ logo, so it's served that way even though it is not really a standard. Example of Turnbull (in NZ) using the $\mathrm{IG}^{3} \mathrm{IS}$ approval or letter to help get a proposal funded, to raise the profile of a project. There is a hunger for something like that in the stakeholder community.

Turnbull questioned whether it is easier to succeed at the nation-state level. At the nation-state level, there exists a regulatory environment which has been going for a long time, and it may not be as open to new ideas. They have a rigid protocol, whereas at the city level they may be more open to new ideas.

Duren thought that this was a good time to better inform urban stakeholders about recent developments. Perhaps inventory methods work well at national scale but not really at city scale.

92 "New EDF Guide: Mapping and measuring hyperlocal air pollution to drive clean air action", (2019) https://www.edf.org/media/new-edf-guide-mapping-hyperlocal-air-quality-drive-clean-air-action

93 https://www.unido.org/our-focus-safeguarding-environment-implementation-multilateral-environmental-agreements-montrealprotocol/montreal-protocol-evolves-fight-climate-change 
There may be an opportunity to say to cities, this is not the right tool, and you should adopt topdown from the start, although this may be challenging for cities given the technical expertise needed.

Whetstone wanted to remind the group of the point Dickerson had made earlier - it is really the states in the US that tend to have regulatory authority for doing things, and that for the most part although cities have good intentions, they may lack the necessary political constructs.

There was general agreement that stakeholders were being recognized by the scientific community; this could be, at least at the beginning, in the form of establishing best practices but it needs to be evolved to meet their needs. IG $^{3} I S$ has performed this function and it has had benefit. It was also agreed that communication devices were extremely important - visuals and pictorial representations - to engage many classes of stakeholders. We need to develop a better understanding of the variability of stakeholders and the nuances of their needs. 


\subsection{Circling back to Science/Technology Challenges Moderator: Paul Shepson, Stony Brook University SUNY}

After discussion of interactions with domestic and international stakeholders and ways to meet their needs, the participants were asked to return to a review of remaining scientific and technological challenges. The moderator noted that four years ago we were focused on scientific curiosity and method development; this time, the group is embracing stakeholder needs as an integrated part of what we need and want to accomplish, especially in terms of outcomes. After yesterday's productive discussions, the moderator wanted to get back to the science and technology challenges, and the extent of alignment between our scientific objectives and stakeholder needs.

Before going too far, the moderator wanted to hear from Lucy Hutyra and John Lin about their perspectives, given their success with the CO2 USA (Urban Synthesis and Analysis) Workshops, especially regarding stakeholder engagement. ${ }^{94}$ They were also asked to comment on where we are and what the most important needs of the end-users are, and whether we are aligned in our objectives with user needs?

Hutyra and Lin agreed that the CO2-USA meetings served to bring the community together with stakeholders. They helped create harmonized data sets that are now available for researchers, now on Oak Ridge DAAC. ${ }^{95}$ Four papers have come out from the workshops; and it was time to revisit the approach. Feedback from stakeholders has been very positive about their participation in the CO2-USA conferences; a similar effort was recommended for upcoming IG ${ }^{3} I S$ meetings.

It was mentioned that the next version of ACES was coming, which is on a continental scale, with different time scales. Beta testers would be welcome. It was also pointed out that there was a need to harmonize sector classifications among different models. It was also mentioned that shut down of CDIAC has created a problem. We may need an independent organization to run a data platform that is controlled by the research community (should NIST take on that responsibility?).

One of the topics of discussion was the scale of focus; how many cities should be studied? We have transitioned from Indianapolis and Salt Lake City to LA Megacity and then to the North East Corridor, a regional effort. Then perhaps we would move to a national effort, which is the focus of NOAA GMD.

Emission models are being validated with atmospheric measurements; is this one of the main outcomes of current work? There are still some temporal issues; even though measurements are usually done on a 24-hour bases, only measurements collected during $12 \mathrm{pm}$ to $4 \mathrm{pm}$, when there is a well-mixed PBL, are used in inversions. Only capturing influence of day-time fluxes is also an issue particularly for small urban domains, and less of an issue for larger regional inversions which have sensitivity to more upwind fluxes at both day and night. What about the rest of the day/night? Are we going to be able to constrain emission models (Hestia, ACES, etc.) with atmospheric measurements and is this going to lead into an operational tool? A comment was made that there is

94 CO2 Urban Synthesis and Analysis Network http://sites.bu.edu/co2usa/workshops/

95 ORNL Distributed Active Archive Center for Biogeochemical Dynamics https://daac.ornl.gov/ 
a carbon cycle science plan, SOCCR-2, ${ }^{96}$ and urban carbon cycle workshops etc. have already happened. How do we fit into the larger carbon cycle science goals?

Turnbull mentioned that there were a lot of urban measurements going on in a lot of cities (often Asia), Tokyo, Seoul, Beijing, Jakarta by a Japanese group, Singapore, Mexico City. These new projects are going to leverage the work that has been done here in the US. It was also announced that scientists in Brazil have received funding to establish 3 GHG stations in Sao Paulo; a kick-off meeting is being planned for September 9-11, 2020. Turnbull mentioned that Lauvaux had been actually helping with a lot of these projects (Mexico, Jakarta). IG $^{3} \mathrm{IS}$ has provided a link to people who are interested in starting such projects and who could benefit from the experience of others. It was pointed out that what is involved is a combination of measurement, analysis, data gathering, and each location presents different challenges.

Some felt that we could just improve the methods and discuss the science, then we will have something to deliver to the users. Others disagreed; it was pointed out that what was done with the testbeds have been science-driven, how do we advance the state of the art? That has to continue, it's the R\&D part. Where we are going now is moving to an operational system, has to be engineered, funded, have requirements etc. The two things have to go together. They are parallel efforts.

A question was asked about the direction of this effort. Are we aiming to instrument a large number of cities?

Whetstone responded that the plan is to bring the methods together; the emission models validated with atmospheric observations can be the in-between spreadsheets and all top-down approaches. It may be that even though we put a lot of effort into the atmospheric monitoring systems, at the end the validated emission modeling tool might be the product that is used by cities/states/nations.

Duren brought up another example. He mentioned that they are discussing with CARB to establish a data portal and to transfer to them all the data JPL has acquired with the methane surveys. We have to be realistic; handing over assimilation and modeling for the remote sensing is going to take a while. In the short term we may go where Whetstone mentioned that right now, we need to be realistic about staging. Also, the community should be thinking about data products, can we have a data portal with our operational inversions that will be a service to the community.

Kort noted that clearly, we are really far from consensus. We disagree on what the high-value science part is. He thinks of a vision of how what we are doing could expand and be more useful. This is good because are explicitly airing differences in our objectives and thinking about what is useful. Idea of two objectives and clear communications is noble but not realistic (would be very hard). Paul: but it stimulates the ongoing national and international conversation.

It was pointed out that the "scale" of current urban testbeds was not clear. There are the testbeds funded by NIST; then there are those supported by $\mathrm{IG}^{3} \mathrm{IS}$. They overlap but are not the same. Then there is another set of urban work, like SLC and Boston; where do they fit in, what are the common objectives?

Benkhelifa pointed out the need to work in an integrated manner. We need a common agenda. The fact that we want a common agenda is an objective in itself and a point of consensus.

96 2nd State of the Carbon Cycle Report (SOCCR2), N.Cavallaro, G. Shrestha, R. Birdsey, M. A. Mayes, R. G. Najjar, S. C. Reed, P. Romero-Lankao, and Z. Zhu (Eds.), U.S. Global Change Research Program, Washington, DC, USA, 2018.

https://www.globalchange.gov/content/about-soccr-2 
Gurney feels that he has two masters: we want to know about the impact of GHGs on climate, it also would be nice if our work helped stakeholders. We need to be attentive to their needs but not go too far in either direction. We should not get too trapped by the nuances about what we think they [the stakeholders] want.

One of the questions was how has the intended purpose of the urban testbed changed as we have had successes? Are these successes translatable to less developed environments? After all, the goal was to produce translatable products. How can they be applied to developing countries, especially in the Southern sphere?

Another topic of discussion was the accuracy and reliability of atmospheric transport models. Lin pointed out that modelling systems (STILT, HYSPLIT) are being updated by NOAA ARL, and new versions will be released soon; publications are also forthcoming. The possibility of creating a national center like NCEP to establish best practices for transport models was mentioned.

Manning emphasized the critical need for improving transport models.

Stein mentioned that the community needs to take advantage of tracers of opportunity to assess the transport models. The problem seems to be the distances over which the tracers can be followed. These are usually around $10 \mathrm{~km}$ or $50 \mathrm{~km}$, which may not be enough for model assessment. Organizational connections to the weather community will also help with further development of transport models.

Rudek followed up on the questions about temporal/diurnal measurements. Pointed out that these measurements can do more than differentiating between biogenic and fossil fuel emissions; they can also help discriminate within fossil fuel sources by looking at when certain activities that emit fossil fuel products occur (winter/summer, day/night). Could carefully dissect data set to know when certain activities are occurring. The need to separate between mobile and stationary, not just FF/bio. So, the more general question was, how are we producing sector-specific products.

Keeling mentioned that there is another need to validate the Vulcan/Hestia [bottom-up] approach with the top-down methods. There is a complex synthesis to be done in our community. The question is how to do that effectively and efficiently.

Gurney stated that we are, and the world is, interested in emission fluxes at fine scale. That is what we need. It is going to be a combination, an integration effort. We have to test the parts, but we should not be so parochial in how we approach the methods. It is certainly not in our interest to push a system that is not an integrated system. Davis concurred that this is a reasonable question: can we find a way to update the urban emissions model in a way that is general instead of solving for a whole city. We need to develop an operational capability.

Cohen stated that this was a productive tension between doing the whole city vs. sectors which actually is helpful. If you understand both that is useful; if you know something about sectors in a part of the city, that helps you use other data (e.g., traffic, etc.) The sector piece may be translatable to other cities.

Gurney gave the example of a climate model constrained by observations where you have them not measuring all the time everywhere. Why are we stuck on being translatable? At the end, what we are trying to produce, after all, is "emission fluxes", in sectors, space, time. Cities were useful with the ability to focus on one component. We should be doing the whole landscape end to end. You can pull out a city, or just focus on on-road. We should aim for the whole picture. 
Davis offered a reflection. He did not think we were stuck. We should be trying to improve the process models. In ecosystem carbon cycle, atmospheric inversions have not been used to improve ecosystem carbon models because their scales were not relatable (slower to come by, but possible). Historically, flux towers were used for that, and we are doing that more in urban systems.

Sweeney added that the EDF studies did look at processes. The next phase for this work is to go beyond the whole city, to sectors and processes. Gurney agreed and pointed out that Hestia and ACES are doing that, and they are process-based. There was general agreement that there is a desire to get to that level. 


\subsection{Future Planning for Science to Serve Stakeholders Moderators: Jocelyn Turnbull and Riley Duren}

At this point of the workshop, the discussion returned to advances in science that are needed to better serve the stakeholders. Several areas of improvement were discussed. One of the topics was the need for more cross fertilization across studies done in different cities. For example, comparing satellite data obtained for different cities could be quite informative; studying $\mathrm{OCO} 2$ and OCO3 data acquired for $\mathrm{CH}_{4}, \mathrm{CO}$ and $\mathrm{CO}_{2}$ would be quite valuable. TROPOMI is also expected to provide useful data. It was pointed out that several groups have started to make this linkage.

Davis wanted to further explore the topic of evaluation of the performance of atmospheric transport models in different cities; the question was asked if the High-Resolution Rapid Refresh (HRRR) model of NOAA was applicable for all cities. Another question was whether it would be useful to work with NCEP to get an urban-adapted version of this model, and if participation by NCAR would be beneficial in that activity? It was pointed out that participation by NOAA/ARL would be more critical.

Kort suggested that tower-based inversion methods have precision but maybe bias was the problem. If you knew the true sensitivity you could scale the different models. How can you evaluate the truth? Some found it unsatisfying that some studies evaluate WRF for a specific project vs. profiles, PBL depth, then move ahead. A study may say the winds are off systematically, but how does that map into the uncertainty of the inverse model?

Davis said Deng's paper does that and they are working on more. ${ }^{97}$ Keeling suggested that perhaps we should stratify the problem by meteorological typology. We should perhaps be working harder to show if the system is broken; if we get a different answer depending on the category of the meteorological regime, perhaps the answer is yes.

It was pointed out by Lopez-Coto that, when we talk about evaluating transport models, we are often talking about wind speed, wind direction, PBL height. While that is important, what we really need is to evaluate the sensitivity of mixing and dispersion. More tracer experiments would be useful in this regard. It was mentioned that Karion's paper on Barnett shale showed that this was an issue; Eulerian and Lagrangian models gave different results. ${ }^{98}$ It was agreed that we don't currently have transport models that work for all cases.

Kort stated that tower based urban networks provide unique value for measurements of diurnal cycles, with higher time variability. Aircraft data could lead to periodic absolute measurements. Inversions based on tower measurements should focus on getting diurnal and sectoral rather than absolute totals.

Karion mentioned that tower system network design was based on assumed emission sources; we need to circle back on that assumption. But tower locations are usually based on infrastructure availability. We may need to plan a phased activity to figure out optimal locations, and we should focus on the ability to monitor expected changes. Use of different observational platforms, such as

97 A. Deng, T. Lauvaux, K.J. Davis, B.J. Gaudet, N. Miles, S.J. Richardson, K. Wu, D.P. Sarmiento, R.M. Hardesty, T.A. Bonin, W.A. Brewer, and K.R. Gurney, "Toward reduced transport errors in a high resolution urban $\mathrm{CO}_{2}$ inversion system", Elem Sci Anth, Vol. 5, p. 20. (2017) DOI: http://doi.org/10.1525/elementa.133

98 A. Karion, T. Lauvaux, I. Lopez Coto, C. Sweeney, K. Mueller, S. Gourdji, W. Angevine, Z. Barkley, A. Deng, A. Andrews, A. Stein, and J. Whetstone, "Intercomparison of atmospheric trace gas dispersion models: Barnett Shale case study”, Atmos. Chem. Phys., 19, pp. 2561-2576 (2019). https://doi.org/10.5194/acp-19-2561-2019 
mobile observations with electric vehicles could complement tower observations. The remaining question was how to integrate the data from two types of platforms. Is there a need for an Observing System Simulation Experiment (OSSE) that can do this (look at integrating data from various platforms)? And can incorporate cost in network design?

There was general agreement that, in terms of network design, the biggest limitation was the available infrastructure itself. The related question was how our network design and sampling plan impacts what we learn? Miller suggested that you might think of doing it as a phased activity; start with a preliminary design and then build it out as more data is obtained. We also need to keep in mind what is likely to change. You might want to focus not on the largest signal, but where you expect a change (e.g. a move to electric vehicles or from coal to a natural gas plant).

Kort stated that we don't know the value added by different types of measurements; as a result, many studies are exploratory in nature. We may not want to assimilate them all into one system. The transfer function between scales etc. is in fact the emissions model. Different systems (spacebased, low-cost/dense, AQ, etc) are meant to validate a different component of the emissions model. Miller asked the benefit of overlaying Cohen's network on top of one of the other networks. We may be able to find out since such a system is planned for Pasadena. It was pointed out that there is very little standardization of emissions data formats, time resolution, etc. If we expect to be able to combine data from different instruments like towers, aircraft and satellites, not to mention road vehicles and drones, some emphasis needs to be put on data standardization.

Davis suggested that we could do different studies using existing or new data. One such study using existing data would be to look at complexity of $\mathrm{CO}_{2}$ and $\mathrm{CH}_{4}$ backgrounds over different cities, using multiple background towers. Hutyra mentioned that there has been a lot of discussion of background and the CO2-USA unified data set may be useful for such an experiment.

Keeling expressed his concern that too much focus on background may obscure the issue; perhaps inversions could be set up to not be as sensitive to this. We could minimize the differences between the modeled and observed gradients between two sites, rather than the enhancement above a background, as done by Lauvaux in Indianapolis. ${ }^{99}$

Davis stated that time resolution in the towers (i.e. getting temporal emission variability) would be best if they were eddy covariance flux towers.

J. Kim stated that FluxNET and urban flux towers have been running for some time; this community may have to connect with those researchers.

Davis pointed out that there are some interactions between these groups, but not much. None have $\mathrm{CO}$ measurements that can help disaggregate the anthropogenic from the biogenic; there are also a lot of issues with uncalibrated data. It was pointed out that there is an eddy covariance flux tower in Baltimore (Cub Hill Tower) but there are many data quality issues and was not recommended. For reference, it was noted that several review papers on eddy flux towers are available that point out problems that a researcher should consider. Some data is from suburban area to stay within the instrument limitations and eddy covariance modeling assumptions.

Hutyra stated that there is a huge need for better understanding of biogenic fluxes in urban areas, particularly how human practices are mediating what the biological fluxes are (things like watering

99 T. Lauvaux, N.L. Miles, A. Deng, S.J. Richardson, M.O. Cambaliza, K.J. Davis, B. Gaudet, K.R. Gurney, et al. (2016), High-resolution atmospheric inversion of urban CO2 emissions during the dormant season of the Indianapolis Flux Experiment (INFLUX), J. Geophys. Res.-Atmos., 121(10), pp. 5213-5236 (2016); doi:10.1002/2015jd024473 
and fertilizing). Things are different in managed lands and cannot be modeled with current systems like VPRM (Vegetation Photosynthesis Respiration Model). Our mechanistic understanding is limited in such models (It was suggested that VPRM may be getting the right answer for the wrong reason). What is the best thing to do in the context of urban test beds? If VPRM is not good enough, do we need CASA, Sib4 and other models to be improved instead?

Hutyra responded that we need ground based direct measurements of fluxes as well as measuring the soil respiration within the footprint of flux towers.

Another topic of concern raised by Lauvaux was the prior errors (i.e., the emission model uncertainties), such as errors in emission factors, activity data, etc. If we are to resolve contributions of different sectors, we need their uncertainties and how they correlate in space and time.

There was general agreement that we need to work harder on getting fluxes at night; so far, researchers have focused on mid-afternoon emissions to avoid complications associated with PBL height, incomplete mixing, etc. Inversions are also difficult at night; but it was pointed out that this is usually a problem of small domains and could be overcome.

At this point, Duren presented a tool NASA JPL has developed called "Methane Source Finder" which decision makers may find useful. They have overlaid GIS Layer of Methane Relevant Infrastructure, point sources such as power plants, landfills, etc. that is used to generate gridded emissions maps, and sources are identified using the LA Megacity network. This system was used, for example, to identify a leaking shutoff valve that was leaking methane for months. The State of California is now interested in taking over this tool for their monitoring efforts.

After the discussion, an attempt was made by the moderators to identify "Compelling Applications" that would identify applications and specific tools that would serve stakeholders' needs and document proofs of concept that have already been demonstrated. 


\begin{tabular}{|c|c|c|c|c|}
\hline Category & Compelling applications & $\begin{array}{l}\text { Supported objectives } \\
\text { (and derivative } \\
\text { products/services) }\end{array}$ & Data products & $\begin{array}{l}\text { Existence proofs } \\
\text { (case-studies) }\end{array}$ \\
\hline \multirow[t]{2}{*}{ I } & \multirow{2}{*}{$\begin{array}{l}\text { Independent emission estimation } \\
\text { and monitoring for countries and } \\
\text { large states/provinces }\end{array}$} & Formal UNFCCC reporting & $\begin{array}{l}\text { Seasonal to annual net emission } \\
\text { estimates and uncertainties }\end{array}$ & $\begin{array}{l}\text { UK F-gas, } \mathrm{CH}_{4} ; \text { Australia F-gas, } \\
\text { Switzerland } \mathrm{CH}_{4} \text {; Graven et al CA }\end{array}$ \\
\hline & & $\begin{array}{l}\text { Inventory improvement, expose } \\
\text { accounting issues, collective } \\
\text { learning }\end{array}$ & $\begin{array}{l}\text { Sectoral/process resolved emission } \\
\text { estimates, constraints on emission } \\
\text { factors, and their uncertainties }\end{array}$ & China CFC-11 \\
\hline III & $\begin{array}{l}\text { Estimation of key urban carbon } \\
\text { management quantities }\end{array}$ & $\begin{array}{l}\text { Urban carbon sink management } \\
\text { and reporting, urban planning }\end{array}$ & $\begin{array}{l}\text { Urban biogenic flux estimates, } \\
\text { mapping of onroad } \mathrm{CO}_{2} \text { emission } \\
\text { hotspots, time-series and } \\
\text { uncertainties }\end{array}$ & \\
\hline IV & $\begin{array}{l}\text { Methane and } \mathrm{CO}_{2} \text { point source } \\
\text { mapping and monitoring }\end{array}$ & $\begin{array}{l}\text { Persistent independent emissions } \\
\text { monitoring for large facilities and } \\
\text { point sources (non CEMS) }\end{array}$ & $\begin{array}{l}\text { Facility-scale emission estimates, } \\
\text { time-series, and uncertainties }\end{array}$ & \\
\hline $\mathrm{V}$ & $\begin{array}{l}\text { Science based data to support } \\
\text { Global Stocktake (progress } \\
\text { towards Paris goals) }\end{array}$ & $\begin{array}{l}\text { Assess impact of national and } \\
\text { sub-national mitigation actions on } \\
\text { global totals and trends; Identify } \\
\text { and diagnose discrepancies } \\
\text { between reported national and } \\
\text { sub-national impacts. }\end{array}$ & & \\
\hline
\end{tabular}




\subsection{Breakout Group 1 - IG ${ }^{3}$ IS Focused \\ Moderators: Riley Duren, University of Arizona Thomas Lauvaux, LSCE, Paris}

The objective of this breakout session was to review the activities of IG $^{3} I S$ from a programmatic perspective towards identifying and resolving potential opportunities and the gaps and challenges. The scope of the discussion included governance, institutions, workforce, finance/funding, etc.

The following meeting summary notes are organized along the lines of a simple SWOT analysis (Strengths, Weaknesses, Opportunities and Threats) for IG ${ }^{3}$ IS in its current form, referred to here as the "baseline".

\section{IG ${ }^{3}$ IS Strengths:}

1. With WMO backing, IG ${ }^{3} I S$ offers a stamp of legitimacy especially in areas of the world that have few "experts" able to evaluate proposals; an example is the $\mathrm{CO}_{2}$ project in New Zealand.

2. As a WMO program, $I^{3} I S$ is part of a powerful platform that can illustrate the utility and relevance of atmospheric observations and other advanced methods for estimating emissions. WMO is able to help develop, disseminate and promote standards and metrics (e.g., past successes with GAW GGMT).

3. As a WMO program, $\mathrm{IG}^{3} \mathrm{IS}$ could be critical both in developing countries as well as sub-national jurisdictions globally that lack the institutions and resources to develop and maintain accurate GHG monitoring and accounting systems. WMO has an existing relationship with UNEP and could be essential in securing funding for projects and capacity building from the development banks. [Other relevant WMO project sponsoring partners are World Bank, national development banks and climate funds, Green Climate Fund, Global Environment Facility, and more.]

4. Current broad and flexible definition of IG $^{3} I S$ scope and objectives has been useful in minimizing barriers, enabling innovation and collaboration, and building a coalition of interested parties. There is an open question of whether this could become a weakness over time.

5. Current IG ${ }^{3} I S$ configuration is a community of practice with a number of subject matter experts who are not part of agencies or Services ${ }^{100}$. This offers valuable independence and validation. Many IG $^{3} I S$ experts have established standing as trusted agents and honest brokers.

\section{IG $^{3}$ IS Weaknesses (Challenges):}

h. As an organically grown activity, the mission, scope, and future trajectory of $\mathrm{IG}^{3} \mathrm{IS}$ are not always well understood (or mutually agreed to) within and beyond the IG ${ }^{3} I_{S}$ community. The IG ${ }^{3}$ IS "community" itself lacks formal definition; for example, it arguably includes expert practitioners, stakeholders/sponsors at governmental organizations and agencies, and other key non-governmental and private sector practitioners, stakeholders and customers.

i. IG IS baseline objectives are not necessarily well aligned with the overall mission and could be too broad and numerous to yield an implementable program with actionable products. This is an identity issue. A key question is where on the continuum of the GHG measurement and

100 This may be because the ISO norms/standards paradigm has changed, perhaps because standards take too long to develop in this rapidly evolving market(?). 
decision support enterprise does the $\mathrm{IG}^{3} \mathrm{IS}$ program seek to "live" - it is a set of prototype/pilot projects that promote the need for (operational) services, an R\&D program and consulting service that delivers tools and expert advice for agencies and companies. Does it have role like an IPCC TFI in defining and promoting technical standards, and/or will it grow into an operational System/Service?

j. Clear communication channels both within and beyond the $\mathrm{IG}^{3} \mathrm{IS}$ team needs to be established. Process for decision making and communication between $\mathrm{WMO}$ and the $\mathrm{IG}^{3} \mathrm{IS}$ team needs to be established.

k. Ultimate success in mitigating GHG emissions will require broad support and action by many institutions globally. How should $\mathrm{IG}^{3} \mathrm{IS}$ deal with a diverse set of potential stakeholders and partners beyond WMO? For example, how is $\mathrm{IG}^{3} \mathrm{IS}$ work for companies and state/local governments governed and funded in light of the WMO relationship? Does $\mathrm{IG}^{3} \mathrm{IS}$ operate as a subsidiary program of WMO (in which case WMO is "prime") or does IG $^{3} I S$ need to support multiple sponsors (closer to FFRDC or academic model)?

1. Currently, the strongest connections between $\mathrm{IG}^{3} \mathrm{IS}$ and sub-national entities are via ad hoc efforts of $\mathrm{IG}^{3} \mathrm{IS}$ scientists. We don't yet have a clear plan for more systematic and larger scale entrainment of sub-national sponsors and stakeholders. WMO has well-established mechanisms and standing with national governments but currently lacks strong links with many sub-national governments, companies and federations (e.g., C40, ICLEI, WBC-SD, etc.).

$\mathrm{m}$. The lack of connections to the private sector especially through WMO is a major challenge

\section{IG ${ }^{3}$ IS Threats (future problems that may materialize)}

a. Currently $\mathrm{IG}^{3} \mathrm{IS}$ team is rather small which could preclude future expansion due to conflict of interest issues and basic workforce capacity issues. Example 1: how can one be a member of the $\mathrm{IG}^{3} \mathrm{IS}$ steering committee and part of a proposed project that is under review or advise agencies on program funding priorities when one's home institution may benefit? Example 2: how can we scale up current pilot efforts to cover (potentially) dozens of countries and hundreds of cities? Suggested solutions: a) expand the $\mathrm{IG}^{3} \mathrm{IS}$ community of practice through augmentation to education and early career programs, b) establish conflict of interest protocols for IG $^{3}$ IS Steering Committee Members.

b. IG $\mathrm{IG}^{3} \mathrm{IS}$ is currently a part-time effort for most members due to funding and structural limitations. This is fine for early formulation stages, but without more funding and a more "project based" implementation, $\mathrm{IG}^{3} \mathrm{IS}$ may struggle to achieve the necessary expansion needed to meet its ultimate objectives.

c. WMO has the demonstrated capacity and willingness to issue directives to $\mathrm{IG}^{3} \mathrm{IS}$. Additionally, WMO is expected to undergo a reorganization. It's possible that WMO could choose to change or descope the $\mathrm{IG}^{3} \mathrm{IS}$ program in directions orthogonal to those currently being discussed. The new IG $^{3}$ IS steering committee must include independent, trusted voices who can inform WMO decisions.

d. Recent political developments in some jurisdictions illustrate the possibility of back-sliding by national governments with regards to climate mitigation targets such as the Paris Agreement. Future developments could further threaten $\mathrm{IG}^{3} \mathrm{IS}$ funding and support. $\mathrm{IG}^{3} \mathrm{IS}$ must expand and diversify its sponsors and stakeholders to ensure no single political development can derail the mission. 


\section{IG ${ }^{3} I S$ Opportunities}

1. Four general scenarios to consider

- Status quo: Baseline configuration for the next decade or longer.

- Less than Baseline: cuts in existing personnel and services

- Blue Skies: dramatic increase in support and funding; operational Service(s)

- Something in between

2. Expand range of sponsor-stakeholders. Options generally fall between: $I^{3} I S$ as a singular WMO program and $I^{3} I S$ as a multi-sponsor (perhaps public-private) effort.

3. Converge on $\mathrm{IG}^{3} \mathrm{IS}$ mission, scope, institution type, and governance. Options include one or all of the following options - including potentially spinning off $I G^{3} I S$ successors:

- "Low": IG ${ }^{3} I S$ as a Community of Practice (e.g. the GGMT model) operating under WMO and other agencies

- "Medium": IG IS as an NGO ${ }^{101}$ that conducts R\&D and provides "little s" service from subject matter experts to broad community that includes $\mathrm{WMO}^{102}$.

- "High": IG IS as a "big S" (operational) Service or System with a clear mission and mandate, firm requirements, and most likely funded and staffed by a national agency (or federation of national agencies) supported by their contractors/labs.

\section{Meeting Consensus:}

1. Continue with $\mathrm{IG}^{3} \mathrm{IS}$ Baseline for now

2. Action Items:

- Submit SAG-WMO membership for consideration [complete].

- Prepare for $\mathrm{IG}^{3} I S$ stakeholder meeting in Geneva/October 2020.

- Develop a better definition of IG $^{3} I S$ mission and objectives.

- Continue discussion about IG ${ }^{3} I S$ threats and opportunities on a quarterly basis.

It was generally agreed that there is a lack of clarity about the ultimate mission for and identity of $\mathrm{IG}^{3} \mathrm{IS}$ that presents challenges for moving beyond the current formulation stage. If the $\mathrm{IG}^{3} \mathrm{IS}_{\mathrm{S}}$ team aspires to operate as a research community of practitioners to help promote and inform government programs, it can probably continue in its current state indefinitely. If however the IG $^{3} I S$ team aspires to evolve into an operational System or Service for GHG measurements and situational awareness for public and private sector actors globally, it will likely involve major government program(s) with one or more motivated sponsors who will demand well-documented 1) mission statement (ultimate objective), 2) requirements that flow from that mission, 3) technical architecture, and 4) implementation plan (org chart, work breakdown structure, budget, schedule and governance). Alternatively, as a middle ground, $\mathrm{IG}^{3} \mathrm{IS}$ could evolve into a non-governmental organization or public-private partnership that seeks to underpin and support the operational Systems and Services of national governments. It's possible that all three paths are possible and necessary although most likely not as a singular effort. Additional strategic discussion with a timeline for convergence is recommended.

101 This could be analogous to what EDF has done with oil \& gas methane although there are other organizational options including a Public International Organization (PIO) with UN standing, an FFRDC or public benefit LLC.

102 Phil DeCola, IG3IS Steering Committee Co-Chair, has discussed this option with WMO and they are tentatively receptive However, need to come up with some sort of structure with teeth (e.g., Steering Committee and WMO will have to be willing participants). 


\subsection{Breakout Group 2 - Urban Focused \\ Moderators: Paul Shepson, Stony Brook University, SUNY Anna Karion, NIST}

The objective of this breakout session was to identify the best approach to work with cities, develop a better appreciation of their needs, and plan future urban testbed programs to meet these goals.

One of the goals of this community is to provide tools and feedback to municipalities that want information about their performance towards achieving their emissions reduction goals (all sectoral), and to do it uniformly across all cities. If this is the goal, shouldn't we define a testbed to spin that capability up and refine the quality of our capability? In one or multiple places? We may do the best job if we focus on one environment. But then we need to show it works in different types of cities. [isn't this exactly what we have done?] Have we done this in Indy? Lauvaux has shown over 3 years he detects no trend in either Hestia or inversion. He argues if there was a trend, then he would have seen it.

We should work toward providing cities information: here is your goal, here is the trend we see in our analysis. The trend needs to be linked to sectors for this to be relevant. For Indianapolis, sectors are in the emissions model (Hestia) and some sectoral split in the inversion as well (traffic vs. everything else). Note: in Boston, the emissions reduction is in scope 2 emission that we cannot detect. They can account for it, but top-down cannot.

The other goal is to provide accurate data on city emission totals! This may not be the highest priority for cities, they are more interested in trends, but it has to be a priority for this community. Then the question was what are the technical gaps and what are the future activities we need to undertake to address this gap?

- Establishing trends in sectoral emissions are challenging. How do we observe the building sector from the atmosphere? Or do we rely on the full "system" to give us the sectoral attribution, i.e. from the emissions model (Hestia). But what if the city is making multiple different changes, how do we know the emissions model is getting that right? For example, NYC has a specific law about buildings of certain size. How does Hestia calculate these? Buildings have to report exactly how much electricity is consumed in the building for large buildings. Buildings have air quality sensors for indoor air quality - could this help somehow? For $\mathrm{CH}_{4}$, they have to downscale from square feet, heating fuel source. American Community Survey from census tells you fuel type. Some areas have more information, but some have less, but you do have census block data. Methane would not be well known that way because they leak regardless of usage since they have pressurized distribution lines. Emission models have had some success, but we need to do more. Infrared airborne campaign can be used to find waste (heat escaping from roofs etc.); drones may be useful for that purpose. Tax data (fiscal data) can also be used, and census data, and open data from energy operators, for splitting energy use at district level. Specific tool for building sector. Can identify easier-to-reach targets. In a bottom-up model, you might be able to do better but you want to retain consistency so you might choose not to.

- For what sectors do we need better observational information? Transportation has the largest uncertainty in ACES - a lot of the variables are not well known. This sector could benefit from top-down information/verification. The question is how effective will top down approaches be? What combination of bottom-up and top-down information/data do we need? Perhaps the ratios of gases can tell you this. (including air quality gases). Are there tracers we should be measuring 
to understand traffic emissions? We need to help improve the ratios in the MOVES model. NO ratios etc. Variability between vehicles etc. Also, fuel is not burned where it is purchased (total state may be OK but sub state-level is hard). Rely on state reporting to the FHWA, in-road sensors etc. $\mathrm{NO}_{\mathrm{x}}$ concentration data can be used to get the shape of the traffic emissions in time, used as a proxy for the traffic if you don't have traffic counts.

- The biosphere is a sector that is very uncertain from the bottom-up, so just verifying the total is not enough from the atmosphere.

- Note the methane or non- $\mathrm{CO}_{2}$ story may be quite different from the $\mathrm{CO}_{2}$ story; for non- $\mathrm{CO}_{2}$ emissions, we cannot rely on the emissions model; we have to rely more on the top-down to tell trends etc.

- The trend is dependent on the reference scenario (what year, components included in an inventory, etc.). We need simple information to indicate if we are on track or not. Define how we will monitor, but also how we will define the reference. Year to year emissions variability due to environmental or economic drivers (price of gas, cold weather, etc.) must be considered to not obscure the real trend.

- If the stake holder connection is really the goal, we do need to link scope 2 to scope 1 . Need complete picture. Some cities are buying renewable energy credits. A city may subsidize companies to fund renewable energy credits. Bottom-up inventory has to define the sectors very clearly (transportation, industry, building-level energy use, etc.), have the data to go from scope 1 to scope 2. Can we look at a city's specific Climate Action Plan and find out if there is something there, we can verify as low-hanging fruit?

- Have we really integrated Hestia/ACES and top-down information into ONE system? How do we develop an Integrated system that uses all the parts together? How do we combine measurement networks of different types? How do we move toward a system that can test the integrated/predictive product?

Then the question focused on the future of urban testbed programs. Should there be more testbeds, if so what cities and why?

- There is still significant amount of work to be done in currents testbeds for testing of methods and approaches. Those cities should be continued as test labs. For example, let's use satellites and HRRR (High Resolution Rapid Refresh) model to look at all the testbeds using existing data and then try a new city)? (or same with low-cost network, deploy same network/method to multiple existing cities to show it's extensible/transferable?).

- If the technology has advanced sufficiently, can we move on to other cities to demonstrate that the technology is transferable/extensible/able to be applied somewhere else?

- Have we studied a sufficient range of city typologies? Are the cities we have studied representative?

- Have we demonstrated "Compelling Applications" in existing testbed cities? Can we have a simple indicator that can inform the public of progress? Indicative of progress being made. Davis gives example of Davos experiment, showing the live $\mathrm{CO}_{2}$ enhancement. What kind of value does actual concentration data have? Is there an information item for us to calculate and show?

- Establishing a reference customer/stakeholder, have a relationship with a specific user and working with them, refining their products and services. Creates a political base of support. Can 
lead to legislation and funding/congressional support through starting in districts and improving concepts and capabilities.

- Should we be doing $\mathrm{CO}_{2}$ equivalent? That is what the city goals are usually based on. What is the uncertainty of that total?

- Use aircraft to just check on a model like Hestia. That's what you might do in a new city (transference). We transfer the process model and then check on it. Is there something about the cities we have instrumented now that is not general enough? Cities with biomass burning, biofuel heating?

- We are talking about standardization (transferability): minimum criteria, level of service we need to do what we want (trends, totals, etc.). Needs to be worked out with standards community - that is what transferability is. Key for developing the market, rely on standards of business.

- Remote sensing can be a tool for scaling the typological insights that we gain (nightlights, TROPOMI, Planet Labs? ${ }^{103}$ ) Classify using urban metabolism etc. using satellites.

- Might something change so drastically and fundamentally in time and we lose our calibration? Argues for keeping long-term measurements so you can re-calibrate.

- Extend and educate, keep our testbeds to show new urban research done by local places. Community and community building.

- Community/citizens don't have this kind of network capability. How can we use the current network(s) of measurements to have action with the public about what if this week we reduce emissions by $\mathrm{x}$ ? What if everyone bikes to work this week, or everyone lowers their thermostat 3 degrees. We have a laboratory we are maintaining, a social/political experiment.

It was noted as a fascinating factoid that most of the people who attended the workshop have pivoted from previous discussions focused largely on technical aspects of our work to stakeholder issues and research applications. In fact, the "stakeholder/application" discussions dominated a large portion of the workshop.

Summaries of the discussions of the two breakout sessions were presented to the larger group of participants and further discussed to identify general conclusions and recommendations for future activities.

103 Planet Labs - American private Earth imaging company with the goal to image the entirety of the planet daily to monitor changes and pinpoint trends 


\section{General Conclusions and Recommendations}

Based on the discussions over the two-day workshop, there were several themes that workshop participants emphasized about the scientific accomplishments of the community and remaining challenges.

\section{Scientific Accomplishments - Participants agreed that:}

a. Tremendous methodological progress had been made in the last few years of research in the area of quantifying greenhouse gas emissions. We have an increased understanding of the challenges associated with atmospheric measurements, background problems (i.e. isolating concentration enhancements from the region of interest), biogenic sources and sinks, and emission models; these have become more tractable problems.

b. There has been a growing body of scientific work on emission models (historically referred to as "bottom-up" approaches) such as Vulcan, Hestia, ACES, ODIAC, EDGAR, etc., that represent practical tools for mitigation efforts; these models have different spatial and temporal resolutions, and some provide global coverage. Detailed inventories based on emission models for several cities already exist and are available for use by others. Accurate municipal or regional emissions models are needed as tools for mitigation efforts. Recent literature suggests that a sampling of self-reported city inventories under-estimate emissions ${ }^{104}$.

c. Atmospheric measurements of GHGs are extremely valuable for validation of emissions models. The accuracy of methods relying on atmospheric measurements (top-down approaches) has been shown to approach $3 \%$ on an annual basis. Uncertainty in meteorological parameters affects the accuracy of such emissions estimates, especially on shorter time scales for which random errors do not cancel.

d. Atmospheric transport is a key link between atmospheric measurements of GHG concentrations and the sources and sinks. Understanding the transport models and any associated uncertainties and systematic errors (biases) is fundamental for improving the estimation of emissions.

e. Biospheric fluxes of $\mathrm{CO}_{2}$ are seasonally large compared to anthropogenic emissions, making top-down estimates of $\mathrm{CO}_{2}$ emissions more difficult than for methane or other trace gases. Efforts to estimate $\mathrm{CO}_{2}$ fluxes using atmospheric monitoring systems will require increased emphasis, as biogenic sinks/sources can confound the signal of GHG emissions; winter studies alone, when the biosphere signal is weaker in non-tropical areas, are not sufficient. Current capabilities of biogenic models are not sufficient; there is much uncertainty in predictions of biogenic effects. Other trace gas measurements (e.g., $\mathrm{CO},{ }^{14} \mathrm{CO}_{2}$ ) should continue to be used to isolate contributions the anthropogenic emission signals from the total.

f. There has been an increased emphasis on meeting stakeholders' needs. Some stakeholders (e.g., city governments) may not be interested in constructing inventories; they are more focused on taking mitigation actions and following trends, and on related issues such as air quality and social equity. However, good historical baselines are critical to assess trends. Working with stakeholders requires persistence, especially when officials in city, state and national governments change frequently and new policies are implemented. Specific interests of stakeholders may not always align with the scientists' research goals, but it is fruitful to engage

\footnotetext{
${ }^{104}$ Gurney, K., Liang, J., Roest, G., Song, Y., Mueller, K., \& Lauvaux, T. (2021). Under-reporting of greenhouse gas emissions in
} U.S. cities. Nature Communications (accepted for publication). 
stakeholders in exchanges that could guide the research. In some areas, such as energy related activities, there is more interest from stakeholders in using atmospheric measurements to understand and quantify $\mathrm{CH}_{4}$ emissions, since $\mathrm{CH}_{4}$ emissions modeling and inventories are less accurate compared to $\mathrm{CO}_{2}$.

g. NIST GHG Measurements Program has catalyzed several Urban GHG Testbeds around the globe (including China) and promoted an international effort toward development of systematic measurement approaches for GHG emissions.

h. The IG ${ }^{3}$ IS program of the WMO benefited from the NIST urban testbeds work; it was successful in articulating more directly the operational need and developing an institutional foundation.

\section{Research and Implementation Challenges:}

There was also agreement that much remains to be accomplished in the coming years:

a. Several improvements are needed in analysis of atmospheric measurements.

- Improvements are needed in atmospheric transport models and assessment of biases and how these biases translate into uncertainties in emissions estimates derived from measurements and inverse models. Comparison and performance assessment of emissions estimation methods and transport models will provide confidence for the results of GHG emission estimates.

- Increased integration is needed between tower, aircraft and satellite observations to ensure full utilization of studies and take advantage of their complementary features.

- Measurement of additional trace gases and investigating emissions ratios can shed light on sectoral attribution of emissions, which remains a significant challenge for atmospheric methods.

b. Better integration between GHG emissions research and air quality efforts is expected to benefit both communities, first because pollutants are usually expressed per unit of $\mathrm{CO}_{2}$, but also because air quality is an important issue at the city-scale and directly connected to public health. Any argument that reducing GHGs would also reduce air pollutants is more likely to gain traction.

c. Progress is needed on modeling the biosphere, at urban and broader regional scales. More accurate predictions of $\mathrm{CO}_{2}$ uptake and emissions will help separate biogenic and anthropogenic processes in the atmosphere at short time scales, improving quantification of emissions, but will also help quantify annual net land sinks, which is a topic of interest to various policy makers.

d. Comparison and performance assessment of different emissions models (Vulcan, Hestia, ACES, ODIAC, EDGAR, etc.) will provide confidence for their performance, reliability, and transparency.

e. Currently established Urban GHG Emission Testbeds should continue to be used as laboratories to monitor long-term changes, as well as to determine the impact of local mitigation efforts. Decisions on establishment of new test beds should be based on new features, characteristics, and challenges a new city offers, such as topography, weather patterns, diversity of emissions sources, diversity of biogenic features, etc. and the interest of local stakeholders.

f. Increased stakeholder participation is needed in future meetings to continue the efforts initiated by the CO2-USA Conferences; a strategy needs to be developed to increase stakeholder engagement at all levels. Engagement with politically savvy stakeholders is a must. Engagement with NGOs to articulate the impact of our work would also be beneficial. 
- To encourage efficient development of new methods and tools that will meet stakeholder needs, it is recommended to have a follow up meeting within the next year to discuss tangible goals/objectives for which the community could strive (e.g., papers, marketing, more organization, etc.)

- Better communication tools need to be developed to keep the public informed of developments and to engage wide range of stakeholders. For example, visualization of emissions model outputs and direct engagement with the public (e.g. through a web platform) could generate enthusiasm and may have the potential to provide city sustainability managers easy access to higher-quality information in addition to the simpler city inventories constructed by consultants.

- UNFCCC reporting is done on national levels; however, many of the mitigation efforts will be implemented on a local/regional level. Appropriate stakeholders must be entrained in these efforts, made aware of the tools being developed by this community, and jointly develop dissemination approaches for their use.

g. Continued international coordination and data sharing is required for effective research and development efforts, for the purpose of eventual development of best practices and standards.

- Continued efforts by $\mathbf{I G}^{3} \mathbf{I S}$ are needed for international coordination and validation of test methods. Organizational uncertainties within WMO should be overcome; the $\mathrm{IG}^{3} \mathrm{IS}$ mission and objectives should be better defined; $\mathrm{IG}^{3} I S$ communications with the science community, stakeholders and the private sector should be improved; future $\mathrm{IG}^{3} \mathrm{IS}$ stakeholder meetings can be used for these purposes.

- Establishing best practices, which may eventually lead to development and adoption of international standards, will be critical for the use of atmospheric emission estimation systems to guide implementation of mitigation efforts by the private sector as well as governments at all levels. 


\section{Appendix A: Acronyms}

ACES Anthropogenic Carbon Emissions System, which provides fine-resolution data on $\mathrm{CO}_{2}$ emissions (Boston University)

AQ Air Quality

C40 Cities Climate Leadership

CAP Climate Action Plan

CARB California Air Resources Board

CDIAC Carbon Dioxide Information Analysis Center (ORNL)

$\mathrm{CO} 2$ USA $\mathrm{CO}_{2}$ Urban Synthesis and Analysis workshops

COP Conference of the Parties (UNFCCC)

CRDS Cavity Ring-Down Spectroscopy

EDF Environmental Defense Fund

EDGAR Emission Database for Global Atmospheric Research (European Joint Research Center)

FF $\quad$ Fossil Fuel related emissions

GAW Global Atmospheric Watch (WMO)

GDP Gross Domestic Product

GGMT Greenhouse Gas Measurements and Technology conference

GHG Greenhouse Gas

Hestia A project that quantifies all fossil fuel $\mathrm{CO}_{2}$ emissions for individual cities to the building and street scale every hour (Northern Arizona University)

HRRR High Resolution Rapid Refresh, a NOAA real-time 3-km resolution, hourly updated, cloud-resolving, convection-allowing atmospheric model.

HYSPLIT Hybrid Single Particle Lagrangian Integrated Trajectory Model (NOAA ARL)

ICLEI Local Governments for Sustainability

ICOS Integrated Carbon Observation System (Europe)

$\mathrm{IG}^{3} \mathrm{IS} \quad$ Integrated Global Greenhouse Gas Information System (WMO)

IPCC Intergovernmental Panel on Climate Change (UN)

IPCC TFI IPCC Task Force on national greenhouse gas Inventories

LLNL Lawrence Livermore National Laboratory (Dept. of Energy)

MOU Memorandum of Understanding

NAM North American Mesoscale Forecast System

NASA National Aeronautics and Space Administration 
NDCs Nationally Determined Contributions (UNFCCC)

NDIR Non-Dispersive InfraRed instruments

NEI National Emissions Inventory

NIST National Institute of Standards and Technology (Dept. of Commerce)

NOAA National Oceanic and Atmospheric Administration (Dept. of Commerce)

ODIAC Open-Data Inventory for Anthropogenic Carbon dioxide (NASA)

ORNL Oak Ridge National Laboratory (Dept. of Energy)

OSSE Observing Systems Simulation Experiments (Global Modelling \& Assimilation Office, NASA)

PBL Planetary Boundary Layer

R\&D Research and Development

SOCCR-2 $2^{\text {nd }}$ State of the Carbon Cycle Report (USGCRP)

STILT Stochastic Time-Inverted Lagrangian Transport model

TROPOMI TROPOspheric Monitoring Instrument on board the Copernicus Sentinel-5 Precursor satellite.

UNDP United Nations Development Program

UNEP United Nations Environment Program

UNFCCC United Nations Framework Convention on Climate Change

USGCRP US Global Change Research Program

Vulcan A Project that quantifies all fossil fuel $\mathrm{CO}_{2}$ emissions for the entire U.S. at high spaceand time-resolution with details on economic sector, fuel, and combustion process

WMO World Meteorological Organization (UN)

WRI World Resources Institute 


\section{Appendix B: Workshop Attendees}

\begin{tabular}{|c|c|c|}
\hline 1. & David W. Allen & NIST \\
\hline 2. & Fouzi Benkhelifa & Origins.Earth, France \\
\hline 3. & William Callahan & Earth Networks \\
\hline 4. & Ronald Cohen & Univ. of California, Berkeley \\
\hline 5. & Kenneth J. Davis & Pennsylvania State Univ. \\
\hline 6. & Phillip DeCola & GIST/WMO \\
\hline 7. & \multicolumn{2}{|c|}{ Russell R. Dickerson University of Maryland } \\
\hline 8. & Riley Duren & University of Arizona \\
\hline 9. & Sharon Gourdji & NIST \\
\hline 10. & Kevin Gurney & Northern Arizona University \\
\hline 11. & Ying Hsu & California Air Resources Board \\
\hline 12. & Lucy Hutyra & Boston University \\
\hline 13. & Anna Karion & NIST \\
\hline 14. & Ralph Keeling & Scripps Institution of Oceanography \\
\hline 15. & Jooil Kim & Scripps Institution of Oceanography \\
\hline 16. & Eric A. Kort & University of Michigan \\
\hline 17. & David Lang & The Optical Society (OSA) \\
\hline 18. & Thomas Lauvaux & LSCE, France \\
\hline 19. & Chun-Han John Lin & University of Utah \\
\hline 20. & Israel Lopez-Coto & NIST \\
\hline 21. & Alistair Manning & United Kingdom Met Office \\
\hline 22. & Charles E. Miller & Jet Propulsion Laboratory, NASA \\
\hline 23. & Scot Miller & Johns Hopkins University \\
\hline 24. & Kimberly Mueller & NIST \\
\hline 25. & Kuldeep Prasad & NIST \\
\hline 26. & Xinrong Ren & University of Maryland \\
\hline 27. & Joseph Rudek & Environmental Defense Fund \\
\hline 28. & \multicolumn{2}{|c|}{ Hratch G. SemerjianNIST } \\
\hline 29. & Paul Shepson & Stony Brook University, SUNY \\
\hline 30. & Ariel Stein & Air Resources Laboratory, NOAA \\
\hline 31. & Colm Sweeney & Global Monitoring Div., NOAA \\
\hline 32. & Jocelyn Turnbull & GNS Science, New Zealand \\
\hline 33. & Felix R. Vogel & Environment and Climate Change Canada \\
\hline 34. & Alex Vermeulen & ICOS, Europe \\
\hline 35. & Ray Weiss & Scripps Institution of Oceanography \\
\hline 36. & James R. Whetstone & NIST \\
\hline 37. & Tamae Wong & NIST \\
\hline
\end{tabular}




\title{
Appendix C: Agenda
}

\section{Workshop on Urban Greenhouse Gas Measurements}

NIST Testbed Systems, Other U.S. Urban Examples, and International Coordination

Lecture Room D, NIST, Gaithersburg, Maryland

January $30 \& 31,2020$

\section{Day 1 - January 30, 2020 - Morning Session}

\author{
8:15 8:40 Welcome, Logistics, and Meeting Objectives \\ J. Whetstone \\ 8:40 9:15 Overview: Integrated Global GHG Information System (IG ${ }^{3}$ IS) \\ P. DeCola \\ Scientific and Technical Successes and Barriers, Impacts, and Gaps \\ 9:15 9:45 Five Minute Panel Member Summaries \\ Urban and Regional GHG Measurements \& Analysis Research \\ Panel: K. Davis, T. Lauvaux, A. Karion, R. Cohen, A. Manning, \\ C. Miller, R. Keeling, F. Vogel \\ Panel and Discussion Moderator: P. Shepson \\ 9:15 10:45 Plenary Discussions \\ 10:45 11:00 Coffee Break \\ International Stakeholder Experiences / Broader Impacts \\ 11:00 11:30 Five Minute Panel Member Summaries \\ Individual experiences engaging stakeholders outside U.S. (urban to national) \\ Panel: J. Turnbull, F. Benkhelifa, A. Manning, A. Vermeulen, F. Vogel, \\ J. Whetstone \\ Panel and Discussion Moderator: Kim Mueller \\ 11:30 12:30 Plenary Discussions \\ 12:30 1:30 Lunch
}

Afternoon Session

1:30 2:00 Completion of International Stakeholder Discussion

Domestic U.S. Stakeholder Experiences / Broader Impacts

2:00 2:30 Five Minute Panel Member Summaries

Individual experiences engaging stakeholders in the U.S.

Panel: Kevin Gurney, Paul Shepson, Riley Duren, R. Dickerson, Joe Rudek, Ron Cohen, Eric Kort

Panel and Discussion Moderator: Thomas Lauvaux

2:30 2:45 Coffee Break

2:45 4:15 Plenary Discussion

4:15 5:15 Wrap Up Discussion: Mapping Technical Capability to Stakeholder Needs Moderator: Riley Duren and/or Phil DeCola

6:30 Workshop Dinner 


\section{Day 2 - January 31, 2020 - Morning Session}

8:15 8:30 Comments on Day 1, Objectives of Day 2

James Whetstone

8:30 9:15 Summarize and Synthesize Day 1 Themes

Kevin Gurney

9:15 10:15 Recap of Discussion of Successes and Gaps

Paul Shepson

10:15 10:30 Coffee Break

10:30 12:15 Future Planning for Science to Service Moderators: J. Turnbull, R. Duren

\section{Cross Fertilization between multiple groups (example topics):}

Have we done a careful job of comparing methods both with a single dataset and multiple datasets?

Can we develop community efforts that utilize capabilities from multiple groups? What are examples where there can be movement in this direction?

Technical lessons learned in the different projects, identify key research gaps?

How do we move towards integration of different types of data?

How to foster collaboration with groups outside of the U.S.?

Stakeholders and Stakeholder Group - Engagement and Entrainment:

What are viable options for stakeholder outreach examples?

Is this a cross-fertilization effort or should engagement continue as BAU?

12:15 12:30 Discussion Kick Off - Forming Two Discussion Groups (self-assigned):

Group One (IG ${ }^{3} I S$ focused): Filling Gaps for Delivery of Capabilities

Discussion Leaders: P. DeCola - Lecture Rm A

Group Two (Urban work focused): Future work filling technical gaps

Discussion Leader: P. Shepson - Lecture Rm D

12:30 1:15 Lunch

\section{Afternoon Session}

1:15 2:45 Continue Discussion:

Group One (IG ${ }^{3} I S$ focused): Filling Gaps for Delivery of Capabilities Programmatic Issues (governance, institutions, workforce, finance/funding)

Discussion Leaders: R. Duren, T. Lauvaux

Group Two (Urban work focused): Future work filling technical gaps

Synthesize Morning Discussion and Outline Future Activities

Discussion Leaders: P. Shepson, Anna Karion

2:45 3:00 Meeting Wrap-up and conclusion for those who must catch planes

3:00 3:30 Break

3:30 4:30 Summary Discussion of Actions and New Directions

4:30 Adjourn 


\section{Appendix D: Power Point Presentations by Plenary Lecturers}

\section{Workshop \\ Urban Greenhouse Gas Measurements NIST Testbed System, Other U.S. Urban Examples, and International Coordination}

James R. Whetstone, NIST

January 30 and 31,2020

The NIST Greenhouse Gas Measurements Program

Mission:

- Improve greenhouse gas emissions (GHG) measurement tools to better equip decision makers, mitigation managers, and chart progress

Objective:

- Advance measurements and standards capabilities to improve accuracy of GHG emissions data and remote sending observations

Program Components:

- Measurement tools, standards and reference data

- Urban GHG Measurement Testbed System

- Stationary/point source (smokestack) emission measurements, optical radiocarbon measurements, etc.

- Satellite calibration methods and standards

- Carbonaceous aerosol measurements and standards 


\section{Urban GHG Measurements Testbed System: Rationale}

Mitigating GHG emissions will mainly be implemented locally

- Municipal/State governments and private sector institutions will be primary mitigation policy actors

- Policy approaches likely to be market-based, regulatory, or a combination aided by technology advancements

Means to identify parties responsible for GHG amounts are criticaland accurate data is essential

Consistent, reliable emissions inventory measurements and data are vital to accuracy in reporting - locally and nationally

\section{NIST's GHG Measurements Program}

Emissions crediting can be foundational to both market-based and/or regulatory mitigation systems.

For example:

- Direct measurements of flue gas flows from power plants

- Indirect estimates using models based on proxies for emissions

\section{Current state of Credit quantification methodologies}

- Validity of emissions quantities has been questioned, adversely impacting planning for credit systems

- NIST Program established to address accuracy by improving GHG measurement capabilities - supporting state and local mitigation efforts and emissions crediting systems.

- Key question: What level of accuracy provides sufficient confidence within the climate finance community to provide meaningful resources to city mitigation efforts? 


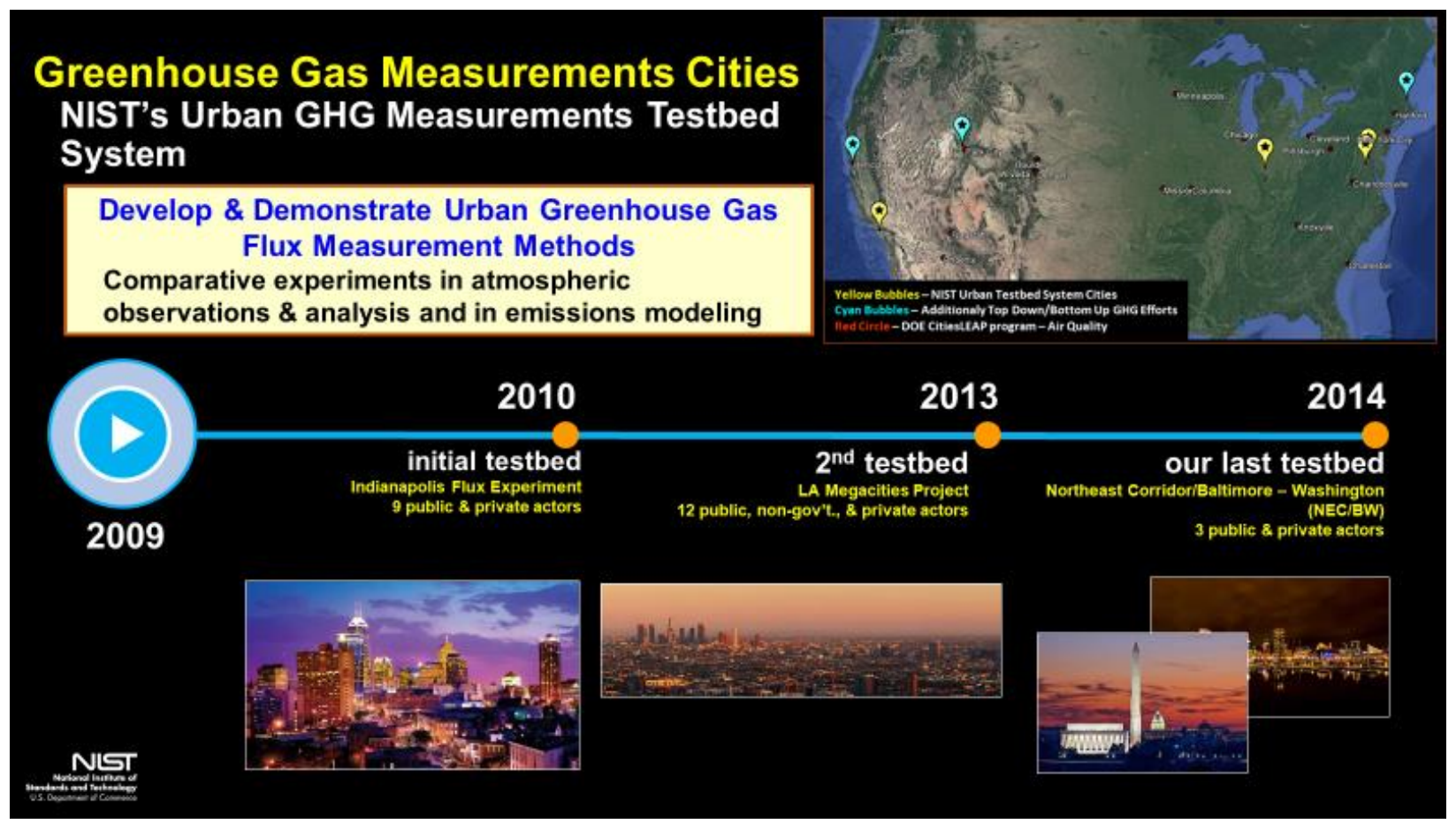

\section{The Indianapolis Flux Experiment (INFLUX)} Whole City Emissions

Agreement among methods:

- Previous estimates $-30 \%$ to $\mathbf{5 0} \%$ differences

- Insufficient performance for assessing mitigation policy impact

- Now $\pm 7 \%$ agreement on whole city emissions

- Useful performance for cities to:

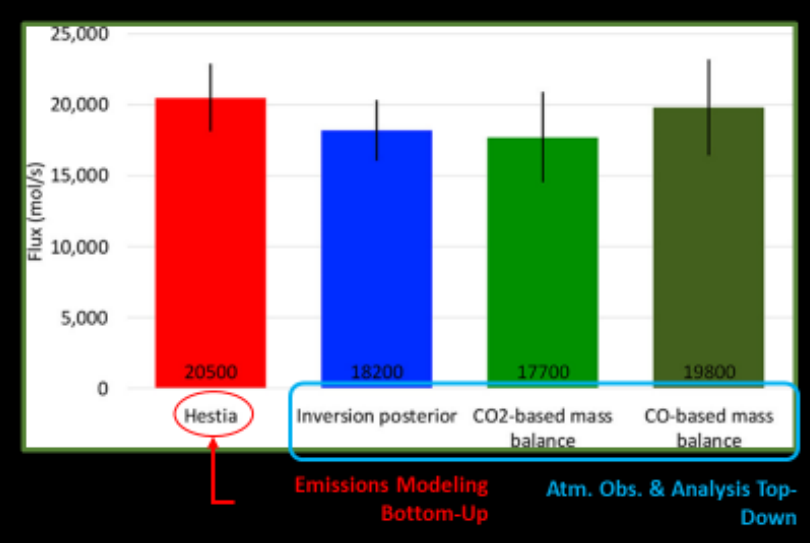

- judge progress toward mitigation effort targets \&

- Validate target attainment

Results Achieved by:

- Harmonizing spatio-temporal mole fraction observation and analysis.,

- Minimizing biological process emissions

- Suppress vegetative emissions and uptake processes 


\section{Recent Advance in INFLUX Data Analyses}

Combined emission modeling and atm. obs. $\&$ analysis

\section{- Urban measurement result convergence}

- Results of atmospheric obs. \& analysis results are highly consistent.

- Results over a 3-year period

- The methodology corrects an intentional input data offset of $+15 \%$ by $-14.2 \%$.

- These results increase our confidence that it is possible to detect a 3 to $5 \%$ change over periods of 1 to 3 years for Indianapolis.

- These tools hold the potential to investigate sectoral mitigation efforts, but require replication and refinement to determine and demonstrate their extensibility to other urban areas.

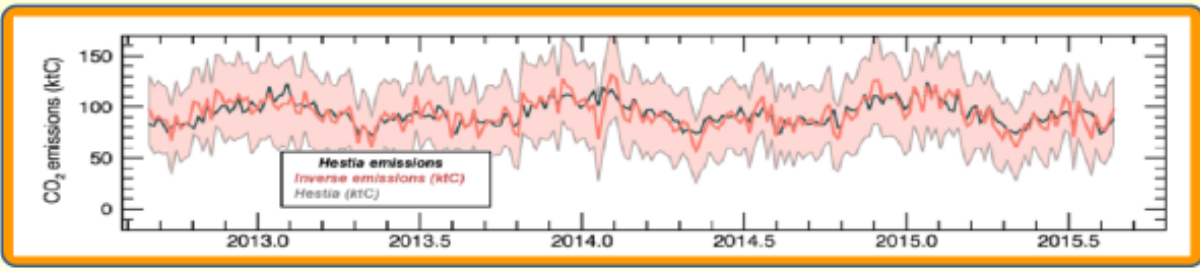




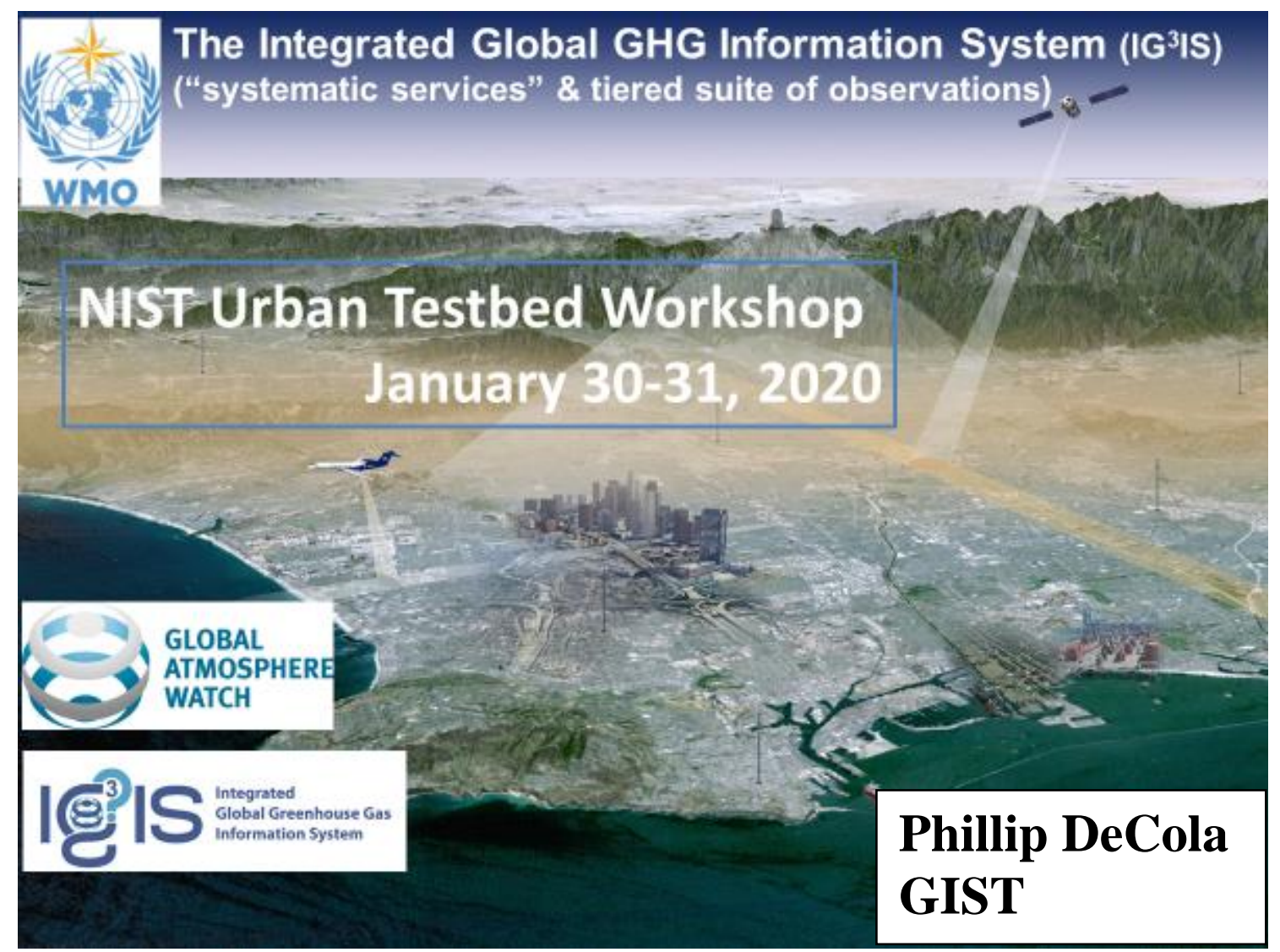

\section{Content of Presentation}

WMO

- IG IS historical context: evolution from birth to formulation to SSC discussions: alignment with WMO structures \& strategy

- Relevant to our discussions for Wednesday and Thursday

- Review of IG ${ }^{3} I S$ Principles and Objectives

- IG IS accomplishments achieved during formulation

- High-level intergovernmental policy impacts

- Project-level accomplishments across the $\mathrm{IG}^{3}{ }^{\mathrm{S} S}$ objectives

- Seeds for Discussions

- IG IS draft Terms of Reference

- Potential new organizational structures and governance for $I^{3} I S$ implementation phase and aligned with new WMO structures and strategy

- Questions and discussion 


\section{A Brief History of Time}

$I^{3}{ }^{3} S$ evolution: birth to formulation and now toward implementation

- Idea for an IG ${ }^{3} I S$ presented by Jim Butler and Oystein Hov at the $3^{\text {rd }}$ CAS Management Meeting in 2008

- "White paper" describing with vision for a NWP-like Carbon/GHG Prediction System

- IG ${ }^{3} \mid S$ succeeded by promoting a set of measurement-based "systematic services"

- WMO decides on a sustained effort to advance IG ${ }^{3} I S$ with support from NOAA, NIST, and NASA prior to WMO 17 th Congress in 2015.

- IG ${ }^{3} I S$ resolution prepared, presented, and passed at the $17^{\text {th }}$ WMO Congress in June 2015

- Science team assembled and concept paper with principles and objectives developed

- Approved by Executive Council in 2016

- Work begun on IG ${ }^{3} I S$ Science Implementation Plan

- IG ${ }^{3}$ IS Science Implementation Plan was completed and approved by EC-70 in 2018 and adopted by $18^{\text {th }}$ Congress in June 2019

- Implementation phase of IG ${ }^{3}$ IS officially begins in June 2019

- IG ${ }^{3} I S$ Science Team to work with WMO and EPAC SSC to develop structures and governance for implemention in alignment with WMO strategy and structure

\section{GHG monitoring and reporting in 2010: atmospheric "top-down" versus inventory "bottom-up" \\ Can atmospheric measurements and models "verify" inventories?}
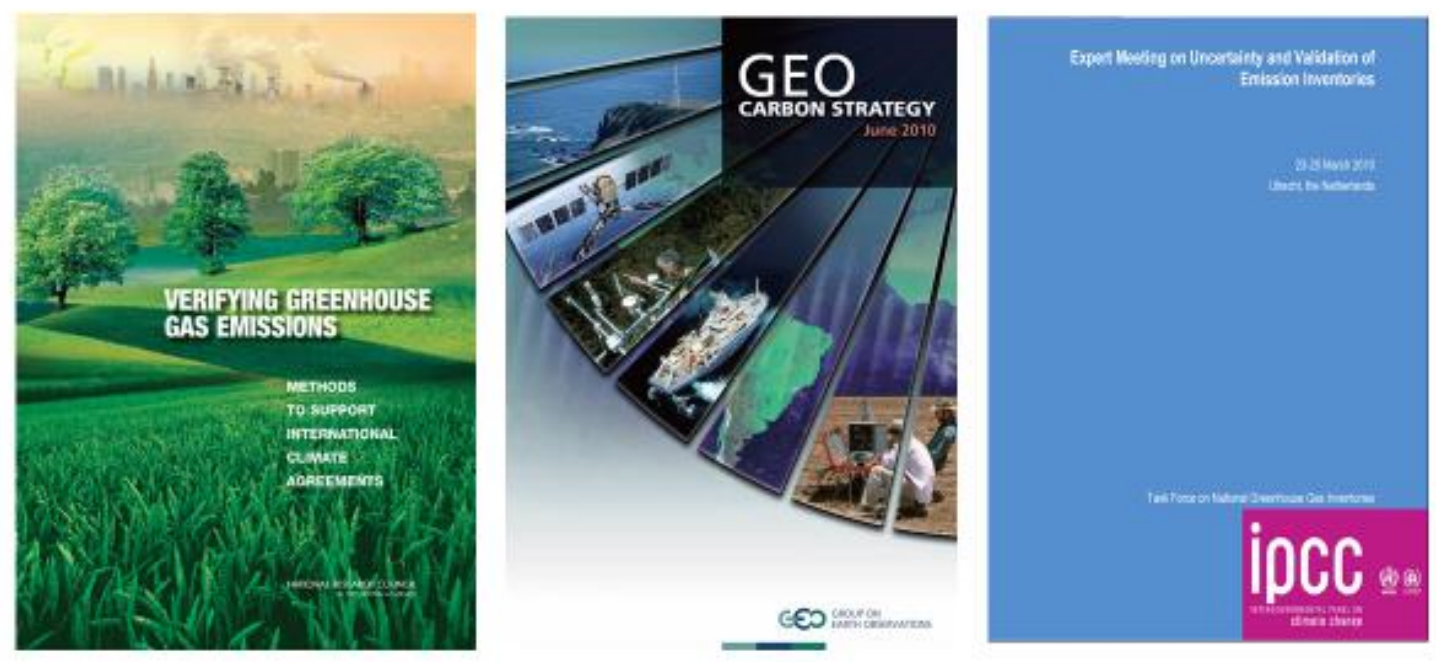


\section{Paris Agreement and GHG Monitoring:}

Moving from a "top-down versus bottom-up" paradigm

Then COP15 (2009)

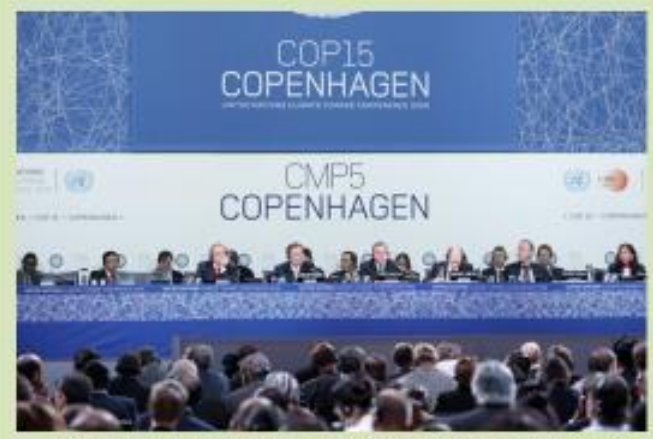

Binding Multi-national Treaty Commitments

"we will verify your reported emissions"

A grand top-down GHG Information System

Advocates: Science Community!!!
COP25 (2019)

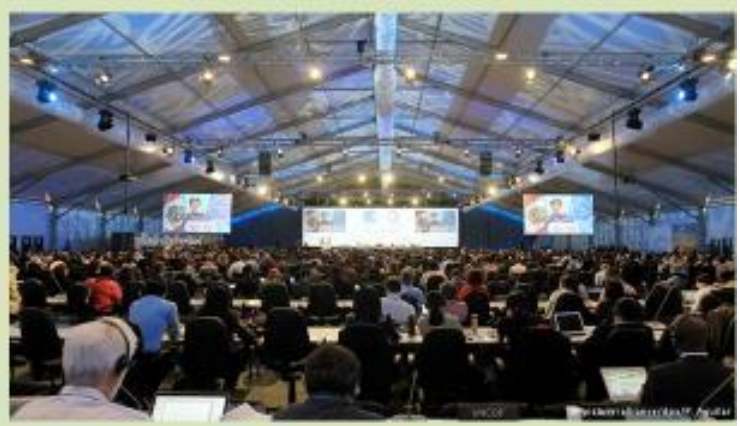

Nationally Determined Contributions

"we will help you improve your data"

Federation of focused monitoring systems

Advocates: WMO (191 countries),UNEP, Cities (eg, C40), NGOs, Industry (eg, Oil Companies)

\section{Some of the IG ${ }^{3} I S$ Principles}

WMO

- Combine (unified approach) atmospheric measurements with socioeconomic inventory data to better quantify and attribute greenhouse gas emissions.

- Stakeholders are entrained from the beginning to ensure that information products meet user priorities and deliver on the foreseen value proposition.

- IG IS, like GAW, will serve as an international mechanism to establish and propagate consistent methods and standards.

- Success-criteria are that the information guides additional and valuable emission-reduction actions.

- IG IS must mature in concert with evolution of policy and technology. 
The bedrock of the UNFCCC process are the high-precision, long-term, science-based (or evidence-based) info; data records like the "Keeling curve" and the global average temperature records
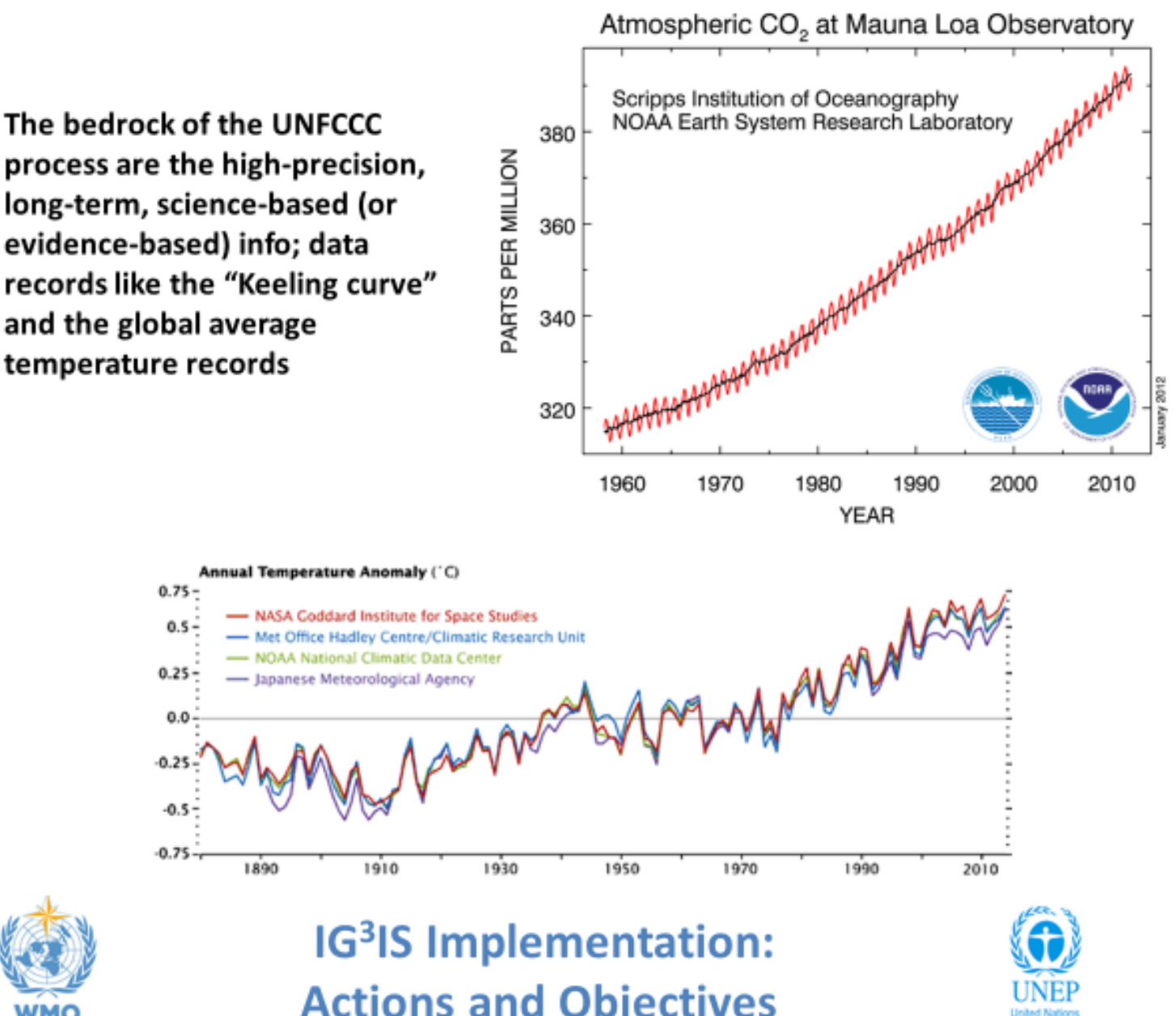

\section{IG ${ }^{3}$ IS Implementation: Actions and Objectives}

Actions

- Promote projects to build user-base and improve skill,

- Document good-practice implementation guidelines

Objectives at different spatial and temporal scales:

- Support for national inventory reporting by making use of atmospheric measurements for all countries

- Timely and quantified trend assessment in support of countries' NDC tracking and "Global Stocktaking" (TBD)

Key sub-national efforts and new mitigation opportunities:

- GHG monitoring in large urban source areas (cities/states)

- Detection and quantifying large unknown industrial $\mathrm{CH}_{4}$ emissions

Crosscutting Activities

- Stimulate high-priority Research and Development

- Inverse Modeling benchmarking, testbed and intercomparison 


\section{IG ${ }^{3}$ S advocacy achievement}

- IPCC TFI guidelines/guidance provide broad international calculation methods (2006):

- Inventory protocols for transparent, documented, consistent over time, complete, comparable, assessed for uncertainties, subject to quality control and quality assurance, and efficient in the use of resources

- IPCC TFI 2019 Refinement to 2006 Guidelines- will improve guidance to countries

- Will include assessment of methods for using atmospheric measurements \& analyses to improve inventory estimates and certainties.

- Establish link with WMO/IG ${ }^{3} \mathrm{IS}$ effort to propagate methods and standards to both developed and developing countries.

\section{Refinement to 2006 Guidelines Shamil Maksyutov \\ Lead Author - Volume 1 Chapter 6 IG ${ }^{3}$ IS Science Team \\ National Inventory Subgroup, Co-Lead}

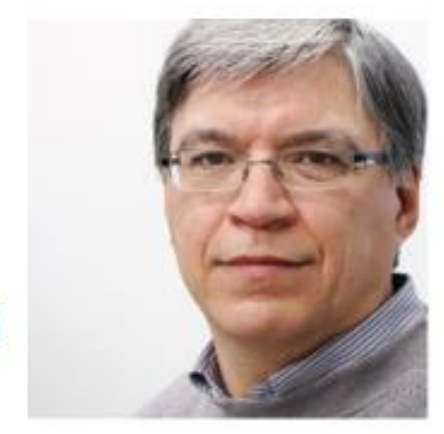

\subsubsection{Comparisons with atmospheric measurements}

\subsubsection{INTRODUCTION TO EMISSION ESTIMATES BASED ON \\ ATMOSPHERIC CONCENTRATION MEASUREMENTS}

This section addresses the state of science for emission estimates based on atmospheric measurements and their application to comparison with national emission inventories. Since the 2006 IPCC Guidelines were published, the most notable advances have been achieved in the application of inverse models of atmospheric transport for estimating emissions at the national scale. An increasing number of countries are considering applying such models.

An ideal condition for verification is the use of fully independent data as a basis for comparison. Measurements of atmospheric concentrations provide such datasets, and recent scientific advances allow using such data as a basis for emission modelling. The approach is particularly valuable as it can be largely independent of standard estimation method drivers, such as sector activity data and implied emission factors. The scale of such models can be designed around local, regional, or global boundaries and can provide information on either level or trends in emissions. Some brief examples of these techniques are provided in this section; however, further discussion and elaboration can be found in more comprehensive summaries on the use of these methods for inventory verification (Rypdal et al. 2005; Benkovitz 2001; Benjey and Middleton 2002; NACP 2002, Jacob et al. 2016; IG3IS Science Implementation Plan 2018; Miller \& Michalak 2017; Bergamaschi et al. 2018). 


\section{IG3IS Inverse Modeling Crosscut Case Studies: Urban and National Scales}
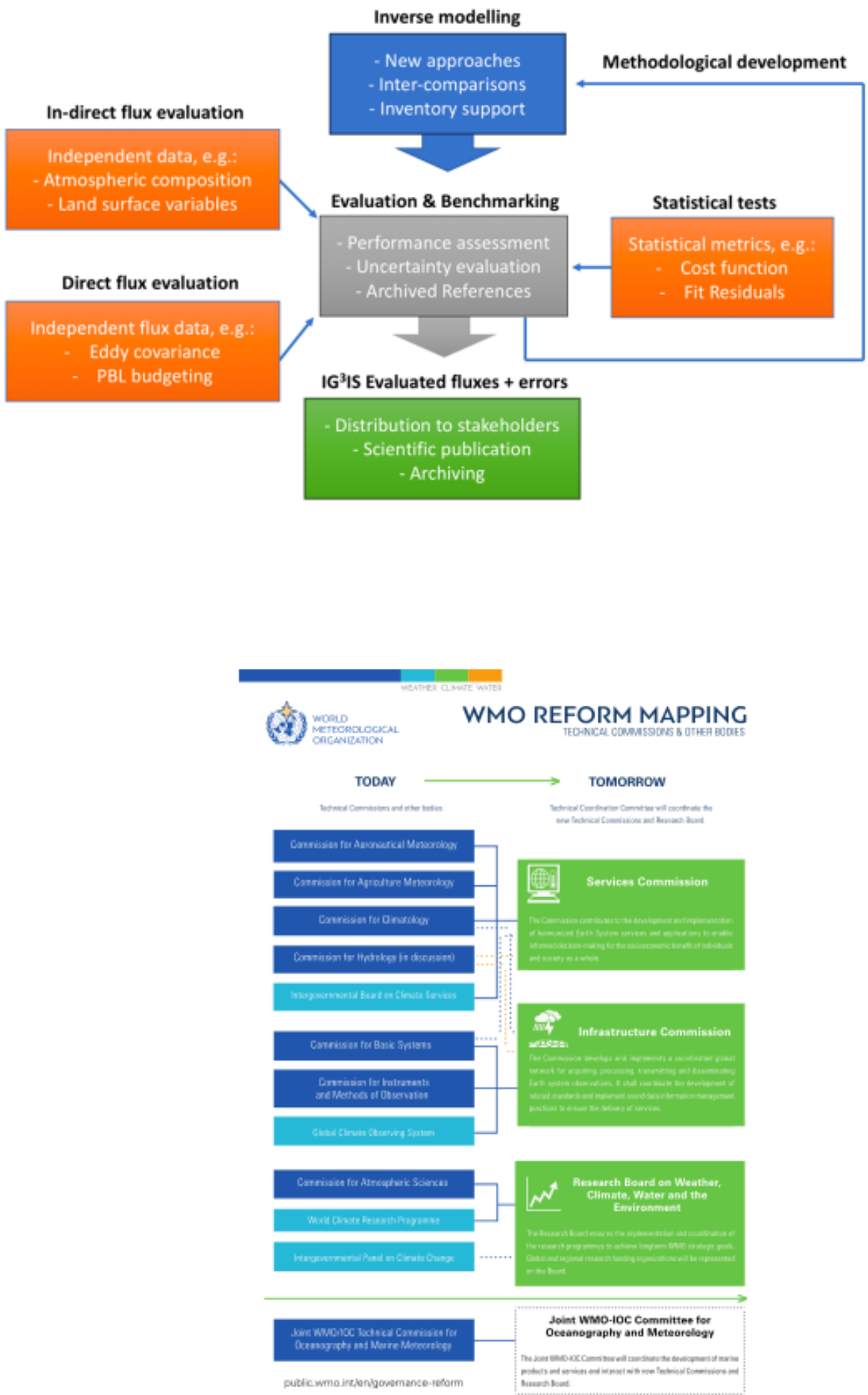


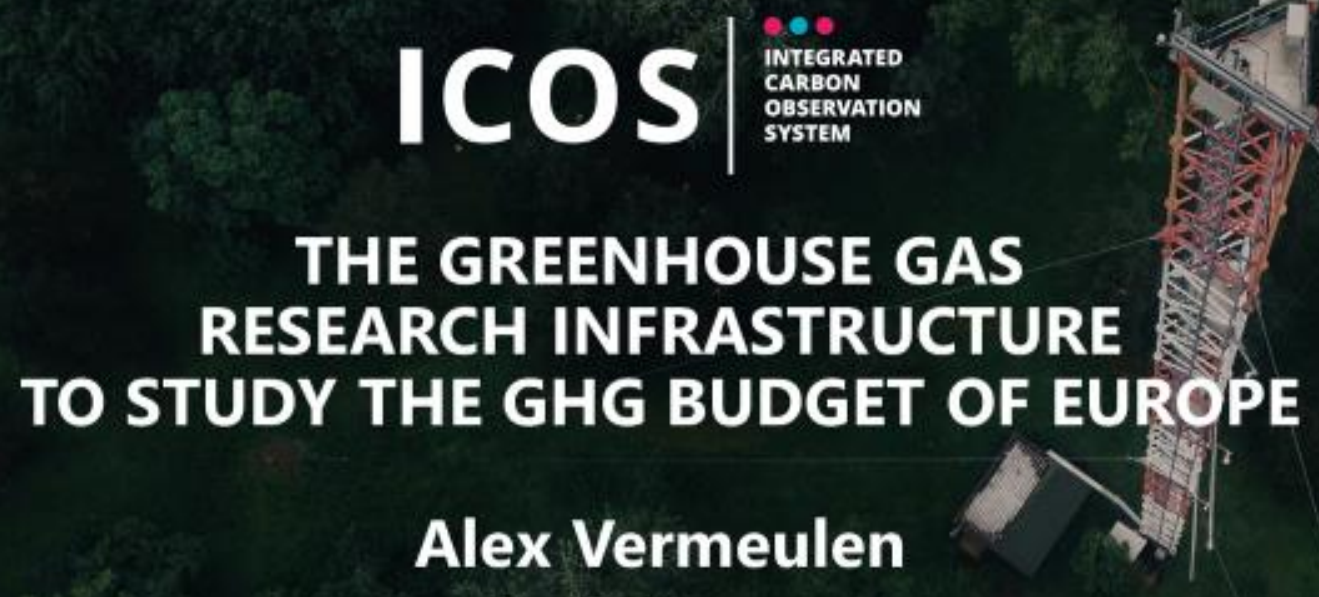

\author{
Alex Vermeulen
}

\section{ICOS in brief}

- Initiated in 2006

- Legal structure since 2015

- 12 member states (2020:15)

- >130 observing stations

- Multi-domain

- Atmosphere $\{>35$ stations

- Marine [>25 stations]

- Ecosystem [Pro stations]

- $>500$ scientists

- $>70$ institutions/universities

- Standardized equipment, protocols, data processing

- All data streams operational

- Central FAIR data portal

- All data is open data, CC4BY licence

- Community platform for elaborated product

- Essential component of global initiatives: - WMO GAW, FluXNET, SOCAT, GLODAP

$\operatorname{Icos} \mid$

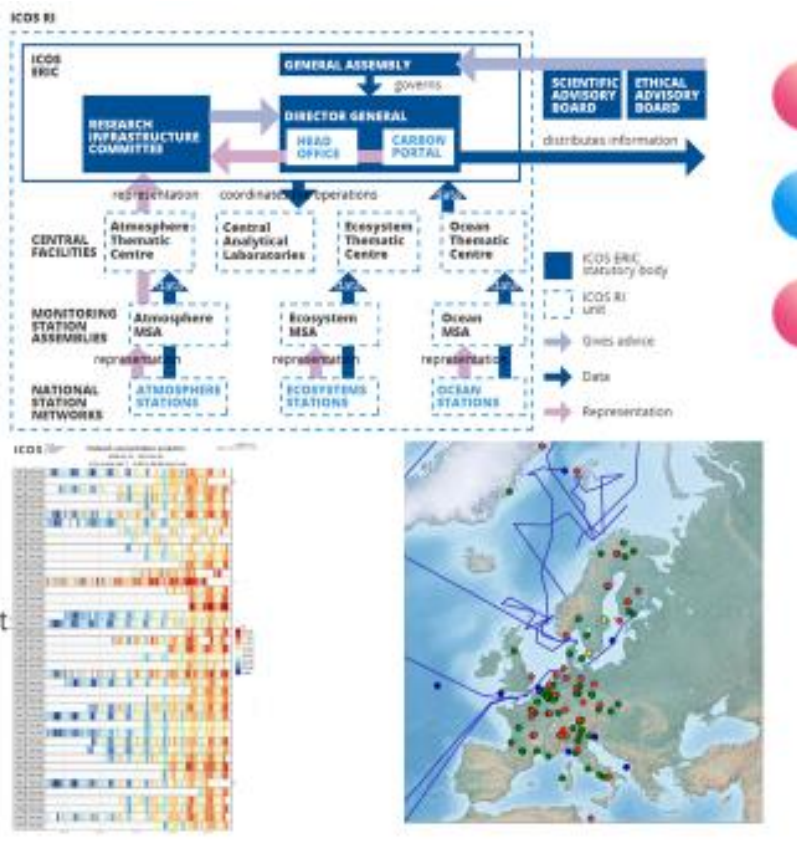




\section{ICOS in the value chain of GHG data}

- Innovation, new methods and instruments

- Support community in developing new products based on ICOS data

- COPERNICUS MVS capacity in Europe ( $\mathrm{CO}_{2}$ report): ICOS as the in-situ component
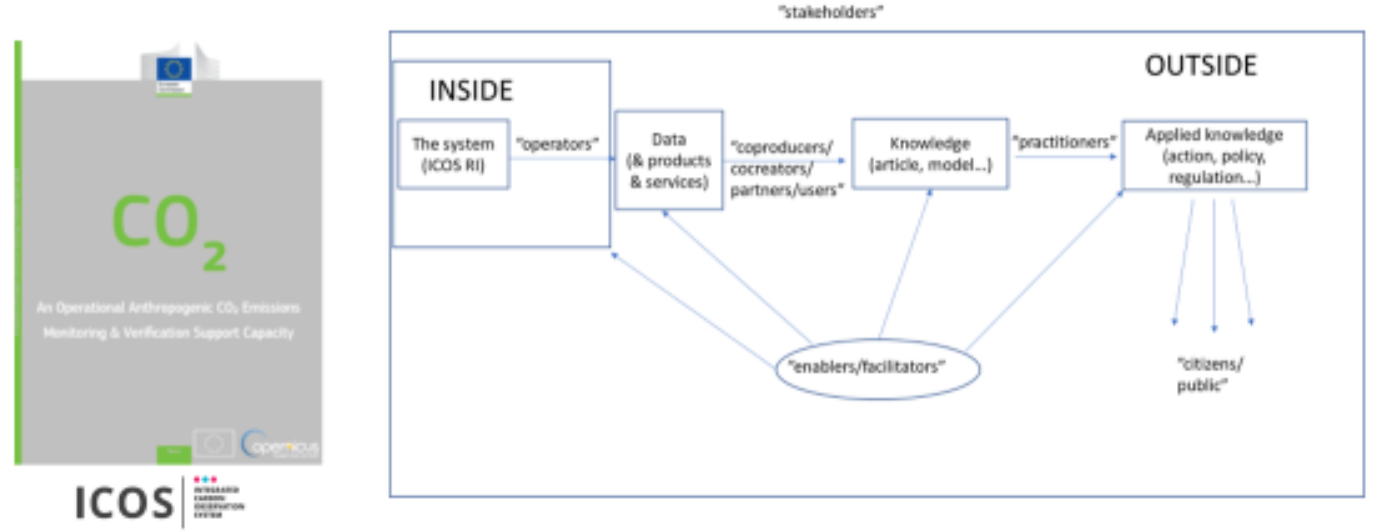

\section{Socio-economic impact: from Observations to Decisions}

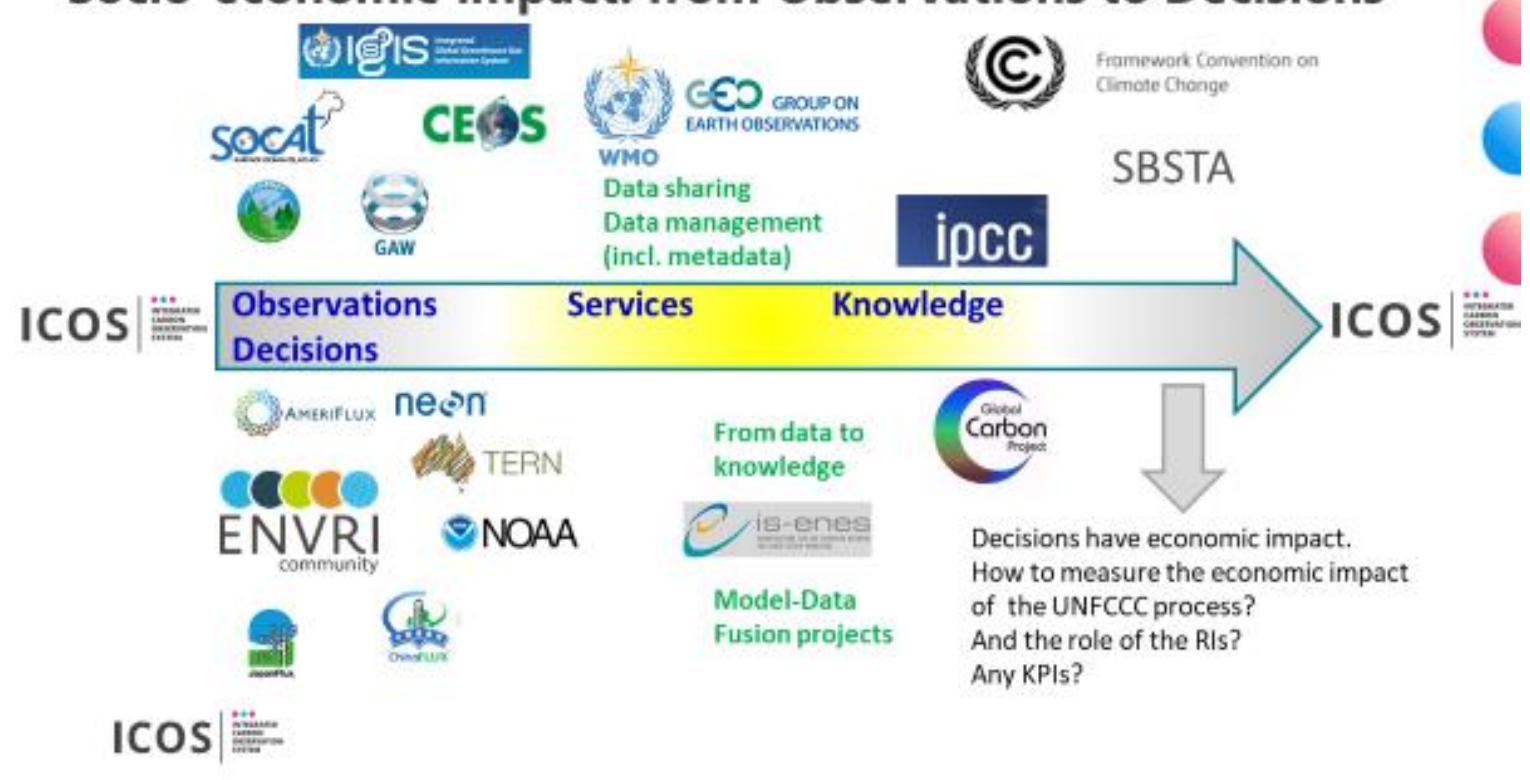




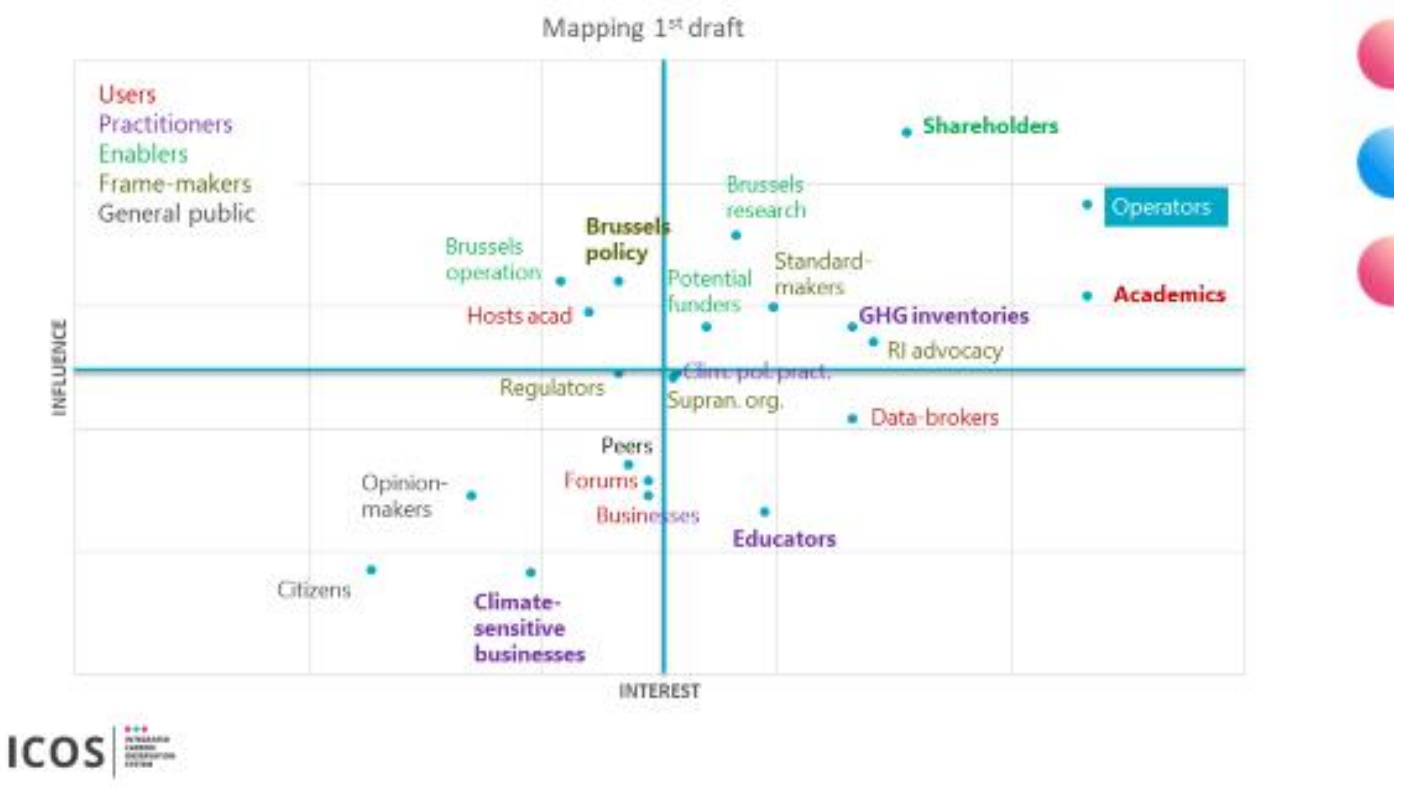

\section{Interactive analysis tools for model results \& data}

- Analysis of simulated fossil fuel $\mathrm{CO}_{2}$ time series (RINGO)

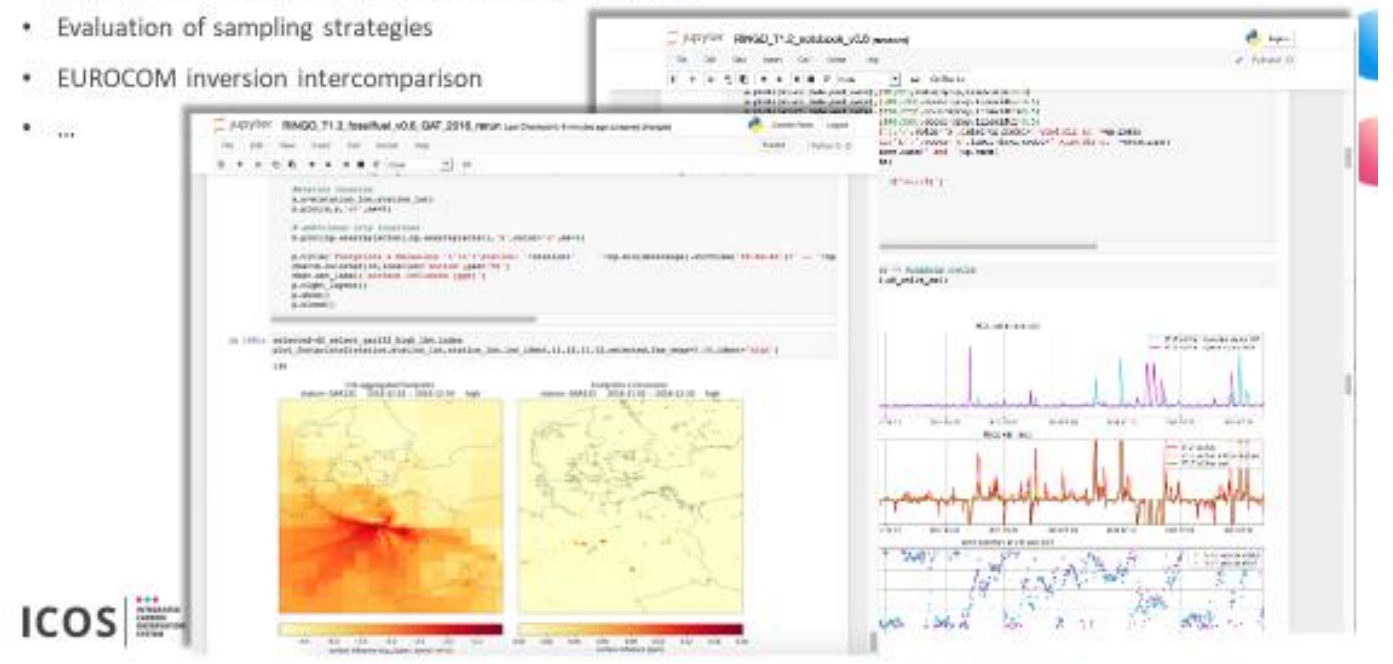




\section{Project-specific Jupyter notebooks}

- Analysis of simulated fossil fuel $\mathrm{CO}_{2}$ time series (RINGO)

- Evaluation of sampling strategies (RINGO)

- EUROCOM inversion intercomparison

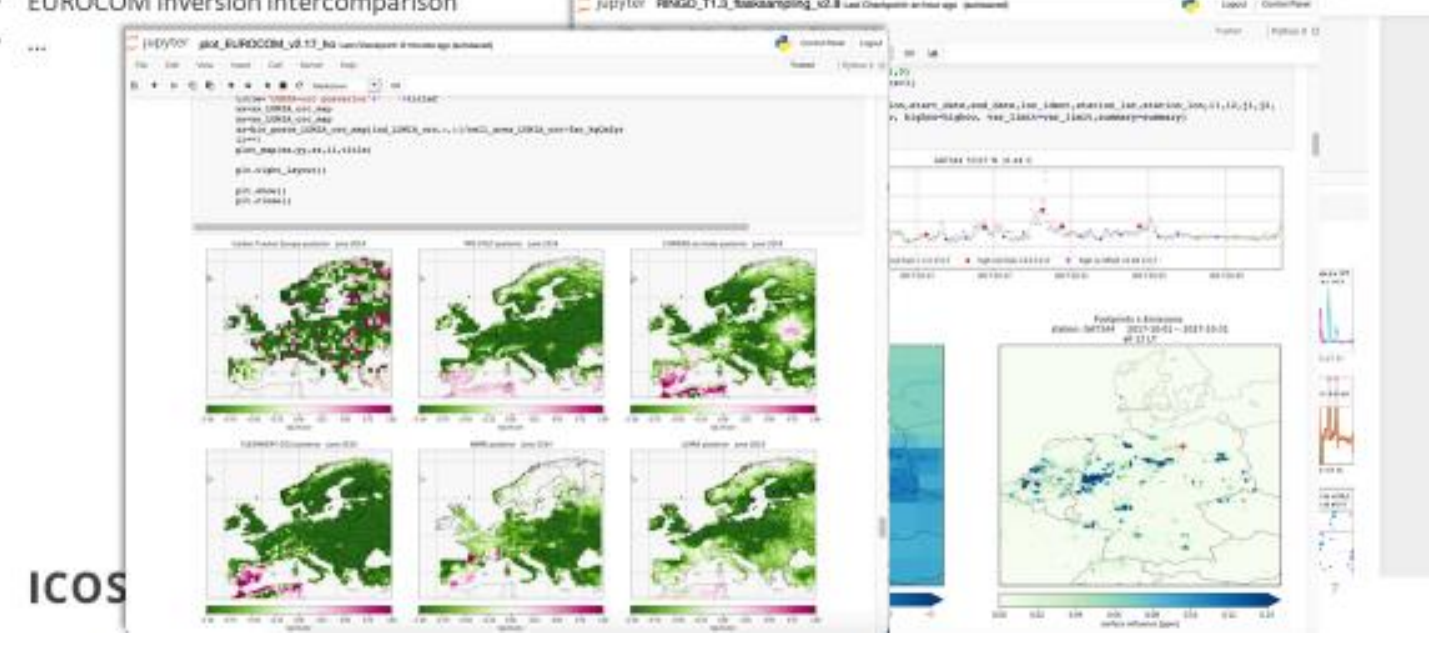

\section{EUROCOM inversions: fuel \& biospheric $\mathrm{CO}_{2}$ flux estimates}

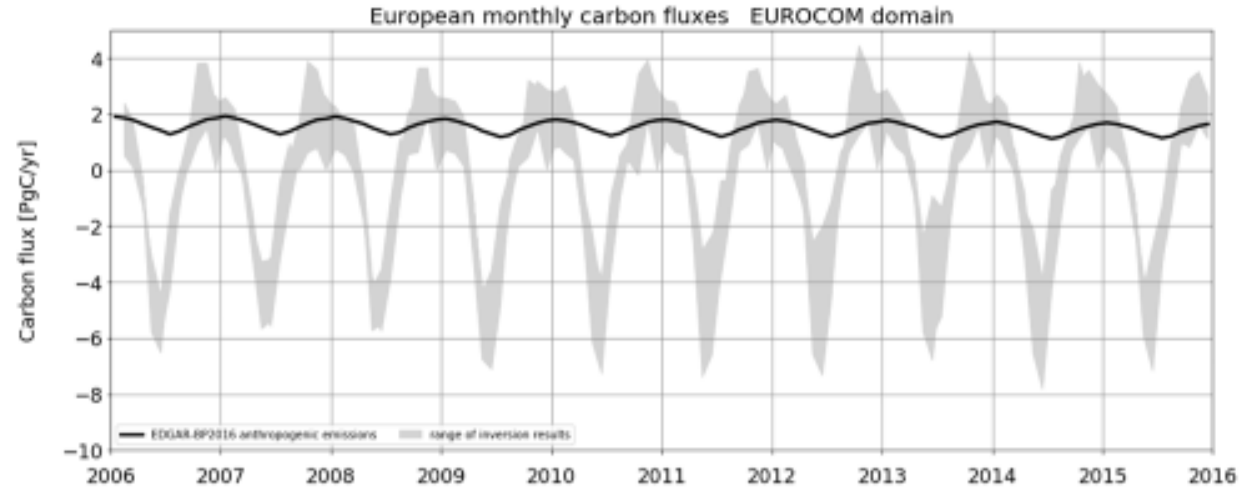

- Inversion results still show large differences => model development $\&$ inherent uncertainties

- Inversion results will be uploaded soon at ICOS CP

- Inversions are currently extended to 2018

$\operatorname{ICOS} \mid=$ 


\section{VERIFY regional inversion results 2006-2017}

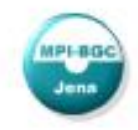

RINGO :...

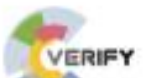

VERIFY $|\cos |$
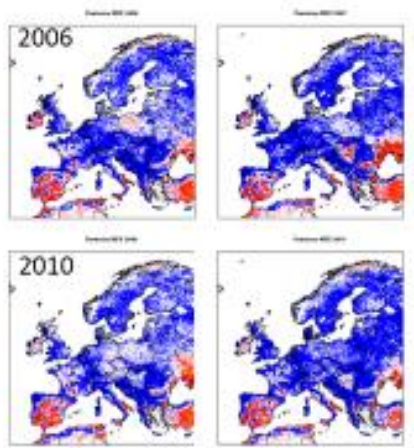

2014
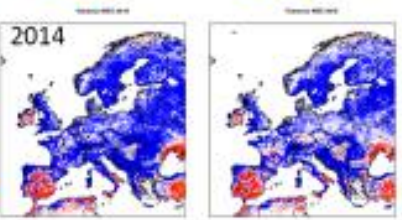
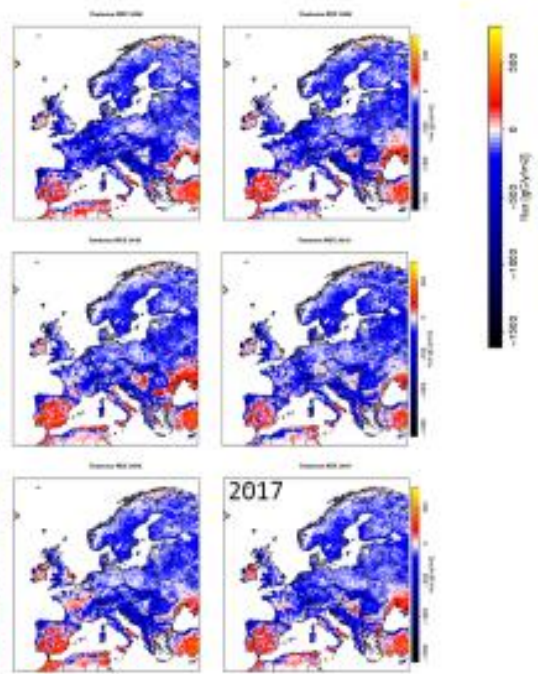

\section{SEACRIFOG network design}

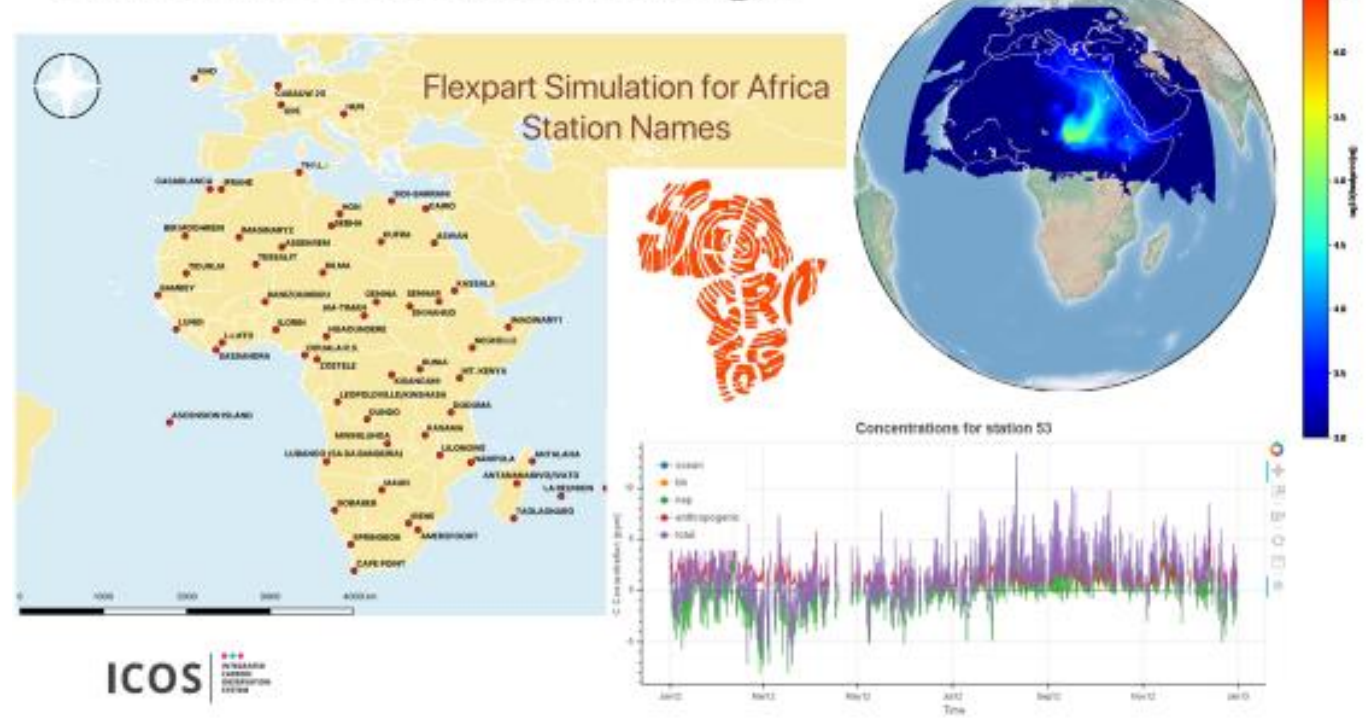




\title{
Optimal Africa network for $\mathrm{CO}_{2}, \mathrm{CH}_{4}$ and $\mathrm{N}_{2} \mathrm{O}$
}
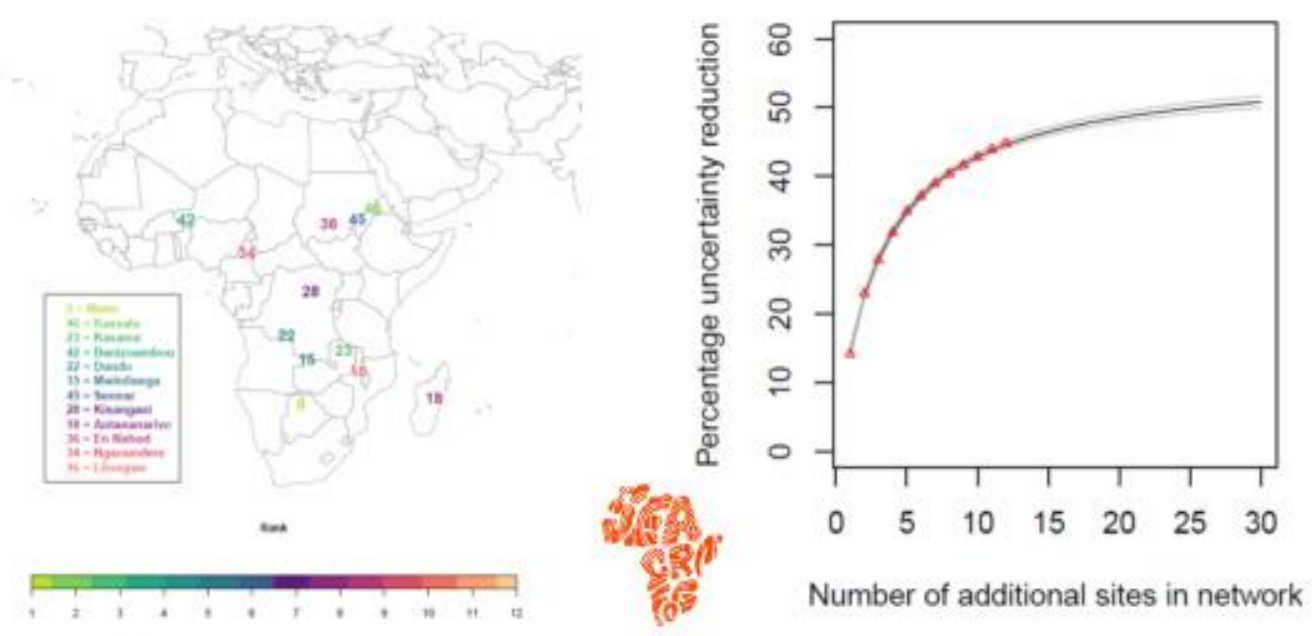

\begin{abstract}
$\operatorname{ICOS} \mid \underline{\underline{w}}$
From: Nickless et al, submitted. Do not cite or quote
\end{abstract}

\section{Some selected links to the ICOS data portal}

\author{
https://data.icos-cp.eu/portal \\ https://exploredata.icos-cp.eu \\ https://www.icos-cp.eu/data-products \\ https://stilt.icos-cp.eu/viewer/ \\ https://stilt.icos-cp.eu/worker/ \\ https://github.com/ICOS-Carbon-Portal \\ https://data.icos-cp.eu/stats/ \\ Account required: \\ https://cpauth.icos-cp.eu/login/ \\ https://iupvter2.icos-cp.eu \\ https://meta.icos-cp.eu/uploadgui/ \\ https://doi.icos-cp.eu/ \\ https://meta.icos-cp.eu/sparqlclient/ \\ https://fileshare.icos-cp.eu
}

Main search interface

Anonymous Jupyter notebooks

Main ICOS obs. data products

View footprints and concentrations

Calculate your own footprints

ICOS CP source code repo

Download statistics

Login/create account

Jupyter service (sep. account needed)

User friendly data upload

DOI minting and metadata edit service

GUI for open SparQL endpoint

ICOS fileshare, online document editing

$\operatorname{ICOS} \mid \underline{\Xi}$ 